LINKOPING STUDIES IN SCIENCE AND TECHNOLOGY.

DISSERTATION NO. 1679

\title{
System studies of the use of industrial excess heat
}


System studies of the use of industrial excess heat SARAH BROBERG VIKLUND

ISBN 978-91-7519-042-6

Copyright (C) Sarah Broberg Viklund, 2015

Linköping Studies in Science and Technology, Dissertation No. 1679

ISBN 978-91-7519-042-6

ISSN 0345-7524

Distributed by:

LINKÖPING UNIVERSITY

Department of Management and Engineering

SE-581 83 Linköping

Sweden

Phone: +46 (0)13-28 1000

Printed by:

LiU-Tryck, Linköping, Sweden, 2015

Cover design by Per Lagman, LiU Tryck 
This thesis is based on work conducted within the interdisciplinary graduate school Energy Systems. The national Energy Systems Programme aims at creating competence in solving complex energy problems by combining technical and social sciences. The research programme analyses processes for the conversion, transmission and utilisation of energy, combined together in order to fulfil specific needs.
PROGRAM

ENERGISYSTEM

वर्2

Forskning och forskarskola

The research groups that constitute the Energy Systems Programme are the Department of Engineering Sciences at Uppsala University, the Division of Energy Systems at Linköping Institute of Technology, the Research Theme Technology and Social Change at Linköping University, the Division of Heat and Power Technology at Chalmers University of Technology in Göteborg, as well as the Division of Energy Processes at the Royal Institute of Technology in Stockholm. Associated research groups are the Division of Environmental Systems Analysis at Chalmers University of Technology in Göteborg as well as the Division of Electric Power Systems at the Royal Institute of Technology in Stockholm.

www.liu.se/energi 
System studies of the use of industrial excess heat

\title{
SARAH BROBERG VIKLUND
}

\author{
Division of Energy Systems \\ Department of Management and Engineering \\ Linköping University
}

\begin{abstract}
Energy, materials, and by-products, can be exchanged between companies, having positive effects in the form of improved resource efficiency, environmental benefits, and economic gains. One such energy stream that can be exchanged is excess heat, that is, heat generated as a by-product during, for example, industrial production. Excess heat will continue to play an important role in efforts to reduce greenhouse gas (GHG) emissions and improve energy efficiency. Using excess heat is therefore currently emphasized in EU policy as a way to reach EU climate targets.
\end{abstract}

This thesis examines the opportunities of manufacturing industries to use industrial excess heat, and how doing so can positively affect industry, society, and the climate. Since different parts of the energy system are entangled, there is an inherent complexity in studying these systems and introducing excess heat in one part of the energy system may influence other parts of the system. This analysis has accordingly been conducted by combining studies from various perspectives, by applying both quantitative and qualitative methods and covering a broad range of aspects, such as technical possibilities as well as climate, policy, economics, and resource aspects.

The results identify several opportunities and benefits accruing from excess heat use. Although excess heat is currently partly used as a thermal resource in district heating in Sweden, this thesis demonstrates that significant untapped excess heat is still available. The mapping conducted in the appended studies identifies excess heat in different energy carriers, mainly low-temperature water. Analysis of excess heat use in different recovery options demonstrated greater output when using excess heat in district heating than electricity production. Optimizing the trade-offs in excess heat used in a district heating network, heatdriven cooling, and electricity production under different energy market conditions while minimizing the system cost, however, indicated that the attractiveness of excess heat in district heating depends on the type of heat production in the system. Viewing excess heat as a low-cost energy source also makes it economically interesting, and creates opportunities to invest in excess heat-recovery solutions. Excess heat is often viewed as $\mathrm{CO}_{2}$ neutral since unused excess heat may be regarded as wasted energy. The GHG mitigation potential of using excess heat, however, was found to be ambiguous. The appended studies demonstrate that using excess heat for electricity production or for applications that reduce the use of electricity reduces GHG emissions. The effects of using excess heat in district heating, on the 
other hand, depend on the energy market development, for example, the marginal electricity production and marginal use of biomass, and on the type of district heating system replaced. The interviews performed reveal that energy policy does influence excess heat use, being demonstrated both to promote and discourage excess heat use. Beyond national energy policies, internal goals and core values were identified as important for improved energy efficiency and increased excess heat use. 
System studies of the use of industrial excess heat

\section{SARAH BROBERG VIKLUND}

Avdelningen Energisystem

Institutionen för ekonomisk och industriell utveckling

Linköpings Universitet

\section{SAMMANFATTNING}

Energi, material och biprodukter kan utbytas mellan företag och därmed leda till positiva effekter i form av förbättrad resurseffektivitet, miljövinster och ekonomiska vinster. Ett sådant energiflöde som kan nyttjas är industriell överskottsvärme, det vill säga, värme som genereras som en biprodukt vid till exempel industriell produktion. Överskottsvärme kommer att fortsätta att spela en viktig roll $i$ arbetet med att minska utsläppen av växthusgaser och öka energieffektiviteten och lyfts därför fram i EU policy som ett sätt att nå klimatmålen.

Denna avhandling undersöker möjligheterna för den tillverkande industrin att använda industriell överskottsvärme och hur detta kan medföra positiva bidrag till industrin, samhället och klimatet. Eftersom olika delar av energisystemet påverkar varandra så finns en inneboende komplexitet $\mathrm{i}$ att studera dessa system. Användningen av överskottsvärme i en del av energisystemet kan alltså påverka andra delar av systemet. Denna analys har därför gjorts genom att kombinera studier från olika perspektiv, genom användning av både kvantitativa och kvalitativa metoder och genom att täcka in ett brett spektrum av aspekter såsom tekniska möjligheter, och klimat-, policy-, ekonomiska- och resursaspekter.

Resultaten visar flera möjligheter med, och fördelar som kommer från, användning av överskottsvärme. Även om överskottsvärme redan idag delvis används som värmekälla i fjärrvärme så visar denna avhandling att tillgången på outnyttjad överskottsvärme fortfarande är betydande. Kartläggningen som genomfördes identifierar överskottsvärme i olika energibärare, i huvudsak i vatten med låg temperatur. Användningen av överskottsvärme analyserades för olika användningsalternativ och visade på en större output vid användning $i$ fjärrvärmesystemet än när den användes för elproduktion. När fördelningen av användning av överskottsvärme mellan utnyttjande i fjärrvärmesystemet, för produktion av kyla eller el optimerades under olika energimarknadsvillkor, med syfte att minimera systemkostnaden, visade det sig dock att effekterna från användning av överskottsvärme i fjärrvärme beror på typen av befintlig värmeproduktion i systemet. Om man ser på överskottsvärme som en billig energikälla skapas en ekonomisk möjlighet att investera i olika lösningar för överskottsvärmeanvändning. Överskottsvärme ses ofta som $\mathrm{CO}_{2}$ neutral eftersom outnyttjad överskottsvärme kan ses som bortkastad energi. Möjligheten för minskning av växthusgaser vid användning av överskottsvärme visade sig dock vara tvetydig. Avhandlingens studier visar att användning av överskottsvärme för elproduktion och för tillämpningar som minskar 
elanvändningen minskar utsläppen av växthusgaser. Effekterna från överskottsvärme i fjärrvärme beror däremot på energimarknadens utveckling, såsom framtida elproduktion och alternativanvändning av biomassa, och på vilken typ av fjärrvärmeproduktion som ersätts. Intervjuerna som utförts visar att styrmedel påverkar överskottsvärmeanvändningen. Styrmedel visade sig både främja och missgynna användningen av överskottsvärme. Utöver nationella styrmedel så lyftes även interna företagsmål och kärnvärden fram som viktiga för ökad energieffektivitet och ökad användning av överskottsvärme. 
Till Herman 


\section{List of papers}

This thesis is based on the work presented in the following papers, referred to in the thesis by Roman numerals. The papers are not listed in chronological order by publication date, but rather in the order that makes it easier for readers to follow the structure of this thesis. The papers are appended at the end of the thesis.

I. Broberg Viklund, S., Johansson, M.T. Technologies for utilization of industrial excess heat: Potentials for energy recovery and $\mathrm{CO}_{2}$ emission reduction. Energy Conversion and Management 2014;77:369-379.

II. Broberg, S., Backlund, S., Karlsson, M., Thollander, P. Industrial excess heat deliveries to Swedish district heating networks: Drop it like it's hot. Energy Policy 2012;51:332-339.

III. Broberg Viklund, S., Lindkvist, E. Biogas production supported by excess heat - A systems analysis within the food industry. Energy Conversion and Management 2015;91:249-258.

IV. Andersson, V., Broberg Viklund, S., Hackl, R., Karlsson, M., Berntsson, T. Algae-based biofuel production as part of an industrial cluster. Biomass and Bioenergy 2014;71:113-124.

V. Broberg Viklund, S., Karlsson, M. Industrial excess heat use: Systems analysis and $\mathrm{CO}_{2}$ emissions reduction. Applied Energy 2015;152:189-197.

VI. Ivner, J., Broberg Viklund, S. Effect of the use of industrial excess heat in district heating on greenhouse gas emissions: A systems perspective. Resources, Conservation and Recycling 2015;100:81-87.

VII. Broberg Viklund, S. Energy efficiency through industrial excess heat recovery Policy impacts. Energy Efficiency 2015;8(1):19-35.

The co-author statement is presented in Section 1.3.

Other publications by the author not included in the thesis are the following:

- Broberg, S., 2011. System analysis of industrial clusters and biorefineries using methods from social and natural science. In: Karlsson, M. and Palm, J. (Eds.), Metoder för tvärvetenskaplig analys av energisystem - några exempel [Methods for interdiciplinary analysis of energy systems - some examples]. Working paper no. 46. Energy Systems Programme, Linköping University, Linköping, Sweden. 
- Andersson, V., Broberg, S., Hackl, R., 2011. Integrated algae cultivation for biofuels production in industrial clusters. Working paper no. 47. Energy Systems Programme, Linköping University, Linköping, Sweden. (Prestudy for Paper IV)

- Andersson, V., Broberg, S., Hackl, R., 2012. Integrated algae cultivation for municipal wastewater treatment and biofuels production in industrial clusters. Proceedings of WREF 2012, World Renewable Energy Forum 2012, Denver, CO, USA, 13-17 May 2012. (Early version of Paper IV)

- Andersson, V., Broberg, S., Hackl, R., 2013. Dubbel energivinst med alger som biobränsle [Double energy gain with algae as biofuels]. Energimagasinet no. 1. (Popular science version of Paper IV)

- Backlund, S., Broberg, S., Ottosson, M., Thollander, P., 2012. Energy efficiency potentials and energy management practices in Swedish firms. Proceedings of ECEEE Industrial Summer Study on Energy Efficiency 2012, Arnhem, Netherlands, 11-14 September 2012.

- Broberg, S., Karlsson, M., 2013. Systems analysis and $\mathrm{CO}_{2}$ reductions using industrial excess heat. Proceedings of ICAE2013, the $5^{\text {th }}$ International Conference on Applied Energy, Pretoria, South Africa, 1-4 July 2013. (Early version of Paper V) 


\section{Acknowledgements}

This work was carried out under the auspices of the Energy Systems Programme, which is financed by the Swedish Energy Agency. I gratefully acknowledge them for the financial support.

Although my name stands alone as the author of this dissertation, a long list of people contributed to my work as they all made this journey possible. Whether you made small or large contributions, or were just there for me, I am grateful to all of you. Thanks to..

... my supervisor Associate Professor Magnus Karlsson for your guidance and support and for your pep-talk when I felt that the hill in front of me was enormous.

... my co-supervisors Associate Professor Mats Söderström, Professor Jenny Palm, and Associate Professor Helen Peterson for all your encouraging words, valuable input to the work, and guidance through the academic world and its various methods.

... Per-Åke Franck, who commented on the draft of my thesis at my final seminar, for valuable comments and input that helped me improve this thesis and made me feel more prepared for my thesis defence.

... the participants in the industry seminar group and the division seminar group for commenting on my work throughout my years as a $\mathrm{PhD}$ student. Tanks for all your feedback!

... Sandra Backlund, Maria Johansson, Emma Lindkvist, and Jenny Ivner at the Division of Energy Systems for good cooperation and interesting and useful discussions when planning, preparing, and writing our papers. And, a big thanks to Jakob Rosenqvist for spending all those hours on the Gotland ferry helping us sort out the many terms and components.

... all my colleagues at the Division of Energy Systems for the good cooperation, enjoyable coffee-break discussions, wonderful homemade pastries, and a large share of bakery baked vetekransar. A special thanks to Sandra Backlund and Linda Olsson, for being my best PES friends throughout the years as a PhD student, to Klas Ekelöw for all those lunchpromenader where you share your knowledge of everything and nothing and for helping me solve all those little computer problems, to Elisabeth Wetterlund for introducing me to the life of the department and, as my first office neighbour, for letting me enjoy your of the day favourite song over and over again. And finally to Elisabeth Larsson for all your help with everything between heaven and earth and for answering my everyday questions.

... all the people in the Energy Systems Programme. A special thanks to Viktor Andersson and Roman Hackl for the good cooperation on the never-ending algae project, starting with the Tvärprojektet in early 2011 and continuing almost until dissertation day at the end of 2014. I am glad that the two of you followed me though all those years, and not to forget, that the project brought us all the way to that unforgettable trip to Denver and the Rocky Mountains. Thanks also to Mårten Larsson for staying with me in South Africa after the conference in Pretoria to experience that amazing country, for all those glasses of good wine, and not to forget, "meeting Obama". And, to the rest of the D10 group for all the nice fika breaks, the fun after works, and all the new perspectives on my research and on life in general. 
... all the energy managers who completed my questionnaires and answered my interview questions, and the energy manager at the studied food company for responding to our questions and endless e-mails, letting us visit, sharing valuable data with us, and for being our private taxi driver when visiting and sharing all interesting facts and must-sees in the neighborhood.

... to my old Tomelilla friends Josefine, Martina, and Sofie for making me what I am today and for still being such a big part of my life and, of course, for never letting me forget how to speak real Skånska - I said I would move back one day and now was the time!

... to all my (not so anymore) "new" Linköping friends, with special thanks to Elin, you were one reason why I even moved back for this $\mathrm{PhD}$. I will never forget our breakfasts in Baljan, the everyday Extra horoscopes, our shoe-shopping days, our cocktail evenings on my balcony or in your pink-walled kitchen, "lagen om alltings jävlighet", our hangover days eating chili cheese at Burger King, our girl-talk on the "never-ending subject" and the "secret list" one of those talks at campus resulted in, and of course "det är du värd", because you always are!

... my family, mamma Ingrid and pappa Arne for helping me set my mind on things other than work and for believing in me even though I do not think you have ever really understood what it is that I have been doing for the past five years. Thanks also to my sister Linda for helping me keep my mind off energy systems and for bringing those wonderful children, Nora (theneverendingtalkinggirljustashermother) and Albert, into my life. Without you all I would not be the person I am today and come this far. And of course, thanks also to my "new family", the Viklund family for bringing a lot of joy into my life and for making it possible to add this nice name to this book.

... finally, my husband Herman, for believing in me and supporting me through all the everyday challenges. You may not always believe it but I do love "your perfect imperfections" and I know that you love mine. You are the light of my life, your smile makes me melt, you make me never want to go to sleep and, if I do, to go up early so that I do not miss a single minute with you. Herman, I love you to the stars and back. 


\section{Thesis outline}

This thesis gives an introduction to, and a summary of the seven appended papers. The papers are appended at the end of the thesis. The structure of the thesis is as follows.

Chapter 1 introduces the thesis and its research area, and then presents the aim and research questions in focus, gives an overview of the appended papers, a co-author statement, and an overview of the research journey.

Chapter 2 briefly introduces industrial energy use and energy efficiency in industry, but focuses on the concept of industrial excess heat.

Chapter 3 presents an overview of European directives and energy policy instruments related to industrial excess heat.

Chapter 4 gives a brief introduction to the theoretical background of this thesis, i.e., systems analysis and various approaches to assessing greenhouse gas emissions from the use of electricity and biomass.

Chapter 5 describes the systems studied in this thesis.

Chapter 6 presents the methodologies used in this thesis and how they have been applied.

Chapter 7 summarizes selected results from the appended papers. The results are presented in relation to the research questions.

Chapter 8 presents a discussion of the studies performed and the conclusions of the thesis.

Chapter 9 presents an overview of areas of interest for future research. 


\section{Abbreviations}

\begin{tabular}{|c|c|}
\hline CCP & coal condensing power \\
\hline CHP & combined heat and power \\
\hline COP & coefficient of performance \\
\hline $\mathbf{C P}$ & current policy \\
\hline DC & district cooling \\
\hline DH & district heating \\
\hline EED & Energy Efficiency Directive \\
\hline EMS & energy market scenario \\
\hline ENPAC & energy price and carbon balance scenarios \\
\hline EU & European Union \\
\hline EU ETS & the EU emission trading scheme \\
\hline FT & Fischer-Tropsch \\
\hline GHG & greenhouse gas \\
\hline НОВ & heat-only boiler \\
\hline IEA & International Energy Agency \\
\hline IO & investment opportunity \\
\hline IS & industrial symbiosis \\
\hline Klimp & Climate Investment Programme \\
\hline LCA & life cycle assessment \\
\hline LIP & Local Investment Programme \\
\hline MILP & mixed integer linear programming \\
\hline MIND & method for analysis of industrial energy systems \\
\hline NG & natural gas \\
\hline NP & new policy \\
\hline NGCC & natural gas combined cycle \\
\hline
\end{tabular}




$\begin{array}{ll}\text { NPV } & \text { net present value } \\ \text { ORC } & \text { organic Rankine cycle } \\ \text { PCM } & \text { phase-change material } \\ \text { PFE } & \text { the Programme for Improving Energy Efficiency in Energy Intensive } \\ & \text { Industries } \\ \text { TPA } & \text { third-party access } \\ \text { TPV } & \text { Thermophotovoltaic } \\ \text { WW } & \text { Wastewater } \\ \text { WWT } & \text { wastewater treatment } \\ \text { WWTP } & \text { wastewater treatment plant }\end{array}$




\section{Table of contents}

1 Introduction 1

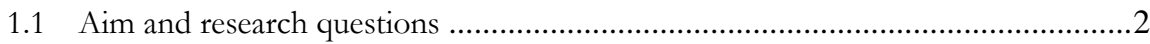

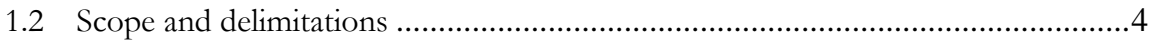

1.3 Paper overview and co-author statement....................................................

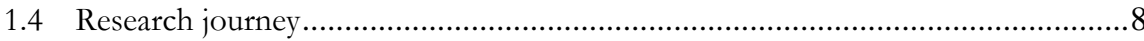

$2 \quad$ Energy efficiency and excess heat $\quad 11$

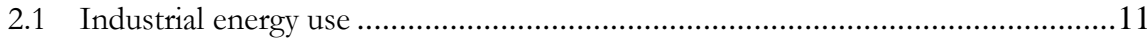

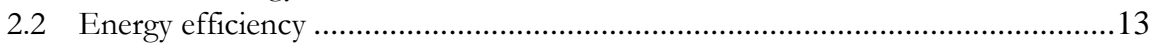

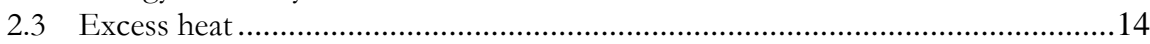

2.3.1 Excess heat: origin and definitions .................................................... 14

2.3.2 Excess heat use opportunities ........................................................... 16

2.3.3 Excess heat availability .................................................................. 19

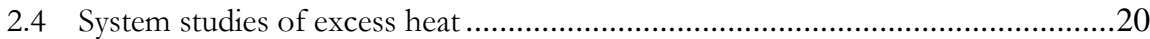

$3 \quad$ Energy policies in relation to excess heat $\quad 23$

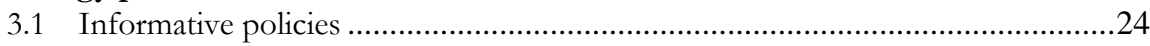

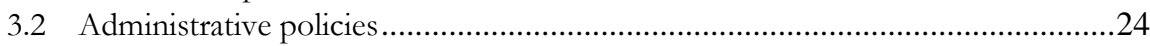

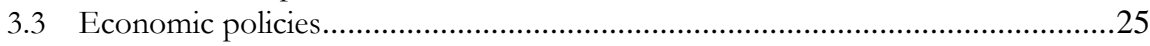

$\begin{array}{lll}4 & \text { Scientific context } & 27\end{array}$

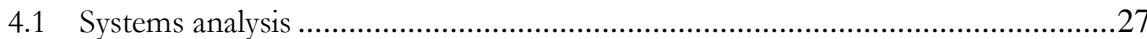

4.2 Assessment of effects on GHG emissions of changes in electricity production

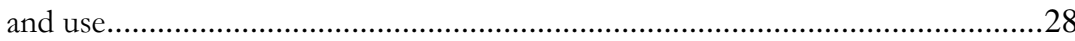

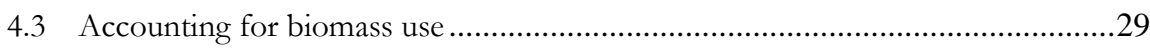

$5 \quad$ Studied systems $\quad 31$

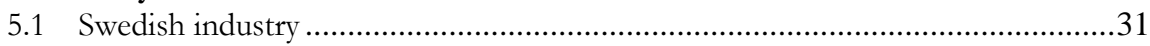

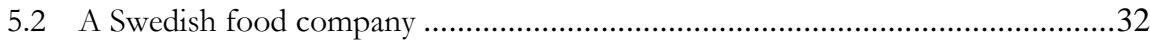

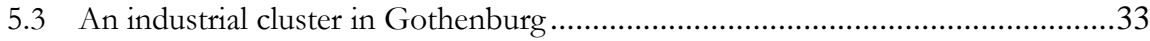

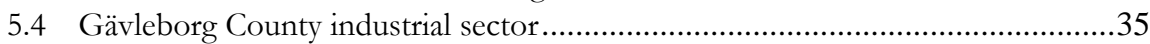

5.5 Östergötland and Örebro counties' industrial sector ..........................................36

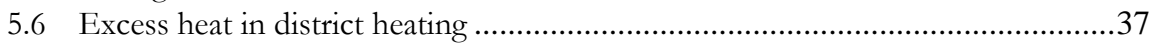

6 Methods 39

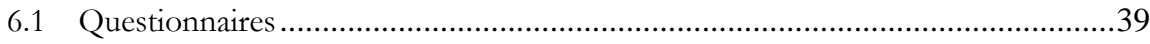

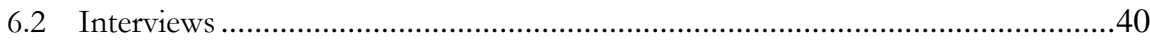

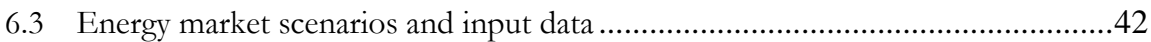

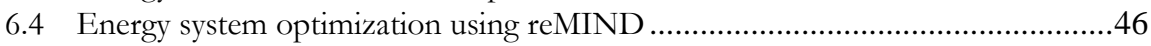

6.5 Economic evaluation: investment opportunity ...........................................47

$7 \quad$ Results and analysis $\quad 49$

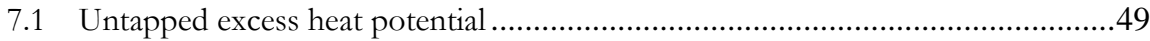

7.2 Implications of different excess heat use options ............................................53

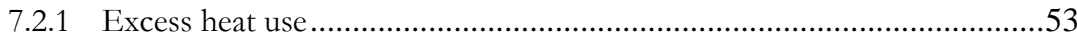

7.2.2 Effects of excess heat use ………..................................................56 


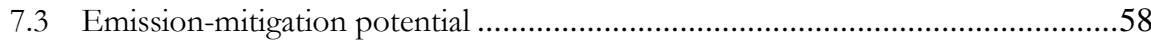

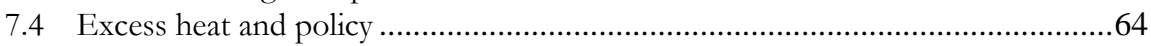

$8 \quad$ Concluding remarks

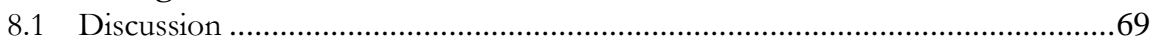

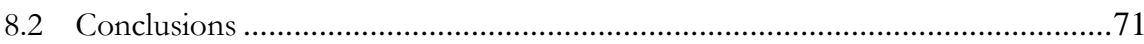

$9 \quad$ Further work $\quad 75$

$\begin{array}{ll}\text { Appendix } 1 & 77\end{array}$

$\begin{array}{ll}\text { Appendix } 2 & 81\end{array}$

$\begin{array}{lc}\text { References } & \mathbf{8 5}\end{array}$ 


\section{Introduction}

This chapter begins with a brief introduction to the thesis, followed by a presentation of the aim of the thesis and a description of the research questions posed. Next, the scope of the thesis and its delimitations are described. The chapter ends with a co-author statement and a description of the research journey.

During the part of the research process when energy managers at Swedish companies were being interviewed, I repeatedly heard statements such as "even if they (i.e., the district heating companies) get the heat for free, they do not want it" and "it does not matter what price we offer", referring to that their heat was still not attractive to district heating (DH) companies. The "heat" referred to was industrial excess heat, a heat resource generated, for example, as a by-product of industrial production. But, what are the opportunities for using industrial excess heat?

Exchanges of by-products between companies have been discussed in previous research. These studies sometimes demonstrate that exchanging, for example, energy, materials, and by-products through the integration of companies has positive effects in the form of, for example, improved resource efficiency, environmental benefits, and economic gains (Chertow, 2000; Martin and Eklund, 2011; Ellersdorfer and Weiss, 2014). The idea is that what is considered waste by one company may be valuable to another, and that these exchanges will result in competitive advantages. Throughout the present research, different approaches have been used to describe this situation, where a broader system boundary were used to emphasize the opportunities and benefits coming from collaboration (Chertow, 2000; Porter, 1998).

Benefits from the use of industrial excess heat, more specifically, have been highlighted. For example, through collaboration between actors, hot water streams that cannot be used in the company that produced them can beneficially be used somewhere else. The literature states that the use of industrial excess heat may provide both economic and environmental benefits. Using excess heat could reduce primary fuel input and hence fuel costs and greenhouse gas (GHG) emissions. Also, since the service output can be increased while maintaining the energy input, using excess heat can simultaneously improve energy efficiency (Thekdi and Belt, 2011; Cruz et al., 2011; Worrell et al., 2009). Connolly et al. (2014) also describe excess heat as an unused resource that could be used in European heating systems to reduce GHG emissions. 
Climate change and its associated risks are well known today, and national and international policy measures are being taken to stop this negative trend. In "Europe 2020: A European strategy for smart, sustainable and inclusive growth", the European Union (EU) presents strategic objectives for 2020. Seven focus areas were established and, under the heading of "Resource-efficient Europe", the EU set the "20-20-20" climate targets. These targets ${ }^{1}$ call for a 20\% reduction in GHG emissions (compared with 1990 levels), a 20\% share of final energy use from renewable resources, and a 20\% increase in energy efficiency (EEA, 2014; European Commission, 2010). The targets were updated at the end of 2014 with new targets of $40 \%, 27 \%$, and $27 \%$ for these three areas, respectively, by 2030 (European Commission, 2014a). Since the targets are partly interconnected, improved energy efficiency, for example through the use of excess heat, may reduce not only primary energy use but also GHG emissions.

Despite the targets and increased attention to energy efficiency, forecasts indicate that the EU's energy-efficiency target might not be met (EEA, 2014; European Commission, 2011). These forecasts indicate the importance of further energy-efficiency efforts. The potential benefits related to the use of excess heat make this resource valuable in efforts to achieve the EU energy and climate targets, and have in recent years been highlighted in EU policy (European Commission, 2012). Also, increasing globalization is putting pressure on industries as they are now facing greater competition from around the world, and energyefficiency measures are claimed to be a way to handle this competition (Thollander et al., 2010). However, as the various parts of the energy system are entangled, introducing excess heat in an energy system will influence other parts of the system. This means that the consequences of using excess heat may be complex to assess. Given this complexity, a systems approach could be useful when studying the effects of excess heat use. Although it is a promising resource, industrial excess heat has been paid little attention in the scientific literature.

\subsection{Aim and research questions}

The aim of this thesis is to identify manufacturing industries' opportunities to use industrial excess heat and thereby make positive contributions to industry, society, and the climate. The aim is set to understand how this resource could be used to improve energy efficiency and reduce industry's climate impact.

This thesis addresses the following four research questions:

1. What is the current untapped potential for industrial excess heat in terms of quantity, quality, and carrier medium?

\footnotetext{
${ }^{1}$ Based on each member state's potential, national targets have been set. The Swedish "20-20-20" targets entail a $40 \%$ reduction in GHG emissions, a $49 \%$ share of final energy use from renewable resources, and a $20 \%$ increase in energy efficiency.
} 
2. What are the implications of using different technologies and systems solutions based on the use of industrial excess heat?

3. How do different excess heat use options and energy market conditions influence global $\mathrm{CO}_{2}$ emissions?

4. How does policy influence industrial excess heat use?

To achieve the aim of this thesis and handle its inherent complexity, as previously mentioned, the research questions were addressed by analysing a broad range of aspects, such as technical possibilities as well as climate, policy, economic, and resource aspects, which all affect the benefits of using excess heat. These factors are elucidated using a range of methods, both quantitative and qualitative, which enables the topic to be studied from various perspectives. Table 1 presents an overview of the research questions considered in each of the appended papers.

Table 1. The appended papers in which each research question is addressed.

\begin{tabular}{|c|c|c|c|c|c|c|c|}
\hline \multirow[b]{2}{*}{$\begin{array}{l}\text { Research } \\
\text { question }\end{array}$} & \multicolumn{7}{|c|}{ Paper } \\
\hline & I & II & III & IV & $\mathrm{V}$ & VI & VII \\
\hline 1 & $\bullet$ & $\bullet$ & $\bullet$ & & & & \\
\hline 2 & - & & • & • & • & & \\
\hline 3 & • & & • & & • & • & \\
\hline 4 & & • & & & & & • \\
\hline
\end{tabular}

This thesis provides information on industrial excess heat use for the industrial sector, researchers, and authorities. The intention is that this thesis can provide useful information for stakeholders, so they can make better-informed decisions regarding the use of industrial excess heat, and for policy makers when introducing new instruments that may influence industrial excess heat use. This is done to facilitate decisions related to industrial excess heat so that this industrial by-product can be used more efficiently, resulting in reduced GHG emissions. In addition, the ambition is that these results will provide the research community with insights into the opportunities, benefits, drawbacks, and preconditions associated with industrial excess heat use by illustrating how industrial excess heat integrate with various technologies, the energy market, and policy instruments.

Chapters 1 until 8 of this compilation dissertation should be read as a whole together with the appended papers. The studies presented in the appended papers, and their underlying assumptions and input data, will not be presented in detail in this part of the thesis. 


\subsection{Scope and delimitations}

This thesis applies a systems perspective to the use of industrial excess heat. In this thesis, excess heat refers to industrial excess heat unless otherwise specified. The focus is on manufacturing industries in Sweden, although other businesses have been considered as possible heat sinks in the appended studies of heat cooperation. Though excess heat can possess various characteristics, the focus here is on the heat's quantity (i.e., amount of energy), temperature (i.e., quality), and in which carrier medium the heat can be found. The thesis does not evaluate whether or not the identified excess heat arose from a thermodynamically optimized process. Excess heat potential refers to the theoretical potential of untapped excess heat.

There are several excess heat-recovery options, both technologies and systems solutions, a number of which are examined here. The focus will be on excess heat used externally or for electricity production and the studied measures will be specified in connection with the results presented in the appended studies. Although the systems studied here are Swedish, the analysis applies a European energy systems perspective. Since unused excess heat may be regarded as "wasted", this thesis assumes that using excess heat is something good. This assumption will be challenged, however, when studying the robustness of such use related to climate aspects. In this thesis, climate aspects are limited to the emission consequences of excess heat use, meaning the impact on the amount of GHG emissions. GHG is taken to include emissions of $\mathrm{CO}_{2}$ (carbon dioxide), $\mathrm{CH}_{4}$ (methane), and $\mathrm{N}_{2} \mathrm{O}$ (nitrous oxide).

\subsection{Paper overview and co-author statement}

This thesis is based on the following seven papers. The following describes the appended papers as well as the authors' contributions to each paper.

\section{Paper I}

Broberg Viklund, S., Johansson, M.T. Technologies for utilization of industrial excess heat: Potentials for energy recovery and $\mathrm{CO}_{2}$ emission reduction. Energy Conversion and Management 2014;77:369-379.

This paper presents the range of technologies for recovery and use of excess heat. The technologies are classified and presented in four categories: heat-harvesting technologies, heat-storage technologies, heat-utilization technologies, and heat-conversion technologies. The paper also investigates, through a questionnaire, the amount of untapped excess heat in Gävleborg County and applies some of the studied measures to this untapped excess heat. The energy use potential of these measures is presented and discussed together with the effect on the amount of global $\mathrm{CO}_{2}$ emissions under different energy market conditions as of 2030 . 
The paper was planned and written in collaboration with Dr. Maria Johansson, a postdoctoral fellow at Linköping University. Data on available excess heat in Gävleborg County were obtained from a questionnaire formulated and compiled by the author in collaboration with Dr. Sandra Backlund, formerly of Linköping University. Calculations of electricity generation from excess heat were performed by Maria Johansson. All other parts of the paper were calculated, analyzed and written jointly with Maria Johansson. The work was supervised by Associate Professors Magnus Karlsson and Mats Söderström.

\section{Paper II}

Broberg, S., Backlund, S., Karlsson, M., Thollander, P. Industrial excess heat deliveries to Swedish district heating networks: Drop it like it's hot. Energy Policy 2012;51:332-339.

The paper estimates, through a questionnaire, the untapped excess heat in Östergötland and Örebro counties. Based on this unused heat resource, the paper discusses whether using this heat in $\mathrm{DH}$ would be influenced by altered $\mathrm{DH}$ market conditions, such as the introduction of a third-party access (TPA) to the DH network. The discussion is based on calculations of estimated investment costs and revenues, which give an indication of whether the realization of a TPA could enable profitable excess heat investments.

The paper was planned and written jointly with Dr. Sandra Backlund, formerly of Linköping University. Data on available excess heat in Östergötland and Örebro counties were obtained from a questionnaire originally formulated by Associate Professor Patrik Thollander, Linköping University and sent out by the Östergötland and Örebro county administrative boards. The data on excess heat were then compiled and calculations performed by the author of this thesis, while the economic calculations were performed by Sandra Backlund; the analysis was carried out jointly. Associate Professors Magnus Karlsson and Patrik Thollander, Linköping University, supervised and commented on the work.

\section{Paper III}

Broberg Viklund, S., Lindkvist, E. Biogas production supported with excess heat - A systems analysis within the food industry. Energy Conversion and Management 2015;91:249-258.

Paper III examines a synergetic use of excess heat. The main aim was to study a change in the use of industrial organic waste, exemplified by a shift from external production and use of biogas to internal production and use at an industrial site. Biogas production at an industrial site may allow for the use of available excess heat to cover the demand for heat associated with biogas production. This option was analysed and compared with the use of biogas to cover the heat demand instead. The paper addresses the effects on GHG emissions and economics resulting from this change in the use of industrial organic waste and use of excess heat, along with the effects on emission mitigation associated with the valuation of biomass. 
The original idea for the paper came from the author of this thesis. The paper was then planned and written together with $\mathrm{PhD}$ student Emma Lindkvist, Linköping University. The necessary data were collected together with Emma Lindkvist with some help from technician Jakob Rosenqvist, Linköping University. Calculations of excess heat use were performed mainly by the author of this thesis, while calculations of biogas production were performed mainly by Emma Lindkvist; other calculations were performed jointly. Associate Professors Magnus Karlsson and Mats Söderström supervised and commented on the work.

\section{Paper IV}

Andersson, V., Broberg Viklund, S., Hackl, R., Karlsson, M., Berntsson, T. Algae-based biofuel production as part of an industrial cluster. Biomass and Bioenergy 2014;71:113-124.

Paper IV presents the outcomes of introducing a biorefinery concept in an industrial cluster. The study investigated the replacement of a current wastewater treatment plant (WWTP) with a biorefinery that consists of combined algae cultivation and wastewater treatment (WWT) and the production of algae-based biofuels (i.e., biodiesel and biogas). The concept enables for the use of excess heat to provide an appropriate algae growth environment and flue gases as an algae nutrient source. This paper describes a possible use of excess heat in a synergistic setup. The heating requirements for the cultivation pond are also studied.

The original report (Andersson et al., 2011) on which this paper is based was planned and written together with Dr. Roman Hackl, formerly of Chalmers University of Technology, and Viktor Andersson, PhD student at Chalmers University of Technology. Calculations of WWT and algae growth were performed by Roman Hackl, calculations of biodiesel production by Viktor Andersson, and calculations of biogas production by the author of this thesis; the analysis was carried out jointly. This published article version of the work was written jointly with Viktor Andersson, who also performed the heat requirement calculations. Roman Hackl commented on the manuscript throughout its preparation. Associate Professor Magnus Karlsson, Linköping University, and Professors Simon Harvey and Thore Berntsson, Chalmers University of Technology, commented on and supervised the work.

Paper V

Broberg Viklund, S., Karlsson, M. Industrial excess heat use: Systems analysis and $\mathrm{CO}_{2}$ emissions reduction. Applied Energy 2015;152:189-197.

Paper V uses a combination of modelling and future energy market scenarios for 2030 to investigate the trade-offs between excess heat use for heating and cooling applications and heat-driven electricity production. The paper studies how excess heat can be used under different energy market conditions to minimize the system cost. Moreover, the paper examines the global $\mathrm{CO}_{2}$ emission consequences of the optimal system solutions under the different energy market conditions. 
The idea for the paper came from the author of this thesis. The paper was planned together with Associate Professor Magnus Karlsson. The chosen model was constructed and run and the paper was written by the author of this thesis. Magnus Karlsson served as a sounding board for ideas and discussions during the work, as well as providing methodological support during the construction of the model. Building the model required data on available excess heat; these data were obtained from a questionnaire formulated and compiled by the author in collaboration with Dr. Sandra Backlund, formerly of Linköping University.

\section{Paper VI}

Ivner, J., Broberg Viklund, S. Effect of the use of industrial excess heat in district heating on greenhouse gas emissions: A systems perspective. Resources, Conservation and Recycling 2015;100:81-87.

This paper analyses and discusses system aspects of the use of industrial excess heat in DH. The analysis is based on GHG emission calculations and the analysis is conducted in two steps: 1) the introduction of excess heat in a contemporary DH system using life cycle assessment (LCA) calculations and 2) calculations based on future energy market scenarios for 2020 and 2030 to further explore system aspects.

This paper was planned and written together with Associate Professor Jenny Ivner, formerly of Linköping University. Calculations based on future energy market scenarios were performed by the author of this thesis, while the LCA was performed by Jenny Ivner; the analysis was carried out jointly. Associate Professor Magnus Karlsson supervised and commented on the work.

\section{Paper VII}

Broberg Viklund, S. Energy efficiency through industrial excess heat recovery - Policy impacts. Energy Efficiency 2015;8(1):19-35.

In this study, eight interviews were conducted with energy managers at Swedish manufacturing companies. Excess heat is a resource that may be used to increase energy efficiency; accordingly, interviews were performed to reduce the knowledge gap regarding factors that influence excess heat use, to improve our understanding of why excess heat use measures are or are not being implemented. This explorative study examines how Swedish industrial companies reason about the effects of policies on the use of excess heat, illustrating how energy policy instruments can be used to promote or discourage excess heat use.

The idea for the paper came from the author of this thesis, who also planned and conducted the interviews, analysed the data, and wrote the paper. Associate Professor Magnus Karlsson supervised and commented on the paper, while the methodological parts were supervised by 
Helen Peterson, a former research assistant at Linköping University now employed as Associate Professor at University of Gothenburg.

\subsection{Research journey}

When I started my $\mathrm{PhD}$, my research was to be oriented towards industrial clusters, particularly addressing how industries are integrated within a cluster and the cluster's connection with the surrounding society. In the interdisciplinary post-graduate school, the Energy Systems Programme, the first year as a $\mathrm{PhD}$ student mainly entailed participating in various courses within the programme's course package. The last course that year was an interdisciplinary project conducted in collaboration with Viktor Andersson and Roman Hackl, two PhD students from Chalmers University of Technology whose research concerned a related topic. Based on our different research topics, a project was formulated the aim of which was to study the integration of an algae-based biorefinery in an industrial cluster. From the work on this project, Paper IV was born.

In parallel, I got involved in a project studying the untapped industrial excess heat in Östergötland and Örebro counties in Sweden, which resulted in Paper II. Paper II also touched on the interaction of energy policies and excess heat use. In combination with the work on the algae project, which examined a possible use of excess heat, this project was the starting point of my research into excess heat use.

After my first year, I started to look more into available excess heat in Swedish industry and into various ways of using this heat resource. This work resulted in papers I and V. Paper I further studied untapped excess heat in Sweden but also considered several technologies for using that heat. Paper V is partly based on Paper I but uses optimization to examine excess heat use under different energy market conditions. These two papers also consider the climate aspects of using excess heat, in terms of effects on $\mathrm{CO}_{2}$ emissions.

As a PhD student in the Energy Systems Programme, I was encouraged to engage in interdisciplinary research. This led to the next part of my research journey, in which I saw new opportunities to highlight and analyse the use of excess heat from new points of view. Paper VII accordingly uses interviews to study how Swedish industries reason about the relationship between excess heat use and policy instruments. One interview was with a Swedish food company's energy manager, who mentioned that the company had just started to look into internal biogas production at the industrial site. This interview marked the beginning of the study that resulted in Paper III, which examined excess heat-supported biogas production at an industrial company, focusing on aspects such as climate impact and economics.

During the project on excess heat in Östergötland and Örebro counties, I got in touch with Associate Professor Jenny Ivner, working in the same project but at another division at Linköping University. A few years later, Jenny Ivner started working at my division, and 
again we started to discuss excess heat in DH. This discussion resulted in Paper VI, whose approach combines various research methods and time-frames to create an overview of the climate impact of the use of excess heat in DH. One of the methods, energy market scenarios, is used in several of the appended papers, whereas the other method, LCA, was added to gain a more reliable understanding of the prerequisites for and climate impact of the use of excess heat. 


\section{Energy efficiency and excess heat}

This chapter describes the context in which the constituent papers of this thesis were written. Industrial energy use, energy efficiency, and excess heat issues are presented.

\subsection{Industrial energy use}

The industry sector accounts for a large share of the final energy use in Europe (EU-28) as well as in Sweden. Approximately one-fourth of European (Eurostat, 2014) and two-fifths of Swedish (SEA, 2014b) energy end-use originates from industrial activities (see Figure 1 and Figure 2). A few sectors dominate the Swedish industrial sector in terms of energy use. This can be seen in Figure 2, which shows that the pulp and paper, iron and steel, and chemical industries accounted for almost $75 \%$ of the industrial energy use of approximately $146 \mathrm{TWh}$ in 2012.

The Swedish industrial energy use constituted of the following energy carriers in 2012: electricity (36\%), DH (3\%), biofuels and peat (40\%), coal and coke $(10 \%)$, oil products $(8 \%)$, and natural gas (NG) and town gas (3\%) (SEA, 2014b). The use of these fuels is associated with emissions of GHG. The industrial sector accounts for approximately one-fourth of the $\mathrm{CO}_{2}$ emissions in Europe (EU-28) and in Sweden, corresponding to approximately 1000 and 11 million tonnes of $\mathrm{CO}_{2}$ emissions, respectively, in 2012 (IEA, 2014). The industrial sector clearly contributes significantly to European and Swedish energy use, and consequently to the use of primary energy resources and GHG emissions. To prevent a global temperature increase of more than $2^{\circ} \mathrm{C}$, global GHG emissions have to be reduced significantly, i.e., more than $40 \%$ by 2050 (IPCC, 2014). In view of the above-noted industrial energy use, together with its GHG emissions, and increasing global industrial competition, efficient use of energy resources in this sector is necessary. 


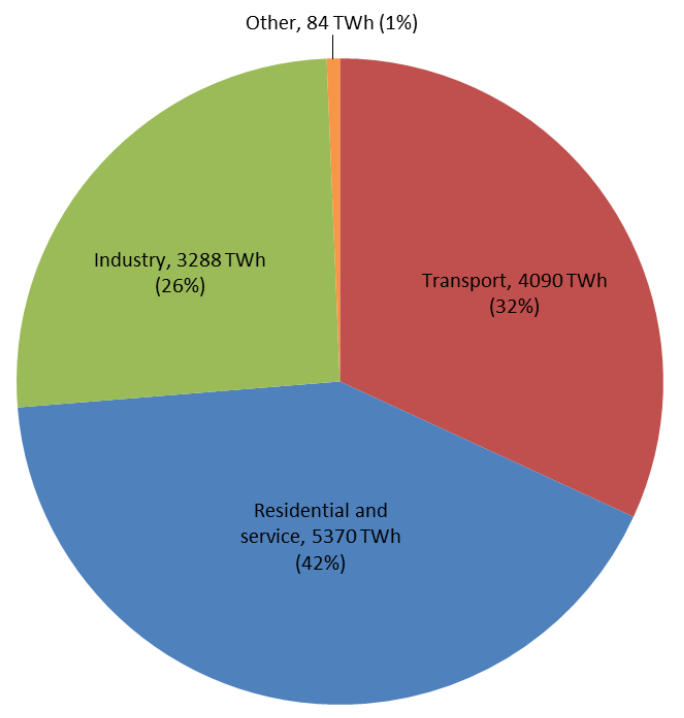

Figure 1. Final energy use by sector in Europe (EU-28) in 2012. Data on energy use taken from Eurostat (2014). Eurostat (2014) specifies data for the "service" (13\%) and "agriculture/forestry" $(2 \%)$ sectors, but in this graph the energy used in these sectors is included in the "residential and service" category to adapt the presentation to the Swedish energy use data illustrated in Figure 2.

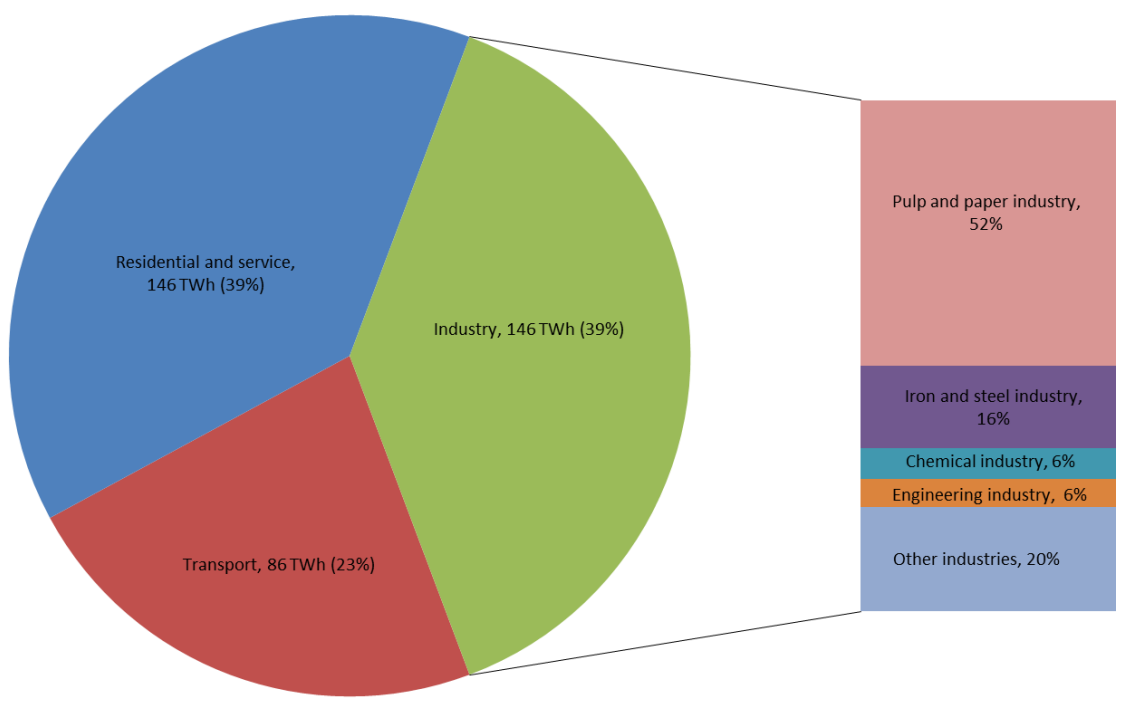

Figure 2. Final energy use in Sweden in 2012 by sector. The bar to the right specifies the industrial energy use by industry. Data on energy use taken from SEA (2014b). 


\subsection{Energy efficiency}

Improving energy efficiency is said to be key to reducing climate impact and increasing industrial sector competitiveness. Energy efficiency relates to the ratio between energy input (input resources) and the services provided (output) (Pérez-Lombard et al., 2013). Improved energy efficiency usually means using less energy while still providing the same service output; however, improved energy efficiency can also mean maintaining the amount of energy input while increasing the services provided (Ryan and Campbell, 2012). The benefits of improved energy efficiency are stressed in the literature. Ryan and Campbell (2012) present these benefits at four levels: international (e.g., reduced GHG emissions), national (e.g., increased energy security), sectoral (e.g., increased industrial competitiveness), and individual (e.g., increased disposable income).

Several opportunities exist to improve energy efficiency in the industrial sector. Worrell et al. (2009) review the opportunities for improved energy efficiency in industry. Among the sector-wide measures identified are improved motor system efficiency and energy recovery in the form of heat, power, and fuel recovery. Energy-efficiency improvement through industrial collaboration by exchanges of by-product, exchanges of excess heat, and integrated energy systems constitute the inter-industry opportunities. In addition, process-specific and management measures are enumerated (Worrell et al., 2009). Although energy-efficiency technologies and measures are well known, cost-effective technologies are not always implemented. This is referred to as the energy-efficiency paradox. The energy-efficiency gap is the difference between the current or expected future energy use and the optimal current or future energy use (Jaffe and Stavins, 1994). The existence of this gap can be explained by barriers to energy efficiency, where an energy-efficiency barrier can be defined as a "mechanism that inhibits a decision or behavior that appears to be both energy-efficient and economically efficient" and that "prevent investment in cost-effective energy efficient technologies" (Sorell et al., 2004). Examples of such barriers are: limited access to capital (i.e., opportunities may be overlooked due to lack of funds); imperfect information (i.e., opportunities may be overlooked because of insufficient information on energyefficiency potentials and technologies); and bounded rationality (i.e., opportunities may be overlooked due to lack of time or rule-of-thumb decisions) (Sorell et al., 2004). Policies can be used to overcome these barriers and encourage energy-efficiency measures.

In Europe, energy efficiency has steadily improved compared with energy use projections since the 2020 targets were set. However, part of the reduction in energy use can be explained by the economic recession during this time (EEA, 2014). Therefore, actions are still needed to reach the 2020 energy-efficiency target, and any additional targets that may be set beyond that. As part of this development, the EU launched the Energy Efficiency Directive (EED) in 2012 to address target for improved energy efficiency; the EED is further described in Section 0. 


\subsection{Excess heat}

\subsubsection{Excess heat: origin and definitions}

The large energy use in the industrial sector, the need for improved energy efficiency and the opportunities associated with the use of waste products from industrial processes direct our attention towards industrial excess heat use and associated opportunities and benefits. This thesis accordingly focuses on this industrial heat resource.

Industrial excess heat is an industrial process by-product characterized by lower exergy than that of the original energy carrier used in the production process in which it arose. No process achieves 100\% efficiency and not all the energy added to a system comes out as useful work; rather, part of this energy is always emitted as heat. Carnot efficiency is given by Eq. (1):

$$
\eta_{\text {Carnot }}=1-\left(\mathrm{T}_{\mathrm{c}} / \mathrm{T}_{\mathrm{h}}\right)
$$

where $T_{h}[K]$ is the temperature of the heat source (i.e., the higher-temperature medium) and $\mathrm{T}_{\mathrm{c}}[\mathrm{K}]$ is the temperature of the heat sink (i.e., the lower-temperature medium, e.g., the environment). This gives the maximum theoretical efficiency of a heat engine operating between two temperatures. The larger the temperature difference between the hightemperature medium, $T_{h}$, and the low-temperature medium, $T_{c}$, the higher the efficiency. However, practical restrictions, such as the temperature limits of various materials, limit the realizable efficiency. For example, if the construction of a coal power plant can withstand $380^{\circ} \mathrm{C}\left(\mathrm{T}_{\mathrm{h}}\right)$ and the cooling water is at a temperature of $40^{\circ} \mathrm{C}$, this would give a maximum efficiency of $52 \%$, so almost half of the input energy would be released as heat. In reality, the efficiency would be even lower than the Carnot efficiency due to inefficiencies such as friction in the system (Wolfson, 2011). This relationship is illustrated in the schematic picture in Figure 3.

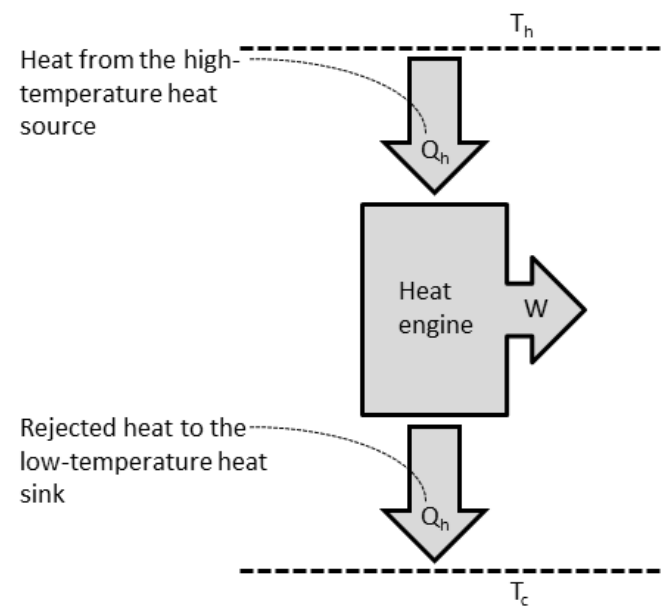

Figure 3. Schematic picture of a heat engine operating between two temperatures. 
The following general definition of excess heat is used in this thesis: Industrial excess heat is heat (bound in liquids, gases, or hot materials) generated in an industrial process and currently not used internally in the processes. There is no generally accepted uniform definition of excess heat, and several terms and definitions have been proposed and used throughout the literature, some of which will be described ${ }^{2}$ here. Waste heat, surplus heat, secondary heat, and excess heat are all terms used to describe the heat rejected from industrial processes. Grönkvist et al. (2008) discuss two ways of defining excess heat: "Excess heat is heat that is left over after an industrial process has become (thermodynamically) optimized" and "Excess heat [is heat] that cannot be used directly in the industrial process". Both definitions are problematic, as it may be a complex task to determine when a process has been optimized, while one interpretation of the second definition would include industrial production intended to produce excess heat for $\mathrm{DH}$ networks (Grönkvist et al., 2008). In a report included in the IEA Annex ${ }^{3}$ on industrial excess heat recovery, excess heat is defined as "the heat content of all streams (gas, water, air, etc.) which are discharged from an industrial process in a given moment". However, in addition to this general definition they presents a number of subcategories defining different shares of excess heat, such as technically and economically usable excess heat as well as green excess heat originating from biomass (Berntsson and Åsblad, 2015). All three definitions presented here refer to heat generated at an industrial facility, while in other contexts other types of heat are included. For example, in the EED, the term "waste heat" also comprises heat generated at electricity generation plants (European Commission, 2012), and sometimes energy gases generated as a by-product of industrial processes are included (Grönkvist et al., 2008). Compiling a uniform definition is clearly not easy.

As the first definition of excess heat implies that the processes considered should be thermodynamically optimized, what is or is not "true" excess heat can be questioned. The concept is sometimes used to refer to the share of excess heat that can be used externally, after the share that is technically or economically usable internally has been deducted (Berntsson and Åsblad, 2015). Bendig et al. (2013) distinguish between avoidable and unavoidable heat flows, where avoidable heat flows refer to excess heat from a process that is not optimized and unavoidable heat flows to excess heat from a process that is optimized. By making this distinction, it is claimed that one can avoid making investments that ultimately overlook more energy-efficient measures. This phenomenon is found in e.g. Klugman (2008) where a paper mill designed their processes for heat deliveries to a $\mathrm{DH}$ network, thereby increasing its internal energy use. Berntsson and Åsblad (2015) also discuss the concept of true excess heat and try to define a reasonable level of internal heat recovery in order to find the true share. They suggest that a reasonable level of excess heat should be recovered internally and subtracted from the potential in order to identify the share of true excess heat. They specify that a reasonable level refers to a level in accordance with "existing practices and traditions in an industry regarding requirements on return on investments"

2 The definitions were mainly given in Swedish and translated by the author of this thesis; for the original formulations, the author refers to the sources of the definitions.

3 Annex XV: Industrial Excess Heat Recovery - Technologies and Applications. 
(Berntsson and Åsblad, 2015). What is clear from these discussions is that what does or does not constitute true excess heat is not clear.

The allocation of $\mathrm{CO}_{2}$ emissions to excess heat may affect whether or not the use of excess heat is encouraged. If the aim is to achieve efficient resource use and reduce primary energy use, then excess heat use is likely desirable. In line with the assumption of this thesis, $\mathrm{CO}_{2}$ emissions are generally not allocated to excess heat as it is considered a by-product of industrial production (Grönkvist et al., 2008; Gode et al., 2010). This zero-emission allocation principle can however be questioned if the industrial energy use increases to enable excess heat deliveries or if the industrial process in which it arose is not optimized (Grönkvist et al., 2008; Grönkvist and Sandberg, 2006).

\subsubsection{Excess heat use opportunities}

Instead of being wasted, industrial excess heat can be used for a number of applications, thereby offering various benefits. The heat can either be recycled in the process in which it arose or recovered and used in another process, either in the industrial plant or in other external applications. Examples of excess heat use in the industrial plant are steam generation, water preheating, and premises heating (Thekdi and Belt, 2011). Thekdi and Belt (2011) look into various excess heat-recovery options and rank them in the order in which they should be considered for improving energy efficiency. The same general hierarchy is discussed in Bendig et al. (2013) and in Law et al. (2013) based on economic factors. The following order of recovery options should be considered (Thekdi and Belt, 2011):

1. Reduction - the amount of excess heat should be reduced through efficient use of heat within the process.

2. Recycle - reuse excess heat within the process in which it arose.

3. Recovery - use excess heat in other parts of the industrial plant or externally.

4. Recovery - use the heat for power conversion.

As described in Section 1.2, this thesis focuses on points three (partly) and four, use of excess heat within the process in which it arose or internally at the industrial plant is not considered.

Several alternatives for the recovery and use of excess heat for external applications exist (Ammar et al., 2012). Broadly speaking, excess heat can be used for heating, cooling, and electricity production applications. Several technologies and systems solutions exist for these alternatives. In addition to these applications, heat exchangers, heat pumps, and radiation collectors can be used to make excess heat accessible for use. Also, heat storage can be used to overcome obstacles associated with intermittent heat flows and distances between heat source and heat sink. This section should not be seen as a comprehensive review of excess heat-recovery solutions; rather, it is intended to visualize the broad variety of opportunities for reusing this thermal resource. 
Using excess heat as a thermal source in DH is a well-known concept. Sweden has well-developed DH systems available in approximately 270 of 290 Swedish municipalities, divided into more than $450 \mathrm{DH}$ systems. The supply temperature in Sweden is approximately $70-120^{\circ} \mathrm{C}$, depending on, for example, the season and weather conditions, and the return temperature is approximately $30-60^{\circ} \mathrm{C}$. Collaborations on excess heat use between industries producing the heat and $\mathrm{DH}$ companies resulted in about $7 \%$ of the $\mathrm{DH}$ energy supply originating from industrial excess heat in 2013 (Swedish District Heating Association, 2014; Arnell et al., 2013). The largest share of industrial excess heat deliveries comes from energyintensive industries such as the pulp and paper, iron and steel, and chemical or refinery industries, which deliver heat to approximately $60 \mathrm{DH}$ networks (Swedish District Heating Association, 2010; Arnell et al., 2013). If the excess heat temperature is too low for direct deliveries, heat pumps can be used to increase the temperature, a solution currently used in several Swedish DH networks (Arnell et al., 2013). To increase the use of excess heat, regional DH systems are also being considered. Connecting several DH systems may also offer advantages of scale, such as more cost-effective electricity and heat production (Sandvall et al., 2015). Sandvall et al. (2015) and Karlsson et al. (2009) studied the integration of several local DH systems and an industrial companies in Sweden and concluded that such setups may reduce both primary energy use and $\mathrm{CO}_{2}$ emissions (Sandvall et al., 2015; Karlsson et al., 2009). The delivery of excess heat to Swedish DH systems has been fairly constant in recent years: the trend only indicates a slight linear increase with actual deliveries of approximately 3500-4200 GWh per year, as illustrated in Figure 4 (Swedish District Heating Association, 2014).

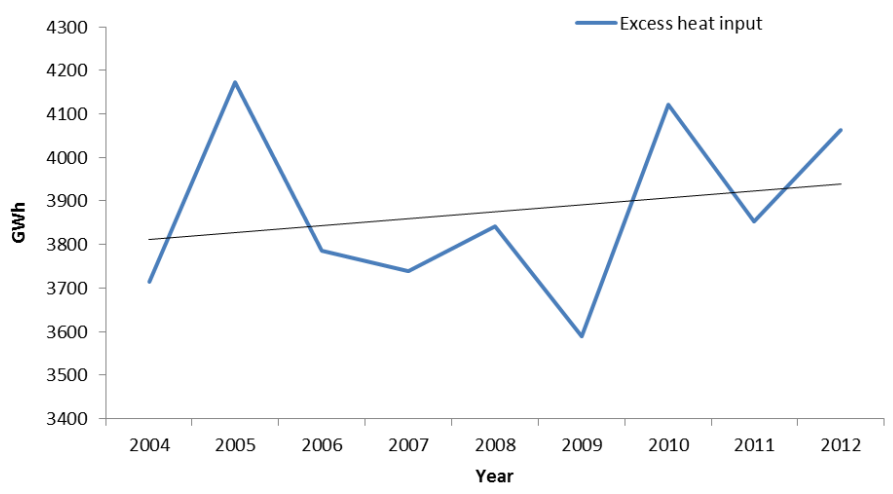

Figure 4. Excess heat input in Swedish DH networks, 2004-2012 (Swedish District Heating Association, 2014).

Sweden is not the only country using excess heat in DH systems. The concept is used both in Europe and elsewhere, although often on a smaller scale (Rezaie and Rosen, 2012; Persson and Werner, 2012).

Cooling constitutes a growing market in Sweden, and district cooling (DC) deliveries are forecast to increase by approximately $40 \%$ between 2014 and 2015, going from 0.9 TWh to 1.3 TWh (Swedish District Heating Association, 2015). The same increasing trend has been 
seen in Europe and throughout the world (Rydstrand et al., 2004). Different technologies exist for cooling production, absorption cooling offering an alternative to compression chilling, which is driven by electricity. Absorption cooling uses the energy in a heat source, such as excess heat, to run a refrigeration system, i.e., the heat source is used to evaporate the refrigerant, only a small amount of electricity being needed for pumping. Lithium bromide $(\mathrm{LiBr})$ and water-based ${ }^{4}$ absorption coolers are commercially available today for large-scale applications. In Sweden a number of energy companies (e.g., in Linköping and Gothenburg) have invested in absorption cooling equipment and provide customers with cooling through DC systems. The temperature of the heat used in absorption cooling production is normally $80-120^{\circ} \mathrm{C}$ (Rydstrand et al., 2004; Arnell et al., 2013). Coefficient of performance (COP) values for absorption chillers are reported to range from approximately 0.5 to 0.8 (Rydstrand et al., 2004; Srikhirin et al., 2001).

Heat recovery also offers possibilities for electricity generation from excess heat, some of which will be discussed in this section. Research and development in this area has resulted in several types of recovery systems for this purpose has been developed and is still evolving (Thekdi and Belt, 2011). These options include Rankine cycles (e.g., the organic Rankine cycle, ORC), thermophotovoltaic (TPV) systems, and phase-change material (PCM) systems. As can be seen in the numbered list at the beginning of this section, Thekdi and Belt (2011) recommend heat recovery for power conversion as the last option due to low efficiency that may lead to poor profitability.

The Rankine cycle, ORC, and Kalina cycle are all power cycles based on the principle of heat energy being converted into mechanical energy used to produce electricity. An external heat source, such as excess heat, is used to evaporate the process working medium. The traditional steam Rankine cycle may have limited use in excess heat-recovery applications because suitable heat should be hotter than $240^{\circ} \mathrm{C}$ (Law et al., 2013). The ORC and the Kalina cycle offer new possibilities because they use different working media with lower boiling points and thus can operate with lower excess heat temperatures. A range of organic working media is available for the ORC process, while the Kalina cycle uses a mixture of ammonia and water (Ammar et al., 2012). A number of ORC plants are running worldwide on different heat sources (U.S. Department of Energy, 2008), and in Sweden plants are running on excess heat in water from two pulp and paper companies (Holmgren and Sjödin, 2008; OES Opcon group, 2015). Another low-temperature power cycle is the PCM cycle. A heat source is used to heat a working medium consisting of a paraffin mixture. The mechanical energy arising from the volume expansion of this mixture when it changes from solid to liquid state, and back again through cooling by water, is used to produce electricity in a generator.

Unlike the Rankine cycles, which use heat to produce electricity through conversion to mechanical energy, new technologies are being developed in which electricity is generated directly from the heat; one such technology is TPV systems. In TPV systems, the radiation

${ }^{4}$ The water serves as a cooling medium (refrigerant) and the LiBr as a working medium (absorber). 
from high-temperature heat sources $\left(>1000^{\circ} \mathrm{C}\right)$ is used to produce electricity. The heat source is used to heat the emitter, which consequently emits electromagnetic radiation that is converted into electricity in a PV cell. However, these technologies are mainly in the developmental stage (U.S. Department of Energy, 2008; Bauer et al., 2004). A more thorough description of the alternatives for excess heat use and their efficiencies is presented in Paper I.

In addition to the technological opportunities discussed above, excess heat can be used in industrial collaborations in which the heat is used in nearby industrial plants or businesses. This possibility will be further discussed in Section 2.4.

\subsubsection{Excess heat availability}

Despite the above discussed opportunities for excess heat use and considering data on current heat use, studies indicate that this resource still remains largely unused. Cronholm et al. (2009) calculate the excess heat potential in Sweden based on the total amount of excess heat delivered to the DH system and the amount of energy used in various industry sectors. Based on the assumption that each company in a sector has the same ability to deliver excess heat, the potential was calculated and finally partly adjusted based on known prerequisites. The theoretical potential totals 6.2-7.9 TWh per year, of which approximately half is used today (Cronholm et al., 2009). Connolly et al. (2014) estimate the excess heat potential in EU27 countries and identify the quantities that could be delivered to $\mathrm{DH}$ networks. Their estimate, which is based on European emission data combined with assumed $\mathrm{CO}_{2}$ emission factors and heat recovery efficiencies, totals $2710 \mathrm{PJ}$ of industrial excess heat annually, which is thought to be more than enough to cover future DH demands (Connolly et al., 2014). Persson and Werner (2012) estimate the heat-recovery potential in EU27 countries' DH systems based on current reported excess heat in DH systems, the figures being adjusted according to Member State best practices. Their theoretical assessment identifies that $430 \mathrm{PJ}^{5}$ of industrial excess heat could be used in DH systems if applying Member State best practices (Persson and Werner, 2012). Studies also indicate that only 3\% of the available industrial excess heat is currently being used in DH (Euroheat \& Power, 2013). Bendig et al. (2013) discuss the division of excess heat potential into resource and reserve potentials, where "resource" refers to a theoretical excess heat potential and "reserve" to a lower potential taking technological and economic restrictions into account (Bendig et al., 2013). These excess heat resources can differ in nature and be found in gases (e.g., flue gases, air, and steam), liquids (e.g., water), and solids (e.g., heat in materials) (Thekdi and Belt, 2011).

Two important parameters related to excess heat recovery feasibility are quantity and quality: quantity refers to the amount of energy contained in the excess heat, while quality refers to the temperature of the heat stream, which determines its usefulness (U.S. Department of Energy, 2008). The concepts of primary and secondary excess heat are sometimes used to distinguish heat of different temperature levels. Primary heat refers to excess heat that meets

5 The analysis includes industries in the following sectors: iron and steel; chemical and petrochemical; non-metallic minerals; non-ferrous metals; paper, pulp, and printing; and oil refining. 
temperature requirements for delivery directly to a $\mathrm{DH}$ network, while secondary heat is lower in temperature and therefore needs upgrading before being used as DH (Cronholm et al., 2009; Arnell et al., 2013).

Studies of excess heat potentials as described in this section are mainly top-down studies; bottom-up studies in the field are scarce, for example, as noted in Bendig et al. (2013) and Persson et al. (2014). The untapped excess heat potentials considered in this thesis are based on site-specific data. In bottom-up studies based on site-specific data, data may be collected not only on the quantity of excess heat but also on other aspects such as temperature and carrier medium.

\subsection{System studies of excess heat}

By broadening the system boundary, industrial excess heat that would otherwise be wasted can find new uses. This section presents a brief overview of system studies of excess heat.

The complexity of trade-offs between internal and external uses of excess heat has been examined. Svensson et al. (2008) develop an approach for determining whether it is more economic to use excess heat internally for electricity generation or externally as DH. The approach also takes account of the $\mathrm{CO}_{2}$ emissions associated with the different uses. The approach is based on modelling with an expanded system boundary, that is, both the company producing excess heat and the energy company are modelled within the same system boundary when exploring conditions for favourable cooperation (Svensson et al., 2008). This approach is applied by Jönsson et al. (2008) to examine excess heat cooperation between a kraft pulp mill and an energy company considering different future energy market conditions. The study demonstrates that the trade-offs between internal and external use depend on several factors: energy market prices, type of heat production, and DH demand. Optimization results indicate that external use, i.e., excess heat delivered to $\mathrm{DH}$, is profitable if the recipient heating systems have small heat loads. ${ }^{6}$ In addition, external use results in larger emission reductions than does internal use (Jönsson et al., 2008). Morandin et al. (2014) also found that it could be profitable to deliver excess heat from a petrochemical cluster to a DH system, but their accounting of the $\mathrm{CO}_{2}$ emission consequences of these heat deliveries provided no clear indication of reduced regional emissions.

A conflict between excess heat use in $\mathrm{DH}$ and combined heat and power (CHP)-based heat production has been discussed in the literature, commonly being explained by favourable economic conditions. This conflict assumes that introducing excess heat in $\mathrm{DH}$ will necessarily displace other types of heat production. Current energy policy however in many cases prioritizes bio-based electricity production (for a description of the electricity certificate

\footnotetext{
${ }^{6}$ Three sizes of DH systems were studied, small, medium, and large. The small system heat demand was set to $117 \mathrm{GWh}$ in the study.
} 
system, see Section 3.3) and, by extension, bio-based CHP production (Arnell et al., 2013; Jönsson et al., 2007). This competition will be further described in Section 5.6.

Law et al. (2013) review the best available opportunities for excess heat recovery in the food and drink processing industry, focusing on excess heat below $260^{\circ} \mathrm{C}$. Both internal options for excess heat use within the industrial plant and electricity production options for excess heat use are considered. They conclude that internal excess heat use is generally the most economic options, but that interest in heat-driven electricity generation projects may increase with rising energy prices and the increasing emphasis on energy efficiency (Law et al., 2013). Johansson and Söderström (2014) discuss opportunities for heat-driven electricity generation in the steel industry and evaluate different technologies based on heat source temperature, conversion efficiency, capacity, and economic factors. Although not all associated costs, such as piping and pumps, are included in the calculations, the study indicates that investment in such technologies could be profitable (Johansson and Söderström, 2014). Campana et al. (2013) estimate the potential for large-scale implementation of ORC technology for electricity production in EU27 cement plants, steel plants, glass plants, and oil and gas industries. The authors conclude that ORC is a viable option for excess heat recovery and identify an energy recovery potential ranging from approximately 13.5 up to 21.5 TWh per year in the studied industries. Such heat recovery enables avoided $\mathrm{CO}_{2}$ emissions and cost savings, as less electricity needs to be purchased (Campana et al., 2013).

Excess heat use is also discussed in the industrial symbiosis (IS) community. Martin and Eklund (2011) and Ellersdorfer and Weiss (2014) both identify opportunities to use excess heat in biofuel production. Martin and Eklund (2011) focus on biofuel production industries and consider how to improve their environmental performance by applying IS theories. Among other things, they note that low-temperature thermal requirements could be fulfilled by excess heat, thereby reducing the energy used in these processes (Martin and Eklund, 2011). Ellersdorfer and Weiss (2014) look into the synergy effects of integrating cement works and biogas production using a process model based on energy and mass flow balances. The proposed synergy setup includes using excess heat in biogas production and the produced biogas to replace fossil fuels in the cement works, reducing associated $\mathrm{CO}_{2}$ emissions and bringing economic gains (Ellersdorfer and Weiss, 2014). A technical and economic methodology that considers the viability of exchanges between industries and greenhouses is presented by Andrews and Pearce (2011). This is done through a case study of exchanges between a glass manufacturing plant and a tomato greenhouse, taking account of energy-efficiency improvements accruing, for example, from external excess heat use. Greenhouses require low-temperature heat and may also offer use for $\mathrm{CO}_{2}$ containing flue gases as a carbon source in crop cultivation. The authors mainly highlight the economic benefits in terms of reduced heating costs and reduced costs of $\mathrm{CO}_{2}$ emissions (Andrews and Pearce, 2011). This concept is currently used in a Swedish tomato greenhouse using excess heat from pulp and paper production and $\mathrm{CO}_{2}$ from spirits production, thereby reducing climate impact (The Confederation of Swedish Enterprise, 2013). Wolf et al. (2007) investigate the possibility of developing an IS network between existing industries in the forest industry, a municipality, and an energy service company and identify several excess 
heat use opportunities. Excess heat deliveries to the DH system would either reduce the use of fossil fuels in that system or replace biofuels, which could in turn replace oil in other parts of the energy system. Another opportunity discussed is heat use in the drying process in pellet production (Wolf et al., 2007). 


\section{Energy policies in relation to excess heat}

This chapter gives an introduction to energy-related policy instruments and European directives that affect the Swedish industrial sector and that can affect industrial excess heat use.

European directives specify the objectives that Member States are obliged to achieve. The directives are binding in terms of their goals, but Member States are free to determine how to achieve these goals, for example, by introducing new legislation. As the purpose of the directives is to harmonize the national legislation of Member States, EU directives will greatly extent influence Swedish policies. Policy instruments can be used to create incentives to change the use of various resources in order to achieve more efficient resource use. Policy instruments can be divided into three main categories, which sometimes overlap: informative policy instruments, administrative policy instruments, and economic policy instruments. Research and development policies are sometimes said to constitute a fourth category of policy instruments. This chapter focuses on directives and policies relevant to this thesis and that are discussed in the appended papers, i.e., policies and directives that deal with or may affect the use of excess heat.

The EU energy-efficiency target calls for energy efficiency to be improved as part of the European strategy for achieving smart, sustainable, and inclusive growth (European Commission, 2010; European Commission, 2011). To move towards improved energy efficiency, the Energy Efficiency Directive (EED) provides a framework for the development of new energy-efficiency policies (European Commission, 2012). The Directive aims to tackle both the supply and user sides by helping remove barriers and overcome market failures affecting energy efficiency. Among the measures for improving energy efficiency, the Directive identifies recovery of excess heat as one way to improve the efficiency of heating and cooling systems. The Directive states that a cost-benefit analysis of excess heat use should be performed whenever an industrial facility ( $>20 \mathrm{MW}$ thermal input) is planned or extensively refurbished, when a new DH or cooling network is planned, and when a new energy generation facility $(>20 \mathrm{MW})$ in an existing network is planned or extensively refurbished (European Commission, 2012). This is also the basis of the implementation of the Directive in Sweden (Swedish Government, 2014a); however, there is no requirement that the most profitable option identified by the analysis should be implemented (SEA, 2015). 


\subsection{Informative policies}

Informative policies can take various forms such as information, advisory services, and education. These instruments can be used to overcome various information-related market failures that emerge when, for example, information is not available or when different parties have different degrees of access to information. Also, they can form a basis for other policy measures by, for example, creating acceptance for the implementation of administrative and economic instruments (Swedish Environmental Protection Agency, 2012). Information campaigns that enable dialogue have been discussed as a measure that may promote excess heat cooperation. It is also claimed that other kinds of informative policies, such as advisory services, could support DH companies and industrial companies regarding, for example, technology, finance, and contractual and agreement issues, to advance the development of excess heat cooperation (Holmgren and Sjödin, 2008).

\subsection{Administrative policies}

Administrative policy instruments can take various forms, such as regulations, limit values on emissions, fuel type and energy-efficiency requirements, long-term agreements, and environmental classifications. The Swedish Environmental Code is a central administrative policy instrument in Sweden (Swedish Environmental Protection Agency, 2012). The aim of the Code is to promote sustainable development. One of its missions, which is connected to excess heat use, is that the Code should be applied so that "reuse and recycling as well as other economization measures for materials, raw materials, and energy are promoted so that a closed loop is achieved" (Chapter 1, 1 』) (Swedish Government, 1998). This mission should be taken into account and provide guidance in, for example, the process of licensing industries. The Environmental Code also states that "measures should be taken to economize [the use of] raw materials and energy and use opportunities for reuse and recycling" (Chapter 2, 5 \) (Swedish Government, 1998). However, several environmental targets may be incompatible, in which case the Environmental Code will be applied in such a way that best meets the overall aim (Mansikkasalo et al., 2011).

In accordance with current Swedish regulations, new heat producers, such as industrial companies with untapped excess heat, have no automatic right to access the DH grid. The DH companies are obliged to negotiate with potential new suppliers but are entitled to refuse access. In 2009, a commission was appointed to investigate the possibility of competition on the DH market through the introduction of a TPA. The report, tabled in 2011, recommended the introduction of a TPA to the DH network, to give all heat producers the right to access the grid. Also, the framework suggested changing the ownership structure by dividing the market into three parts: distribution (via the grid owners, which form natural monopolies), heat production, and companies selling the heat (SOU 2011:44 (Ministry of Enterprise Energy and Communications), 2011). Limited conditions for effective competition combined with significant entry barriers to the DH market (e.g., economy of scale) formed the basis of the decision still not to implement TPA. Instead, the introduction 
of regulated access to the DH network was proposed (SOU (Ministry of Enterprise Energy and Communications), 2012). The government bill on regulated access to the DH network, which passed in 2014, aims to strengthen the excess heat suppliers' position. The bill proposes that actors that want to access the grid should receive regulated access under certain conditions. The obligation to give access to the network is limited to primary excess heat and new actors that have not been connected to the grid. However, the bill also states: "The DH company has no obligation to allow regulated access if the company can show that there is a risk that it will suffer damage as a result of the access" (Swedish Government, 2014b).

\subsection{Economic policies}

Economic policy instruments are used to internalize external costs (i.e., costs associated with negative externalities) or for fiscal reasons. Economic policy instruments include taxes and tax reductions, grants, market-based trading systems, and fees and subsidies (Swedish Environmental Protection Agency, 2012). In Sweden there are taxes on fuels, electricity, carbon dioxide, and other pollutants; however, biofuels and fuels used for electricity generation are exempt from taxation. The tax on fuel and electricity use is imposed mainly for fiscal reasons, whereas the $\mathrm{CO}_{2}$ tax aims to reduce environmental impact through internalizing environmental costs. Sectors with low price sensitivity are subject to higher tax rates than are sectors exposed to external competition (Mansikkasalo et al., 2011). By either increasing or reducing the costs associated with specific products or services, the policy measures try to direct various actors' actions. As a result, the taxation system can affect the desirability of excess heat as an energy resource.

The EU Emission Trading Scheme (EU ETS), now in its third phase (2013-2020), was implemented in 2005 and aims to limit maximum $\mathrm{CO}_{2}$ emissions in a cost-effective manner. A maximum level of allowable $\mathrm{CO}_{2}$ emissions is set and the level is reduced annually. Cost-effective emission reduction is achieved because companies within the system can trade their emission permits, meaning that companies with low emission-reduction costs can sell their permits to companies with high emission-reduction costs (European Commission, 2014b; Mansikkasalo et al., 2011).

To obtain a more sustainable energy system, the electricity certificate system was introduced in 2003 to increase electricity production from renewable sources. Producers of renewable electricity receive a certificate for each MWh of electricity produced. Electricity suppliers and some users are obliged to purchase certificates in accordance with a quota based on their total electricity supply or use. The quota is changed annually to increase the demand for certificates and thereby the share of renewable electricity. The system generates an extra source of income for electricity producers, making it more profitable to invest in renewable electricity production (SEA, 2010). Beyond certificates for electricity production from, for example, wind power, solar power, hydropower, and biomass, excess heat originating from biomass used in heat-driven electricity production also entitles the electricity producer to green electricity certificates (Holmgren and Sjödin, 2008). 
The voluntary Programme for Improving Energy Efficiency in Energy Intensive Industries (PFE) was introduced in 2005. The aim of PFE is to increase electricity efficiency in energy-intensive industries, and the incentive to join is that participating energy-intensive companies that use electricity in their production processes can be exempted from the electricity tax. However, the programme entails obligations for the participating firms, including performing energy audits, identifying and implementing electricity-efficiency measures, and implementing a standardized energy management system (SEA, 2005). The energy audit not only considers electricity flows, but heat and fuel flows must also be identified (Holmgren and Sjödin, 2008). A second five-year programme period is running until 2017, but no new programme periods will be started (SEA, 2014c). Although the programme focuses on electricity efficiency, its commitments could affect energy efficiency in general (Stenqvist and Nilsson, 2012), for example, by increasing excess heat use.

Investment grants can be used to benefit specific energy-related investments and may also be offered for investments in excess heat use. Two such investment programmes are the Local Investment Programme (LIP), running between 1997 and 2002, and the Climate Investment Programme (Klimp), running between 2003 and 2012. Klimp and LIP aimed to promote sustainable development, for example, by helping achieve Sweden's climate targets and improve ecological sustainability. Both programmes offered funding for various investments, including for excess heat use (Byman et al., 2005; Swedish Environmental Protection Agency, 2013). The cost-effectiveness of such programmes has been questioned as their effects are difficult to measure, though they may help provide a more reliable grasp of the costs of long-term investments (Holmgren and Sjödin, 2008). 


\section{Scientific context}

This chapter gives a brief introduction to the theoretical background of this thesis; the systems analysis approach and various approaches to the valuation of GHG emission consequences arising from changes in the energy system and new energy-related investments.

This chapter presents three main approaches applied in this thesis. First, the overall systems approach is described. Two approaches related to electricity and biomass use that have greatly influenced the present analysis are then presented.

\subsection{Systems analysis}

A system can generally be viewed as a group of interacting components. Ingelstam (2012) has attempted to summarize what defines a system: A system consists of components and the relationships between them, which in some way form a unity. A system boundary separates the system from the surrounding world. The system is usually not closed; rather, certain components that do not belong to the system itself affect it, and this is called the system environment. The system environment may take various forms and may be just as important for the systems analysis as the system itself (Ingelstam, 2012).

Churchman (1968), a pioneer of systems thinking, linked the difficulties of solving a number of problems, such as access to clean water, air, and food, to their systems characteristics, thereby stressing the need for a systems approach. By using a systems approach, Churchman (1968) stresses that one can avoid sub-optimizations. The approach entails no restrictions in the methods used to analyse systems; instead, the most suitable method for a given problem should be applied (Churchman, 1968).

Like other systems, industrial energy systems and energy systems in general consist of interconnected components. Using a systems approach offers the possibility to study the entangled nature of these systems, since the optimal solutions for single parts of an energy system may differ from the optimal solution for the whole system. Systems analysis mainly studies the interaction of components within a system and the relationship between the system and its surroundings. For example, looking at the effect on GHG emissions of using industrial excess heat and drawing the system boundary around the industry itself may give one result. However, including a DH system in the analysis, where the introduction of excess heat in the thermal system might affect current heat production, may give another result. 
Also, the surrounding energy system will affect the result. This example and the two system boundaries are illustrated in Figure 5.

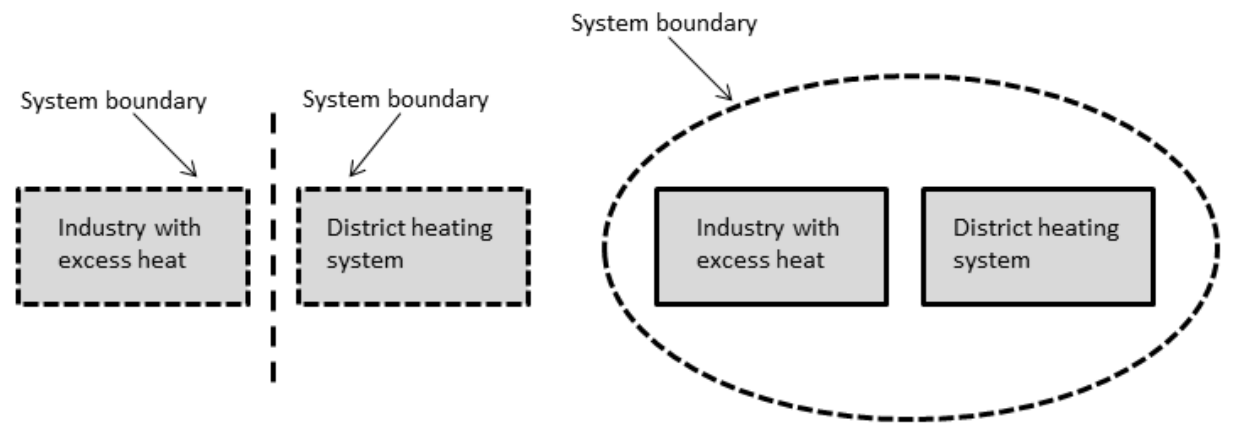

Figure 5. Illustration of a systems approach. An example of how components can be studied via two different system boundaries.

The idea of interconnections between different parts of the energy system forms the basis of this thesis. The system boundaries used in this thesis are extended to encompass not only the source of excess heat and its use, but also other parts of the energy system that will be affected by the introduction of excess heat. This will be further problematized in Section 5.6. The system surroundings include various energy system parameters that the system itself cannot control, such as fuel and electricity prices and energy policy.

\subsection{Assessment of effects on GHG emissions of changes in electricity production and use}

The increase in the concentration of anthropogenic GHG in the atmosphere is largely derived from the combustion of fossil fuels, including in electricity generation processes. Regardless of the localization of the $\mathrm{CO}_{2}$ emission source, the emissions all contribute to global climate change (Vanek and Albright, 2013) and can therefore be considered global emissions. Introducing excess heat in a DH network may displace heat produced by other technologies. If the heat displaced originated from CHP production, less electricity will be produced in that plant. Various approaches can be used to assess the environmental implications of changes in electricity use or production (Sköldberg et al., 2006), two of which are briefly discussed here. One such approach is to calculate average emissions based on electricity production mix data during a given period for a particular country or region, for example (Dotzauer, 2010; Sjödin and Grönkvist, 2004; Sköldberg et al., 2006). This is a straightforward, convenient approach based on the statistics on electricity production in a given area. However this approach may not always best capture the actual changes in an energy system due to system dynamics. Today's deregulated Nordic electricity market allows for exchanges between the Nordic countries (Gode et al., 2009). Besides the Nordic countries, Sweden can exchange electricity with other European countries, such as Germany and Poland, although the transmission capacities are limited (Sjödin and Grönkvist, 2004). 
Sjödin and Grönkvist (2004) discuss how European electricity markets will become even more interconnected and that this development, with increased European cross-border electricity trade, would make the national electricity market less relevant.

The operational marginal electricity approach addresses these electricity system interconnections. Using this approach, a change in electricity use affects the electricity production technology with the highest operational costs at a given time (Dotzauer, 2010). That is, increasing electricity use would increase the electricity production using this marginal technology by the same amount, and vice versa for decreased electricity use. Consequently, the change in $\mathrm{CO}_{2}$ emissions from added or saved electricity corresponds to the emissions associated with the production change in a marginal power plant. A common assumption is that from the short- and medium-term European perspectives, coal condensing power (CCP) plants are assumed to be on the margin, while NG-based production (e.g., natural gas combined cycle - NGCC - plants) is on the margin from a longer-term perspective (Sköldberg et al., 2006; Dotzauer, 2010; SEA, 2002; Sjödin and Grönkvist, 2004; Gode et al., 2009). Historical data have indicated that, during dry years, electricity production from CCP plants increases to cover the reduced hydropower production in Nordic countries (SEA, 2002). Changes in electricity use also affect what investments in new electricity generation technologies will be made in the future, in what is referred to as the build margin. That is, the build margin determines the electricity production that will or will not be built due to changes in electricity demand. Predicting the future build marginal technology is not easy as it depend on several factors, such as future electricity demand (Gode et al., 2009).

\subsection{Accounting for biomass use}

As a result of the increased emphasis on reducing global $\mathrm{CO}_{2}$ emissions, the use of biomass has been brought forward as an important resource in several EU climate targets. In addition to the previously mentioned target that $20 \%$ of final energy use should come from renewable resources by 2020 (EEA, 2014; European Commission, 2010), a target for 10\% renewable energy in the transport sector has been set (European Commission, 2009). The biodegradable fraction of products, waste, and residues from agriculture and forestry as well as biodegradable waste from industries and municipalities all constitute biomass (European Commission, 2009). Various sectors and users are competing for the available biomass. In the energy sector, biomass can be used to produce fuels for transportation and for electricity or heat production (European Commission, 2005). In addition, biomass can be used in producing, for example, food, animal, and forestry-based products (Moriarty and Honnery, 2012). Several studies summarize and discuss future energy projections and estimates of the potential for renewable energy to cover these demands. Although biomass could supply a large share of the future energy demand in Europe, biomass resources are insufficient to cover the total demand and must therefore be used efficiently (Torén et al., 2011; Moriarty and Honnery, 2012; Wetterlund et al., 2012). As well, with the introduction of energy policies to promote the use of biomass, competition for this resource has increased (Kautto et al., 2012). To conclude, biomass cannot be viewed as an unlimited resource. 
The biomass market currently consists of several local markets where national policies and regional conditions result in diversified price setting. Given the movement towards increased biomass use, a well-functioning European bioenergy market may develop (Axelsson and Harvey, 2010), thereby limiting the availability of biomass in the Swedish energy system (Elforsk, 2008). As long as biomass is harvested and regrown without a loss in carbon stock, this resource can be considered $\mathrm{CO}_{2}$ neutral (Watson et al., 2000). However, since biomass is a limited resource, assuming a competitive European market, marginal users of biomass can be considered when analysing energy system changes. These marginal users may, for example, consist of high-volume users of biomass such as for co-combustion in CCP plants and producers of biofuels for transportation. This marginal approach implies that, in this case, reducing the use of biomass in a given process would reduce the need for coal or fossil fuels for transportation, since the released biomass could replace fossil resources in these processes (Axelsson and Harvey, 2010). 


\section{Studied systems}

This chapter describes the different systems studied in the appended papers of this thesis.

Several different systems were studied in the research presented in this thesis. These systems embrace research at different system levels, and this section presents a summary of the systems and their system boundaries according to which the present research was conducted. Although the constituent papers of this thesis present systems studies at different levels, the systems analyses were conducted from an energy systems perspective. In this section, the systems are presented according to system levels, starting from studies of single or a group of industrial companies to studies at a regional level.

Papers I and V are based on data collected from the industry sector in Gävleborg County, and Paper II on data collected from the industry sector in Östergötland and Örebro counties. These three papers study available excess heat and the use of such heat at an aggregated regional level. The regional level is also applied in Paper VI, in which system aspects of the use of excess heat in DH are analysed; however, calculations of the effects of excess heat use on GHG emissions are based on a functional unit of heat. Papers III and IV both examine different synergy setups, Paper III mainly using data from a single Swedish food company and its surroundings while Paper IV uses data from an industrial cluster in Gothenburg. Paper VII studies how eight Swedish manufacturing companies reason about policy impacts on excess heat use.

\subsection{Swedish industry}

Paper VII elucidates how energy policies affect or might affect the use of excess heat in Swedish industries, in order to explore how these instruments can promote or discourage excess heat recovery. This was done using interviews with energy managers (or equivalent personnel) from eight Swedish manufacturing companies (see Table 2). Companies from the pulp and paper, iron and steel, chemical, foundry, nonferrous-metal, and food industries were examined in the study. One criterion when selecting respondents was to cover the industry sectors that account for the largest share of energy use in Sweden. The studied companies belong to the branches of industries in Sweden that account for approximately $70 \%$ of industrial energy use (SCB, 2012). 
Table 2. Summary of industry sectors, annual energy use, and estimated amount of excess heat for the companies included in the interview study presented in Paper VII.

\begin{tabular}{|c|c|c|}
\hline Industry sector ${ }^{1}$ & $\begin{array}{c}\text { Plants' annual energy } \\
\text { use }^{2} \text { (GWh/year) }\end{array}$ & $\begin{array}{c}\text { Plants' annual } \\
\text { excess heat }(\mathrm{GWh})\end{array}$ \\
\hline Pulp and paper & 6720 & 1700 \\
\hline Pulp and paper & 2400 & $>600$ \\
\hline Iron and steel & 130 & $50-100$ \\
\hline Chemical & 5200 & $400-600$ \\
\hline Foundry & 350 & $\mathrm{~N} / \mathrm{A}$ \\
\hline Foundry & 50 & $\mathrm{~N} / \mathrm{A}$ \\
\hline Nonferrous metal & 2040 & $\mathrm{~N} / \mathrm{A}$ \\
\hline Food & 8 & 0.1 \\
\hline
\end{tabular}

${ }^{1}$ Figures given in the table are valid for the production sites visited, i.e., when the company group had several production sites, the sites not visited were excluded. ${ }^{2}$ Approximate numbers. Data for 2011. ${ }^{3}$ Figures estimated by respondents.

\subsection{A Swedish food company}

Organic waste from the food industry can be used to produce biogas. Linné et al. (2008) estimate that $890-1790 \mathrm{GWh}$ of biogas could be produced annually from Swedish food industry residues, the higher potential including waste currently used as animal feed. To create a favourable environment for the process microorganisms, biogas production requires low-temperature heat (Weiland, 2010). Using excess heat to cover this heat demand has previously been discussed as a way to reduce climate impact (Ammar et al., 2012; Martin and Eklund, 2011).

In Paper III, a Swedish food company was used to exemplify a synergy setup of biogas production supported by excess heat at an industry. The food company is Sweden's largest producer of mayonnaise-dressed salads made mainly from root crops. The production site is part of a larger corporate group, but the actual site studied in Paper III is located $32 \mathrm{~km}$ from the nearest town. In 2013, the company had 40 employees and its energy use, originating from oil and electricity, amounted to $8 \mathrm{GWh}$. Oil is used in a steam boiler mainly to produce steam for the production processes. These processes generate excess heat, most of which is not currently used. The production processes also generate streams of organic waste currently used in two external production plants to produce biogas, which is used as vehicle fuel and as fuel in a DH system in the nearest town. Also, a small share of the organic waste is used as animal feed by local farmers. Next to the food company is a pig farm, manure from which could be used as substrate in a biogas plant located at the industry site.

Paper III studies the switch in use of industrial organic waste streams, i.e., from an external production and use of biogas (baseline system) to an internal production and use of biogas within an industry (modified system). Figure 6 presents a schematic of the systems studied in Paper III. 

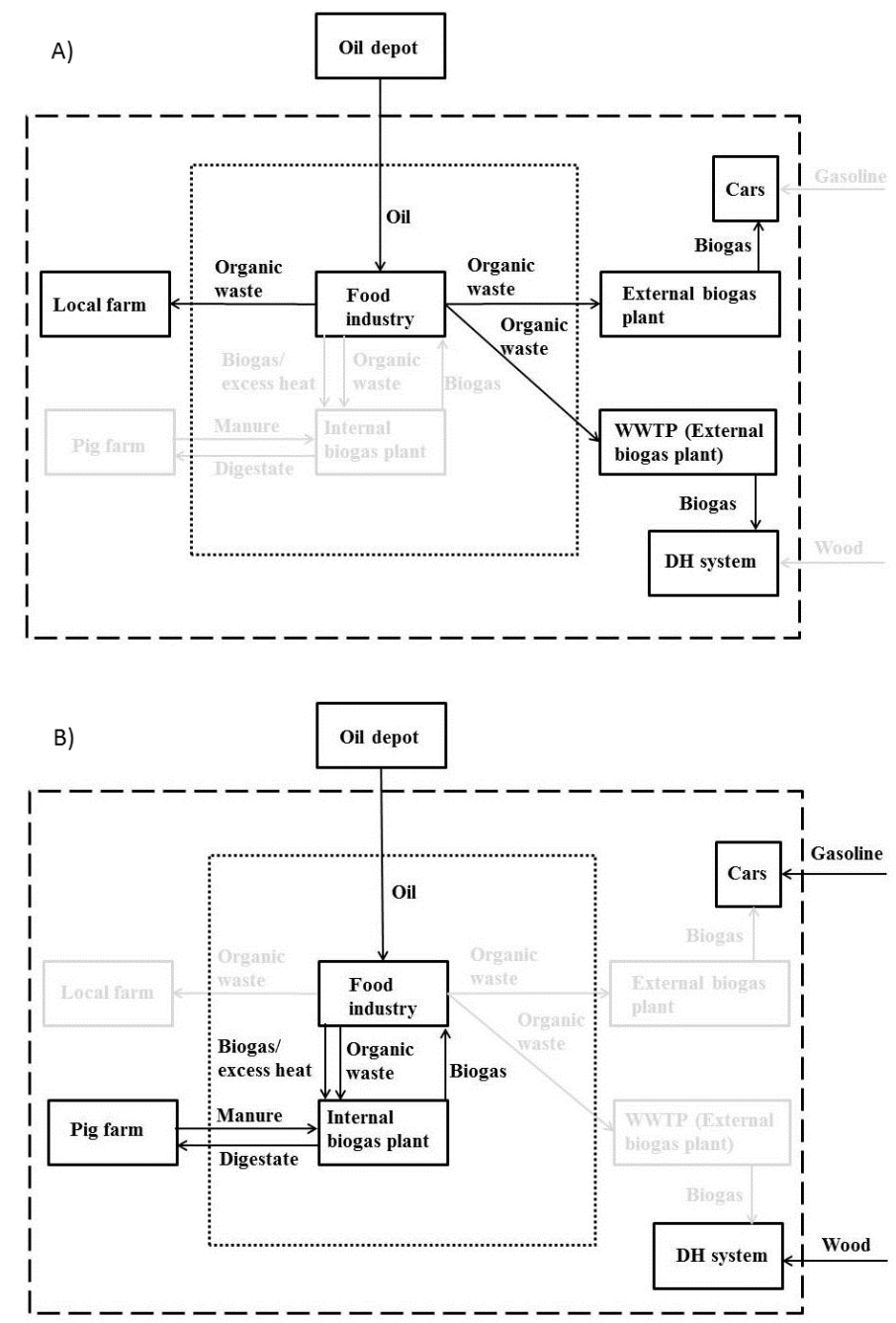

Figure 6. Schematic of the systems studied in Paper III: A) baseline system and B) modified system. The dashed line represents the system boundary used in studying the effects on GHG emissions while the dotted line represents the system boundary used in the economic analysis. The entities in grey represent the differences between the systems. The illustration is from Broberg Viklund and Lindkvist (2015).

\subsection{An industrial cluster in Gothenburg}

Excess heat can be used in a wide range of applications. Paper IV examines one such application, i.e., the production of biofuel from microalgae (hereafter "algae") cultivated in municipal wastewater (WW), representing the replacement of a current WWTP with an algae-based biorefinery concept. Collaboration between actors within the studied cluster 
allowed excess heat to be used to cover the heat demand in the cultivation pond while flue gases could be used as nutrients during algae cultivation.

The system studied constitutes an industrial cluster in Gothenburg, situated on the west coast of Sweden. The cluster includes a WWTP, two oil refineries, and an existing NG grid. As a result of the industrial activity, large amounts of excess heat and flue gases are produced in the region. One of the refineries produces approximately $840 \mathrm{GWh}$ of unused heat per year (Gottfridsson, 2011), while the second refinery is assumed to produce two thirds of that excess heat, as its crude oil capacity is two thirds of that of the first refinery. In total, the two refineries produce $1400 \mathrm{GWh}$ of excess heat annually. The WWTP currently produces $64 \mathrm{GWh}$ of biogas per year by co-digesting food residues from the region and sludge from the WWT process. ${ }^{7}$ Paper IV studies the biorefinery concept based on two end-product solutions, either the production of both biogas and biodiesel or the production of biogas only. A schematic of the studied system is presented in Figure 7.

\footnotetext{
${ }^{7}$ The values in this paragraph have been recalculated to energy values (GWh) instead of power values (MW) as presented in Paper IV. The calculations were performed assuming 8000 production hours per year. The original numbers presented in Paper IV are as follows: unused heat at one refinery $=$ $105 \mathrm{MW}$, unused heat at the two refineries $=175 \mathrm{MW}$, and biogas produced at the WWTP $=8 \mathrm{MW}$.
} 

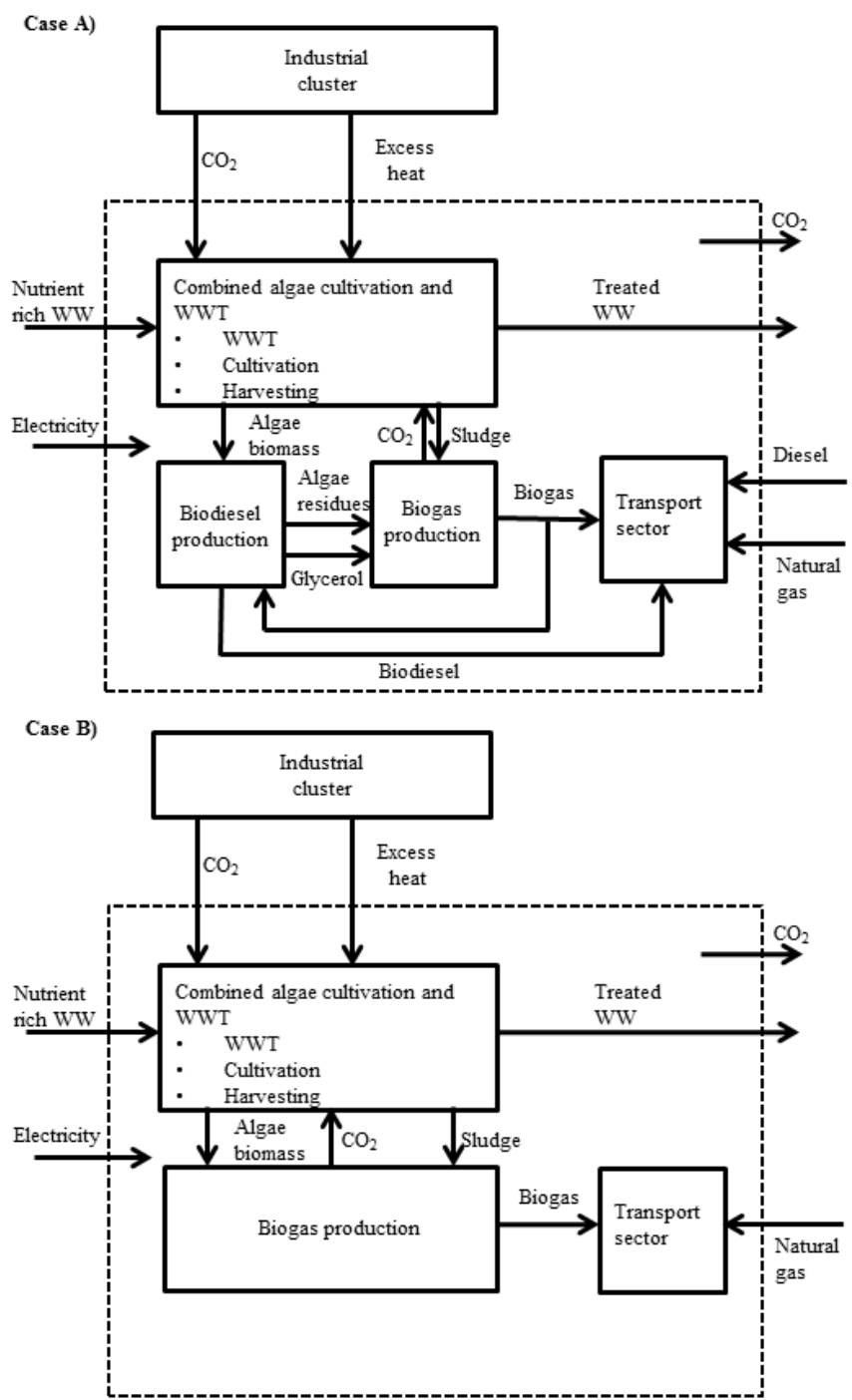

Figure 7. Schematic of the system studied in Paper IV: A) algae-based biorefinery concept with the end-products biogas and biodiesel; B) algae-based biorefinery concept with the end-product biogas. The dashed line represents the system boundary used in studying the effects on GHG emissions. $\mathrm{WW}=$ wastewater, WWT $=$ wastewater treatment. The illustration is from Andersson et al. (2014).

\subsection{Gävleborg County industrial sector}

Papers I and V are based on data on the unused excess heat in Gävleborg County in Sweden. The papers focus on the state of the untapped excess heat, recovery measures, and consequences of its use. Gävleborg County is the tenth most populous of Sweden's 21 counties. The county is located in central Sweden on the Baltic Sea coast. The county used a 
total of 20 TWh of energy in 2011, of which 11.3 TWh was used in the industrial sector (SCB, 2014), corresponding to approximately $8 \%$ of the industrial energy use in Sweden that year. Although the county has diversified business activities, many of its industries are energy intensive and operate in sectors such as pulp and paper or iron and steel.

In Paper $\mathrm{V}$, the identified excess heat is modelled together with three alternatives for using it (Figure 8) for six energy market scenarios (EMSs). The system boundary encompasses the excess heat, measures studied (i.e., deliveries to a DH network, absorption cooling production, and heat-driven electricity production), and alternative technologies for electricity and heat production. These alternative technologies will cover the fixed heat and cooling demand if excess heat is not used for that application. Compression cooling will cover the cooling demand and boilers or CHP plants will cover the heat demand.

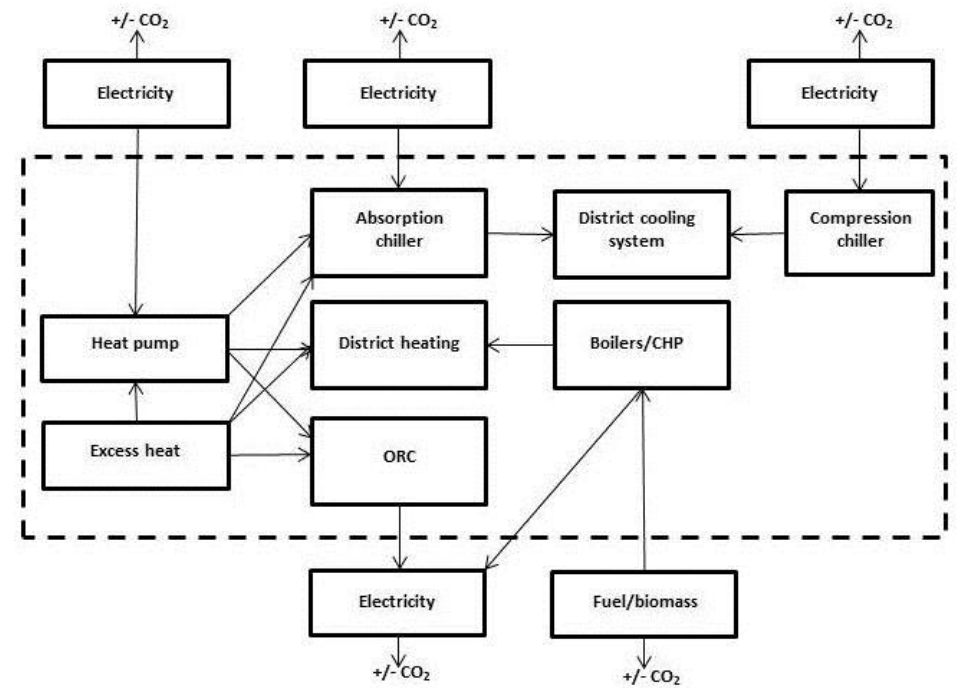

Figure 8. Illustration of the system studied in Paper V. The dashed line represents the system boundary. The illustration is from Broberg Viklund and Karlsson (2015).

\section{5 Östergötland and Örebro counties' industrial sector}

The unused excess heat potential in Östergötland and Örebro counties in Sweden is studied and discussed in Paper II, which also examines the link between policies and the use of this heat resource. Östergötland County is located in south-eastern Sweden, and Örebro County lies on its northern border. In 2010, the industrial energy use in Östergötland County accounted for 6.9 TWh of the county's 18.6 TWh total energy use; the same numbers for Örebro County were $6.8 \mathrm{TWh}$ and $11.9 \mathrm{TWh}^{8}{ }^{8}$ respectively. This corresponds to approximately $5 \%$ of Sweden's total industrial energy use for each of the two counties (SCB, 2014; SEA, 2014a; SEA, 2013).

${ }^{8}$ As data on total energy use in Örebro County are missing for 2010, this figure is for 2011. 


\subsection{Excess heat in district heating}

Both EU and Swedish policy promote excess heat use, although Swedish policy can be regarded as vague (see Section 3). Excess heat is currently used in Swedish DH systems, but untapped heat potentials still exist. In Paper VI, the GHG emission consequences of the introduction of excess heat in $\mathrm{DH}$ are calculated, enabling discussion of the system aspects and policies related to its use.

Assuming constant heat demand, the introduction of excess heat in $\mathrm{DH}$ will result in other types of heat production being displaced. If CHP-based DH is displaced, less electricity will consequently be produced in the system's CHP plant. Given constant electricity demand, other electricity generation technologies will have to make up for the lost electricity production. However, excess heat use in $\mathrm{DH}$ reduces the consumption of fuel resources in the production system, resources that can then be used by alternative users. As the effects of using excess heat in DH are complex, to avoid side effects, the introduction of excess heat in $\mathrm{DH}$ needs to be studied from a systems perspective. The complexity of the use of excess heat in DH is illustrated in Figure 9.

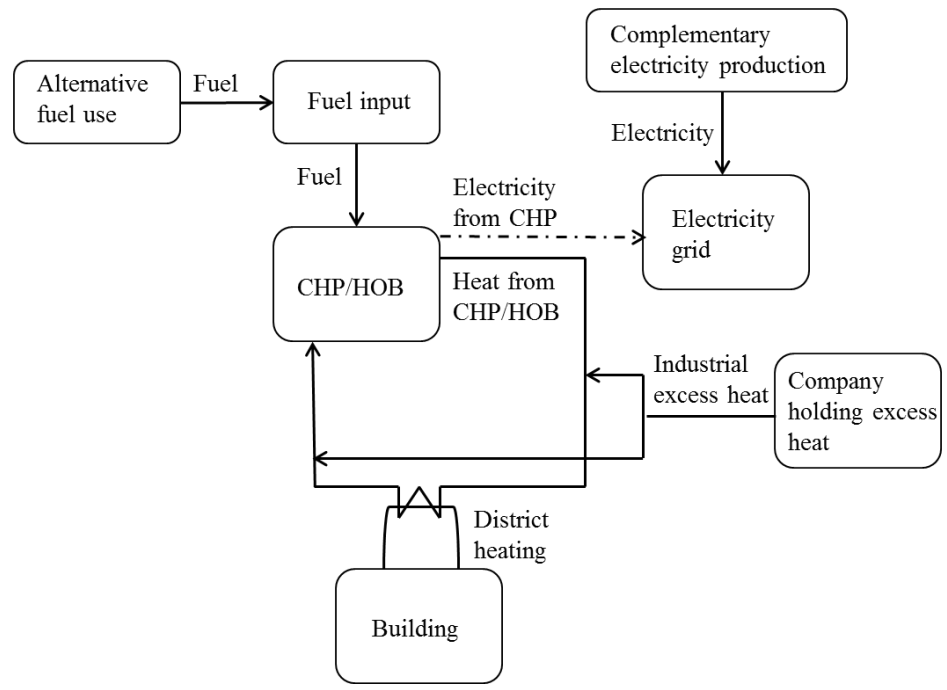

Figure 9. Illustration of the system aspects of excess heat use in district heating. $\mathrm{CHP}=$ combined heat and power, $\mathrm{HOB}=$ heat-only boiler.

The calculations in Paper VI are based on a functional unit of $1 \mathrm{GJ}$ and the assessment uses a two-step process, including LCA and future energy scenarios to embrace excess heat in contemporary as well as future systems. LCA calculations are used to reveal the effects of excess heat in an average Swedish contemporary bio-based DH system. Various production cases are used in the assessment including both heat-only boiler (HOB)-based and CHP-based production systems, summer and winter cases, and a system expansion accounting for the impact of lost electricity production. In winter cases, it is assumed that 
$15 \%$ of the fuel comes from oil. The LCA production cases are summarized in Table 3 . The use of future energy market scenarios will be further described in Section 6.3.

Table 3. Production cases for replaced DH in LCA calculations. CHP = combined heat and power, $\mathrm{HOB}=$ heat-only boiler.

\begin{tabular}{|c|c|c|c|c|c|c|}
\hline Production case & A & $\mathrm{B}$ & $\mathrm{C}$ & $\mathrm{D}$ & $\mathrm{E}$ & $\mathrm{F}$ \\
\hline DH system & \multicolumn{2}{|c|}{$\mathrm{HOB}$} & \multicolumn{4}{|c|}{$\mathrm{CHP}$} \\
\hline Replaced electricity & \multicolumn{2}{|c|}{$\mathrm{N} / \mathrm{A}$} & \multicolumn{2}{|c|}{ Nordic mix } & \multicolumn{2}{|c|}{ EU marginal } \\
\hline $\mathrm{CO}_{2}$-eq. $\left[\mathrm{kg} / \mathrm{MWh}_{\mathrm{el}}\right]$ & & & \multicolumn{2}{|c|}{$64^{a}$} & \multicolumn{2}{|c|}{$880^{a}$} \\
\hline Season & Summer & Winter & Summer & Winter & Summer & Winter \\
\hline
\end{tabular}

${ }^{a}$ Data from Ecoinvent Centre (2010). 


\section{Methods}

This chapter describes the methodology and the energy market scenario input data used in the appended papers of this thesis.

This chapter presents the research methodology used in the seven constituent papers of this thesis. The main concepts, processes, and aspects considered in the studies are outlined here; more detailed descriptions can be found in the appended papers. The methods used were chosen based on the problems identified and research questions formulated for each study.

Papers I, II, and V study untapped excess heat flows and the data for them were collected using questionnaires. Papers I, V, and VI all include evaluations of the impact on global $\mathrm{CO}_{2}$ emissions of excess heat use, these evaluations being based on future EMSs. The optimization study performed in Paper V uses the reMIND energy system optimization tool to study excess heat use under different energy market conditions. Interviews were used in Paper VII to capture respondent reasoning about excess heat use and energy policy. The opportunities to invest in technologies and system solutions for excess heat use are estimated in Papers III and V. The strengths of combining several methods, as done in this thesis, are noted by, for example, Pietrapertosa et al. (2009) and Eklund (2012). The present studies apply multiple perspectives and methods, an approach said to provide a more holistic view of the phenomena studied (Eklund, 2012). This approach is therefore assumed to be adequate to address the complexity of energy systems in general and, as in this thesis, excess heat use more specifically.

\subsection{Questionnaires}

Questionnaires allow questions of interest to be distributed to a large number of respondents at the same time and can be administered more quickly than interviews. Despite similarities between structured interviews and questionnaires, they differ in that questionnaires lack actual interviewer-respondent contact, that is, respondents must complete questionnaires themselves (Bryman, 2012). The lack of personal contact means that questionnaires must be clearly designed, as respondents cannot ask for clarifications. Bryman (2012) states that a questionnaire should have few open-ended questions, to make it easy to complete, and an easy-to-follow design to prevent inadvertent omission of questions. A questionnaire should also be shorter than a structured interview to reduce the risk of respondent fatigue, which may result in reduced data quality or the respondent not completing the questionnaire. It is 
therefore important that the questions be clear and unambiguous, that only one question be asked at a time, and that leading questions be avoided (Bryman, 2012). These guidelines were taken into account when designing the questionnaires used in this thesis.

To collect data on untapped excess heat, questionnaires were used in Papers I, II, and V; Papers I and V are based on data collected from Gävleborg County while Paper II is based on data collected from Östergötland and Örebro counties. The questionnaires contained questions about the companies' excess heat available in different energy carriers, access to this heat, and the current status of the use of this heat resource. The questionnaire sent to Östergötland and Örebro counties served as an inspiration when compiling the questionnaire used in Papers I and V; this questionnaire can be found in Appendix 1. Since the author of this thesis designed only the questionnaire distributed to companies in Gävleborg County, the methodological choices in this section will focus on that questionnaire.

Because of the lack of face-to-face researcher-respondent contact, the questionnaire was accompanied by a short informational letter presenting, among other matters, the name, background information, and aim of the study, the estimated completion time, technical information on how to use the questionnaire software (Webropol), and researcher contact information, in line with the recommendations (Bryman, 2012). Before distribution, the questionnaire for the companies in Gävleborg County was reviewed by senior colleagues and distributed to a test company to collect input regarding, for example, completion time and any necessary clarifications before being sent out to the respondents. The link to the web-based questionnaire was sent by e-mail in the spring of 2012 to 58 industrial companies classified as firms with high environmental impacts according to the regulation (1998:899) on environmentally hazardous activities and health (Ministry of the Environment and Energy, 1998). The companies were contacted before the questionnaire was distributed to discuss who would be suitable to answer the questions. The questionnaire was finally sent to the person identified as working on energy issues at each company (e.g., the energy or production manager). In the Östergötland and Örebro County study, the questionnaire was distributed to 85 companies selected by the county administrative boards based on their energy use. A short version of the questionnaire was distributed to the companies in these two counties that did not respond to the original dispatch.

\subsection{Interviews}

Interviews are used to gain an understanding of a studied subject from the respondent's point of view. Knowledge is created during the interview, through questions posed and answers given, as an interaction between respondent and interviewer (Kvale and Brinkmann, 2009). Since Paper VII was intended to explore how Swedish industrial companies reason about the use of policy instruments to promote or discourage the use of excess heat, interviews were deemed the most suitable method for collecting the required data. 
Eight in-depth interviews were conducted during the autumn of 2012. These interviews were held with the energy managers of companies in the following production areas: the pulp and paper, iron and steel, chemicals, food, foundry, and nonferrous-metal industries. The companies, whose annual energy use was $8-6720 \mathrm{GWh}$, were selected because they were manufacturing companies and in industries accounting for most of the industrial energy use in Sweden. In addition, all companies had to have addressed excess heat use to some extent, although they still had unused heat resources. This criterion was set because it meant that respondents were likely to have reflected on the conditions governing excess heat use.

Before the interview, each respondent received a short pre-interview questionnaire including questions about the company, its energy use, its excess heat resources, and its current excess heat use situation. The questionnaire was intended to help the interviewer by providing an overview of the company before the interview. The interviews were semi-structured, and the format gave the interviewer the freedom to change the order of the questions and, for the purposes of the study, to follow up on interesting answers and discussions by posing supplemental questions (Kvale and Brinkmann, 2009). An interview guide was formulated containing questions on the following themes: background information (e.g., previous work related to excess heat use), excess heat and energy policy, and the need for new policies. An English translation of the interview guide can be seen in Appendix 2.

Each interview was conducted in Swedish in the respondent's office or in a conference room at the respondent's company. The interviews lasted approximately 1 hour each. To keep the interview focused and aligned with the aim of the study, the interviewer guided the questions throughout the interview. The interviews were all audio-recorded and afterwards transcribed verbatim.

Besides the part of the analysis that took place as the interview preceded, the transcribed material was interpreted after the interviews. To gain an overview of the interview material and identify data of interest for the study, the transcribed interview material was coded and then categorized by looking for verbal and conceptual repetitions, similarities, and differences (Kvale and Brinkmann, 2009; Ryan and Bernard, 2003). In this part of the analytical process, various parts of the interview were identified and linked to each other (Boolsen, 2007). The identified categories were based both on the questions and themes from the interview guide and on the categories that emerged from analysis of the transcribed material. Based on these categories, the interview material was analysed to identify the respondents' views on the relationship between policy instruments and excess heat use. The main categories thus identified were: use of excess heat; alternatives to DH deliveries; awareness, commitment, and legitimacy; knowledge development; internally and externally based control; and investments and economic factors. Ryan and Bernard (2003) say that a category is found when one can answer the question "What is this expression an example of?". By using the categories identified, the individual respondents' views could be described and compared. 
The interviews were carefully planned to ensure that the aim of the paper was met, i.e., that the target subject matter was investigated. The interview guide was thoroughly elaborated with a view to formulating open and clear questions. This working process together with methodological transparency was intended to bolster the reliability and validity (i.e., credibility) of the study, in accordance with Kvale and Brinkmann (2009). Paper VII aims to provide indications of the relationship between energy policy measures and excess heat use by answering questions such as "why" and "how". Although the conclusions of Paper VII cannot be generalized to the whole Swedish industry sector, this exploratory study constitutes a first step towards insights into the use of excess heat in the light of policy instruments.

\subsection{Energy market scenarios and input data}

Four of the constituent papers of this thesis (i.e., papers I, II, V, and VI) use EMSs to consider future energy market prices and effects on $\mathrm{CO}_{2}$ emissions. The EMSs were constructed using the Energy Price and Carbon Balance Scenarios (ENPAC) tool developed by (Axelsson and Harvey, 2010). To evaluate the profitability of energy investments and how these investments may influence GHG emissions, the development of the energy market must be considered. Consistent EMSs, with interdependent energy market parameters, can be used to predict possible cornerstones of the future energy market. These scenarios can be used to address the uncertainty of the future energy market, thereby help identify robust investments, and evaluate climate benefits. Two time-frames were used in the appended papers, 2020 and 2030, respectively. Papers I and V use a time-frame of 2030, Paper II uses 2020, and Paper VI uses both 2020 and 2030. The papers focusing on conventional excess heat use measures primarily use a shorter time-frame than do the papers using less-developed measures. Figure 10 gives an overview of the calculation flow used in the tool. The ENPAC tool has previously been used in a number of studies to evaluate the profitability of energy-related investments and associated effects on $\mathrm{CO}_{2}$ emissions (Jönsson et al., 2008; Johansson et al., 2013; Johansson, 2013; Wetterlund et al., 2011). 


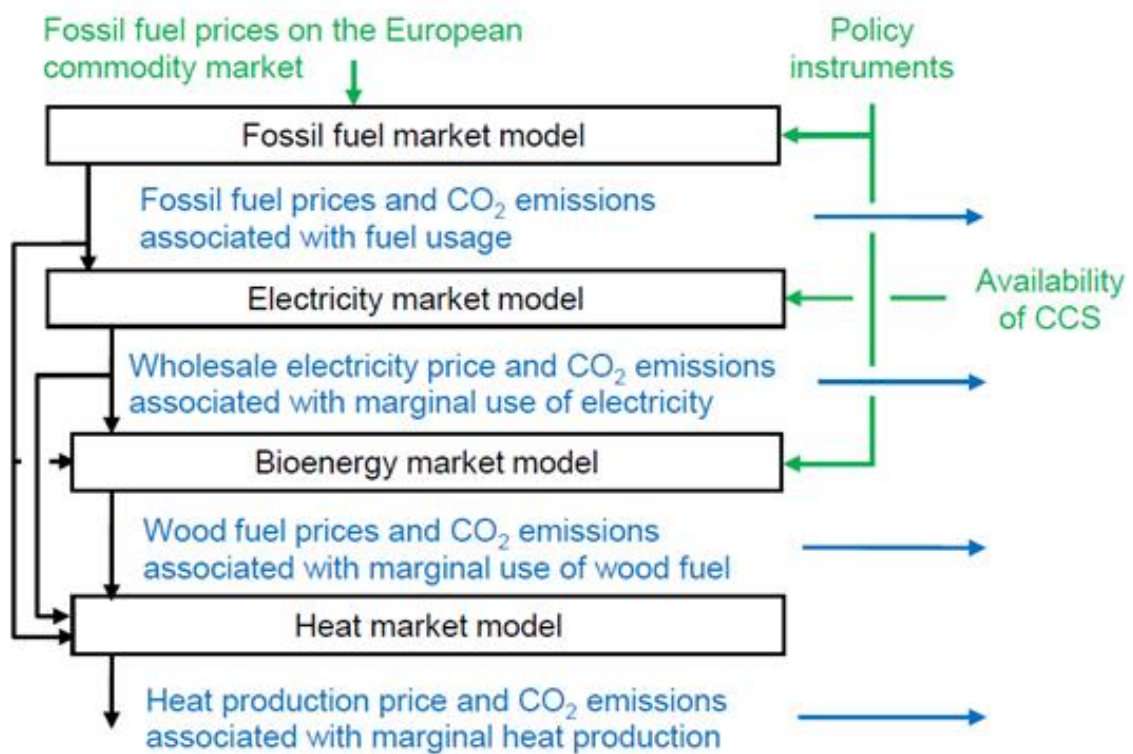

Figure 10. Overview of the ENPAC tool calculation flow. Required inputs are represented by green arrows, calculation units for the different energy markets by boxes, information flows by black arrows, and outputs (i.e., energy market parameters) by blue arrows (reprinted with permission from (Axelsson and Harvey, 2010).

Inputs to the ENPAC tool include fossil fuel prices and policy instruments; charges for emitting $\mathrm{CO}_{2}$, support for producing renewable electricity, and support for renewable transportation fuels. Fossil fuel prices on the European commodity market and $\mathrm{CO}_{2}$ charges are taken from three scenarios presented in World Energy Outlook. 2011 and developed by the International Energy Agency (IEA): the current policy (CP), new policy (NP), and $450 \mathrm{ppm}^{9}$ scenarios (IEA, 2011). The CP scenario assumes that currently adopted government policies will remain in force unchanged; the NP scenario is based on current and announced policy commitments; and the $450 \mathrm{ppm}$ scenario is based on policies needed to limit global warming to $2^{\circ} \mathrm{C}$ with $50 \%$ chance (IEA, 2011). Emissions changes are given in $\mathrm{CO}_{2}$-equivalents ${ }^{10}$ $\left(\mathrm{CO}_{2}\right.$-eq.) and include well-to-gate emissions (i.e., emissions associated with fuel extraction, processing, and distribution) as well as emissions from combustion. In Papers I and V, the effects on $\mathrm{CO}_{2}$ emissions are not given in equivalents; however, the results from these papers have been recalculated in this thesis into $\mathrm{CO}_{2}$-eq. in line with the other papers.

Based on the inputs to the tool, the marginal technology for electricity generation was determined. It was assumed that the technology with the lowest cost of electricity production, under the given inputs, constituted the build margin (the term is briefly

${ }^{9}$ The figure of $450 \mathrm{ppm}$ refers to the need to limit the atmospheric GHG concentration to 450 parts per million ( $\mathrm{ppm}$ ) of $\mathrm{CO}_{2}$-eq. if the $2^{\circ} \mathrm{C}$ target is to be met.

${ }^{10}$ Including $\mathrm{CO}_{2}, \mathrm{CH}_{4}$, and $\mathrm{N}_{2} \mathrm{O}$. 
discussed in Section 4.2 and explained in more detail by (Ådahl and Harvey, 2007). Two build margin technologies, CCP and NGCC plants, were determined for the scenarios in this thesis. The electricity price and the consequences on the amount of $\mathrm{CO}_{2}$-eq. emissions associated with marginal electricity use were calculated based on the build margin.

Biomass is considered a limited resource. The co-combustion of biomass in coal power plants and the production of the renewable transportation fuel Fischer-Tropsch (FT) diesel are the two marginal users of biomass considered here. The marginal user of biomass is the user with the highest willingness to pay for biomass. The marginal user determines the biomass price and the effects on $\mathrm{CO}_{2}$-eq. emissions associated with the marginal use of biomass. In other words, if co-combustion in CCP plants is the marginal user of biomass, the biomass price is based on the price of coal and the $\mathrm{CO}_{2}$ charge, minus the costs associated with co-combustion. It is assumed that there is a deregulated European electricity market and that a well-functioning European biomass market has been developed.

The willingness to pay for heat on the heat market is determined by the price-setting heat-producing technology. Axelsson and Harvey (2010) identify two price-setting technologies, so two Swedish DH systems are considered here: one system based mainly on bio-fuelled heat-only boilers ${ }^{11}$ (bio-HOB) and another system based mainly on bio-fuelled $\mathrm{CHP}^{12}$ (bio-CHP). The price-setting technology determines the heat price, while the effects on $\mathrm{CO}_{2}$-eq. emissions of introducing excess heat in the $\mathrm{DH}$ system are based on the heat production mix in the two DH systems considered and, in the case of a CHP-based system, also on the marginal electricity production. Papers I, V, and VI use the same version of the scenario tool, whereas Paper II uses an earlier version. The EMSs generated using the ENPAC tool can be seen in Table 4 (for Papers I, V, and VI) and Table 5 (for Paper II). The aim of Paper II differs from those of the other papers that use the ENPAC tool, so the results will not be compared. Therefore, the results presented in Paper II have not been recalculated using the later version of the tool. For a more thorough description of the tool, see (Axelsson and Harvey, 2010; Axelsson et al., 2009; Axelsson and Pettersson, 2014).

\footnotetext{
${ }^{11}$ Heat production composition: bio-HOB, 84\% (2020) and 85\% (2030); coal-HOB, 4\% (2020) and $4 \%$ (2030); NG-HOB, $6 \%$ (2020) and 2\% (2030); oil HOB, 5\% (2020) and 4\% (2030); and other renewables, $1 \%(2020)$ and $4 \%(2030)$.

${ }^{12}$ Heat production composition: bio-CHP, 46\% (2020) and 54\% (2030); bio-HOB, 30\% (2020) and $28 \%$ (2030); coal-CHP, 5\% (2020) and 3\% (2030); NG-CHP, 7\% (2020) and 6\% (2030); oil-CHP, $1 \%$ (2020) and $0 \%$ (2030); coal-HOB, 2\% (2020) and 1\% (2030); NG-HOB, 2\% (2020) and 1\% (2030); oil-HOB, $2 \%$ (2020) and 1\% (2030); heat pumps, 6\% (2020) and 4\% (2030); and other renewables, $1 \%(2020)$ and $6 \%(2030)$.
} 
Table 4. Energy market scenarios used in Papers I, V, and VI. CCP = Coal condensing power plant, NGCC $=$ Natural gas combined cycle, FT $=$ Production of FT diesel.

\begin{tabular}{|c|c|c|c|c|c|c|}
\hline \multicolumn{7}{|c|}{ Input data to the ENPAC tool } \\
\hline \multirow{2}{*}{$\begin{array}{l}\text { Year } \\
\text { Scenario in World Energy Outlook } 2011\end{array}$} & \multicolumn{3}{|c|}{2020} & \multicolumn{3}{|c|}{2030} \\
\hline & $\mathrm{CP}$ & NP & 450 & $\mathrm{CP}$ & NP & 450 \\
\hline & & & ppm & & & $\mathrm{ppm}$ \\
\hline \multicolumn{7}{|l|}{ Fossil fuel prices } \\
\hline Crude oil [\$/barrel] & 118 & 109 & 97 & 135 & 117 & 97 \\
\hline Natural gas [\$/Mbtu] & 11 & 10 & 10 & 13 & 12 & 10 \\
\hline Coal $[\$ /$ tonne $]$ & 109 & 106 & 93 & 116 & 109 & 74 \\
\hline \multicolumn{7}{|l|}{ Energy policy instruments } \\
\hline $\mathrm{CO}_{2}$ charge $[€ /$ tonne $]$ & 23 & 23 & 34 & 30 & 30 & 72 \\
\hline $\begin{array}{l}\text { Support }{ }^{\mathrm{a}} \text { for renewable electricity } \\
{\left[€ / \mathrm{MWh}_{\mathrm{el}}\right]}\end{array}$ & 20 & 20 & 20 & 20 & 20 & 20 \\
\hline $\begin{array}{l}\text { Support }{ }^{\mathrm{a}} \text { for renewable transportation fuels } \\
{\left[€ / \mathrm{MWh}_{\text {fuel }}\right]}\end{array}$ & 26 & 26 & 26 & 26 & 26 & 26 \\
\hline \multicolumn{7}{|c|}{ Output data from the ENPAC tool } \\
\hline Energy market scenario (EMS) & 1 & 2 & 3 & 1 & 2 & 3 \\
\hline Build margin for electricity production & CCP & $\mathrm{CCP}$ & CCP & CCP & $\mathrm{CCP}$ & NGCC \\
\hline Marginal user of biomass & FT & FT & СCP & FT & FT & ССР \\
\hline \multicolumn{7}{|l|}{ Energy prices $\left[€ / M W h_{\mathrm{el} / \text { fuel }}\right]$} \\
\hline Electricity (incl. $\mathrm{CO}_{2}$ charge) & 64 & 63 & 69 & 68 & 67 & 86 \\
\hline Biomass & 33 & 30 & 29 & 38 & 33 & 41 \\
\hline Coal (incl. $\mathrm{CO}_{2}$ charge) & 20 & 20 & 23 & 24 & 23 & 35 \\
\hline Coal (excl. $\mathrm{CO}_{2}$ charge) & 12 & 12 & 10 & 13 & 12 & 9 \\
\hline Natural gas (incl. $\mathrm{CO}_{2}$ charge) & 42 & 40 & 41 & 48 & 46 & 49 \\
\hline Natural gas (excl. $\mathrm{CO}_{2}$ charge) & 37 & 35 & 33 & 41 & 39 & 33 \\
\hline Oil (incl. $\mathrm{CO}_{2}$ charge) & 72 & 67 & 64 & 83 & 74 & 75 \\
\hline \multicolumn{7}{|l|}{$\mathrm{CO}_{2}$ emission factor } \\
\hline Electricity production $\left[\mathrm{kg} / \mathrm{MWh}_{\mathrm{el}}\right]$ & 856 & 856 & 856 & 805 & 805 & 376 \\
\hline Biomass use $\left[\mathrm{kg} / \mathrm{MWh}_{\text {fuel }}\right]$ & 118 & 118 & 401 & 119 & 119 & 401 \\
\hline \multicolumn{7}{|l|}{ Industrial excess heat $\left[\mathrm{kg} / \mathrm{MWh}_{\text {heat }}\right]$} \\
\hline Bio-HOB system & 164 & 164 & 413 & 154 & 154 & 408 \\
\hline Bio-CHP system & -28 & -28 & 250 & -40 & -40 & 397 \\
\hline
\end{tabular}

\footnotetext{
${ }^{a}$ European average
} 
Table 5. Energy market scenarios used in Paper II.

\begin{tabular}{lllll}
\hline Year & \multicolumn{5}{c}{2020} \\
\hline Scenario & Scenario 1 & Scenario 2 & Scenario 3 & Scenario 4 \\
\hline Fossil fuel price level $^{\mathrm{a}}$ & High & Low & High & Low \\
$\mathrm{CO}_{2}$ charge & High & High & Low & Low \\
\hline Price of heat $[€ / \mathrm{MWh}$ heat $]$ & 11 & 14 & 2.8 & 2.2 \\
\hline
\end{tabular}

\subsection{Energy system optimization using reMIND}

As real energy systems are generally complex, models can be used to study them because they enable us to represent these systems in simplified forms. For example, a model can be used when studying a system that does not exist or when it is too expensive or time-consuming to experiment with the real system. The simplified configuration allows us to learn about the model and, acquire knowledge about the real system (Gustafsson et al., 1982). Optimization tools can be used to model complex energy systems. Paper V studies the use of excess heat and the trade-offs between alternate measures, thus modelling and optimization are well suited to finding suitable ways to use the excess heat resource. Furthermore, combining the use of optimization and EMSs (see Section 6.3) in Paper V makes it possible to study the energy markets' impact on the optimal use of excess heat. Through modelling, the studied problem is described mathematically as a matrix of equations, and the best solution to the problem is calculated. The problem contains the objective function to be minimized or maximized depending on the purpose, constraints that delimit the possible outcome, and variables.

In Paper V, the reMIND energy system optimization tool was used. The reMIND decisionsupport software is based on the Method for analysis of INDustrial energy systems (MIND), which is based on mixed integer linear programming (MILP). The tool was developed at Linköping University (see, e.g., Nilsson (1993); Karlsson (2011)), originally to model and analyse dynamic industrial energy systems. However, the flexibility of the method makes it suitable for modelling other energy systems as well. The method can be used to elucidate various issues, for example, when seeking an optimal energy system structure, to study changes in an energy system, or, as in Paper V, to study the optimal distribution of a resource in a fixed energy system. The method has previously been used to study both environmental and economic aspects in a wide range of industries, such as the pulp and paper, chemical, forest, and automobile industries (Karlsson and Söderström, 2002; Wolf and Karlsson, 2008; Svensson and Moshfegh, 2011).

The objective of the reMIND tool is usually to minimize the system cost. Costs in the model comprise costs associated with investments, operation and maintenance, and energy and materials. Revenues are included in the model as negative costs. The structure of the model is represented using a network of nodes and branches. The branches represent flows of 
energy and material, while the nodes represent processes for converting energy and materials. Figure 11 shows the user interface of the reMIND software. The functionality of the depicted component is described by assigning each node any number of functions. The model can take time dynamics into account by incorporating a flexible time division, for example, hourly, weekly, seasonal, or annual variations. For a thorough description of the tool and its functions, see (Karlsson, 2011).

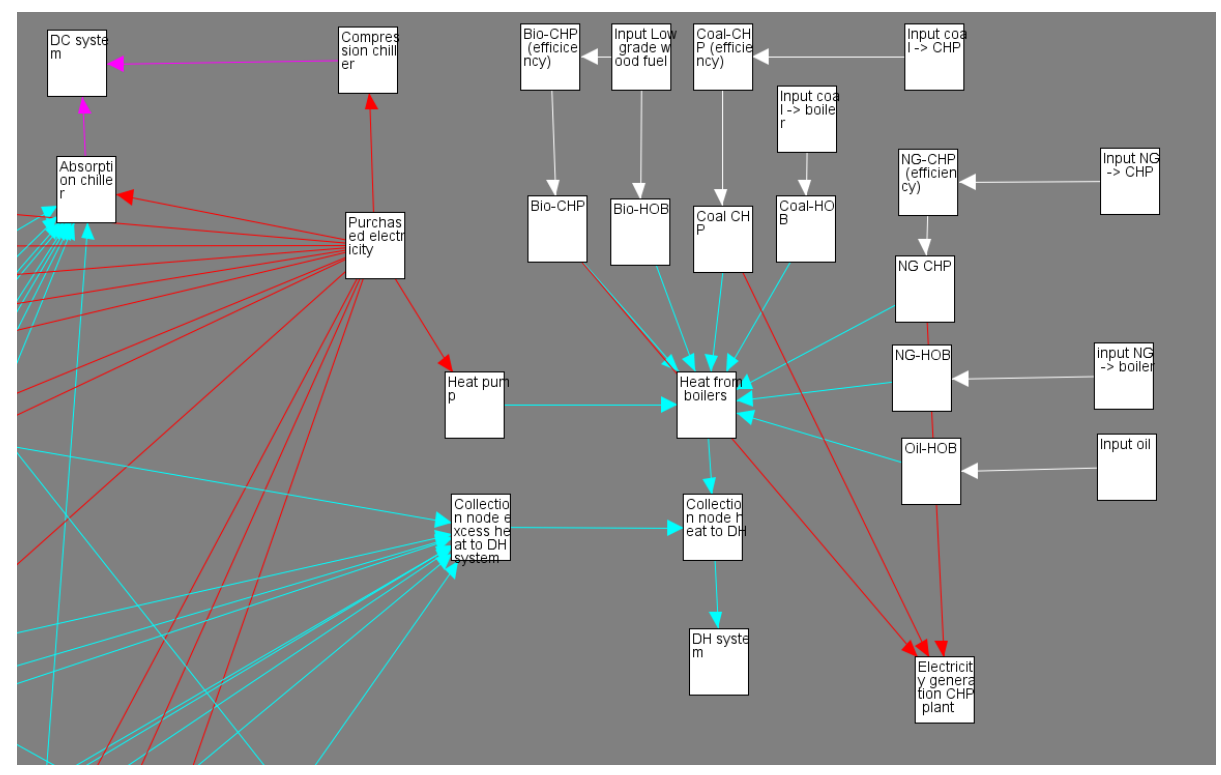

Figure 11. The user interface of the reMIND software.

\subsection{Economic evaluation: investment opportunity}

Calculating the investment opportunity (IO) offers a way to estimate how high the costs associated with a system change can be for the investment to be profitable. The IO is calculated by comparing the costs associated with the existing system and the costs associated with the modified system. A positive value of the opportunity to invest indicates the annual savings potential accruing from making the investment. Therefore, the total IO depends on the company pay-back requirements for the given investment. IO calculation has previously been used to evaluate the economic opportunities for energy-efficiency investments and measures; see, for example, (Bengtsson et al., 2002; Heyne and Harvey, 2013; Wetterlund et al., 2011). The IO needs to include the actual investment cost as well as other associated costs, such as those of operation and maintenance. The IO is given by Eq. (2):

$$
\mathrm{IO}=\mathrm{C}_{\text {existing system }}-\mathrm{C}_{\text {modified system }}
$$


where $C_{\text {existing system }}$ is the annual system cost of the existing system and $C_{\text {modified system }}$ is the annual system cost following the change in the system.

IO calculations are performed in Papers III and V. In Paper III, the annual opportunity to invest is given by the difference in system cost if biogas is produced at the food company or produced externally. Calculations are made for when excess heat is used to cover the heat demand in the digester and for when a portion of the produced biogas is used. The annual system cost is calculated in Paper III according to Eq. (3):

$$
\mathrm{C}_{\text {system, Paper III }}=\mathrm{C}_{\text {Fuel (oil) }}+\mathrm{C}_{\text {Shipments to external biogas plant }}+\mathrm{C}_{\text {Shipments to WWTP }}
$$

where $\mathrm{C}_{\text {Fuel (oil) }}$ is the annual system cost of oil used in production and $\mathrm{C}_{\text {Shipments to external biogas plant }}$ and $\mathrm{C}_{\text {Shipments to wwTP }}$ are the annual system costs associated with organic waste transport. In Paper V, the IO is given as the difference in system cost between when excess heat is available and when it is not. The annual system cost is then calculated according to Eq. (4):

$$
\mathrm{C}_{\text {system, Paper V }}=\mathrm{C}_{\mathrm{el}}+\mathrm{C}_{\text {biomass }}+\mathrm{C}_{\text {Coal }}+\mathrm{C}_{\mathrm{NG}}+\mathrm{C}_{\text {oil }}-\mathrm{R}_{\mathrm{el}}
$$

where $\mathrm{C}_{\mathrm{e}}, \mathrm{C}_{\text {biomass }}, \mathrm{C}_{\text {Coal }}, \mathrm{C}_{\mathrm{NG}}$, and $\mathrm{C}_{\mathrm{oil}}$ are the annual fuel costs and $\mathrm{R}_{\mathrm{el}}$ is the annual revenue from electricity sold. 


\section{Results and analysis}

This chapter presents the main findings from the appended papers in relation to the research questions of the thesis. The results are presented in the same order as the given research questions.

\subsection{Untapped excess heat potential}

Research question 1:

What is the current untapped potential for industrial excess heat in terms of quantity, quality, and carrier medium?

In this thesis, untapped excess heat potentials in Sweden are mainly examined in two regional studies presented in Papers I and II, though untapped potentials are also touched on in Paper III at the company level.

Although excess heat use can be considered well known, and despite its various associated benefits this resource is clearly still largely untapped. Top-down studies estimating excess heat potentials generally do not consider other aspects of excess heat than its quantity, although the literature emphasizes that the quality of excess heat, which determines the usefulness of the resource, is just as important (U.S. Department of Energy, 2008). Taken together, this means that we need further studies of excess heat availability to gain a more thorough understanding of the inherent potential of this resource. This is in line with what is discussed in Bendig et al. (2013) and Persson et al. (2014), where the scarcity of bottom-up studies in the field is emphasized.

In Papers I and II, the untapped excess heat potential in three Swedish regions, Gävleborg, Östergötland, and Örebro counties, was studied using questionnaires. Gävleborg County was covered in one questionnaire (Paper I), while Östergötland and Örebo counties were jointly covered in another (Paper II). The excess heat quantity, flow temperature, and carrier medium were examined in these questionnaires. The response rate of the Gävleborg study totalled approximately 33\%, while in Östergötland and Örebro, 33\% completed the original version of the questionnaire and $16 \%$ the short version. These response rates might be deemed low, but it is worth noting that the companies completing the questionnaire accounted for approximately $84 \%{ }^{13}$ of the industrial energy use in Gävleborg County and

${ }^{13}$ In Paper I this figure was unfortunately incorrectly reported as $62 \%$. 
approximately $77 \%$ in Östergötland and Örebro counties. Among the companies that completed the questionnaire, $74 \%$ in Gävleborg and 60\% in Östergötland and Örebro counties declared that they had excess heat, although only $50 \%$ and $36 \%$ of them, respectively, reported specific values.

The excess heat potential for external use reported in the studies is illustrated in Figure 12 and Figure 13, where the flows are differentiated by identified carrier medium and temperature level.

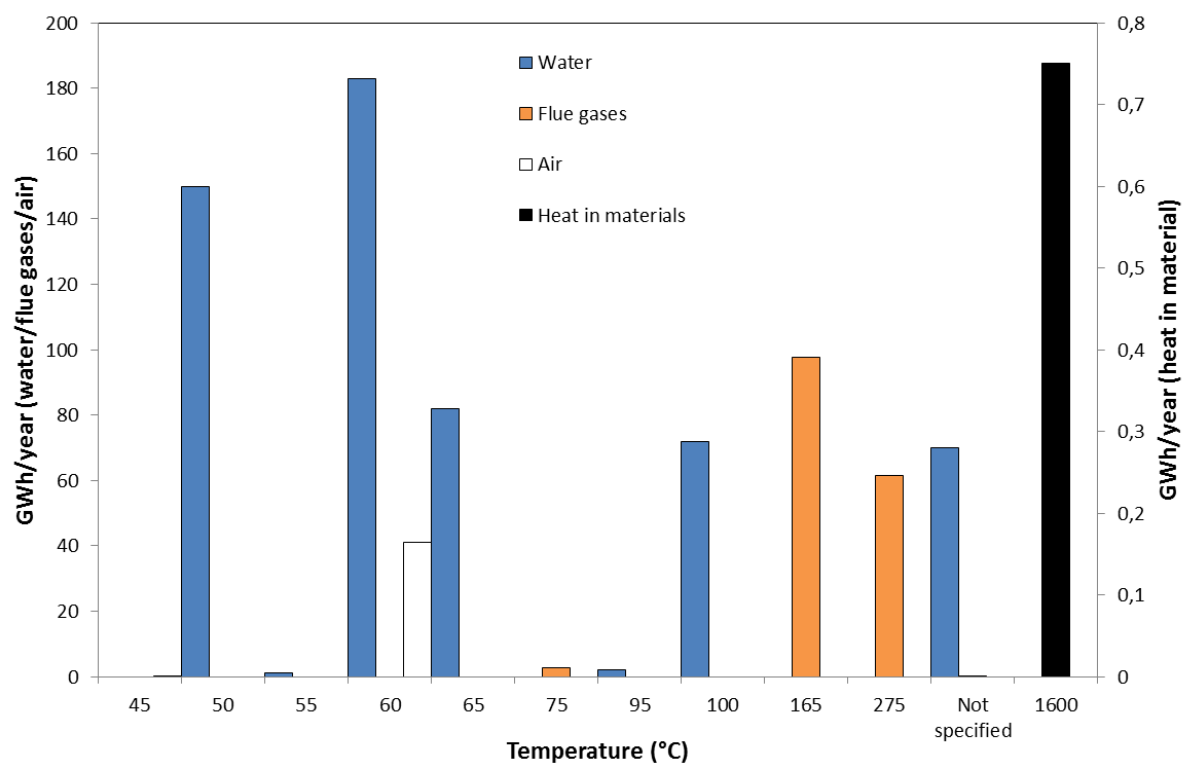

Figure 12. Annual untapped excess heat potential in Gävleborg County differentiated by carrier medium and temperature. Some figures in the graph are close to zero; these are (left-right, in approximate terms): air $\left(45^{\circ} \mathrm{C}\right) 0.05 \mathrm{MWh}$, water $\left(55^{\circ} \mathrm{C}\right) 1 \mathrm{GWh}$, flue gases $\left(75^{\circ} \mathrm{C}\right) 2.8 \mathrm{GWh}$, water $\left(95^{\circ} \mathrm{C}\right) 2 \mathrm{GWh}$, and flue gases (unspecified temperature) $0.1 \mathrm{GWh}$. Note that the left-hand y-axis applies to water, flue gases, and air, while the right hand $\mathrm{y}$-axis applies to heat in materials. 


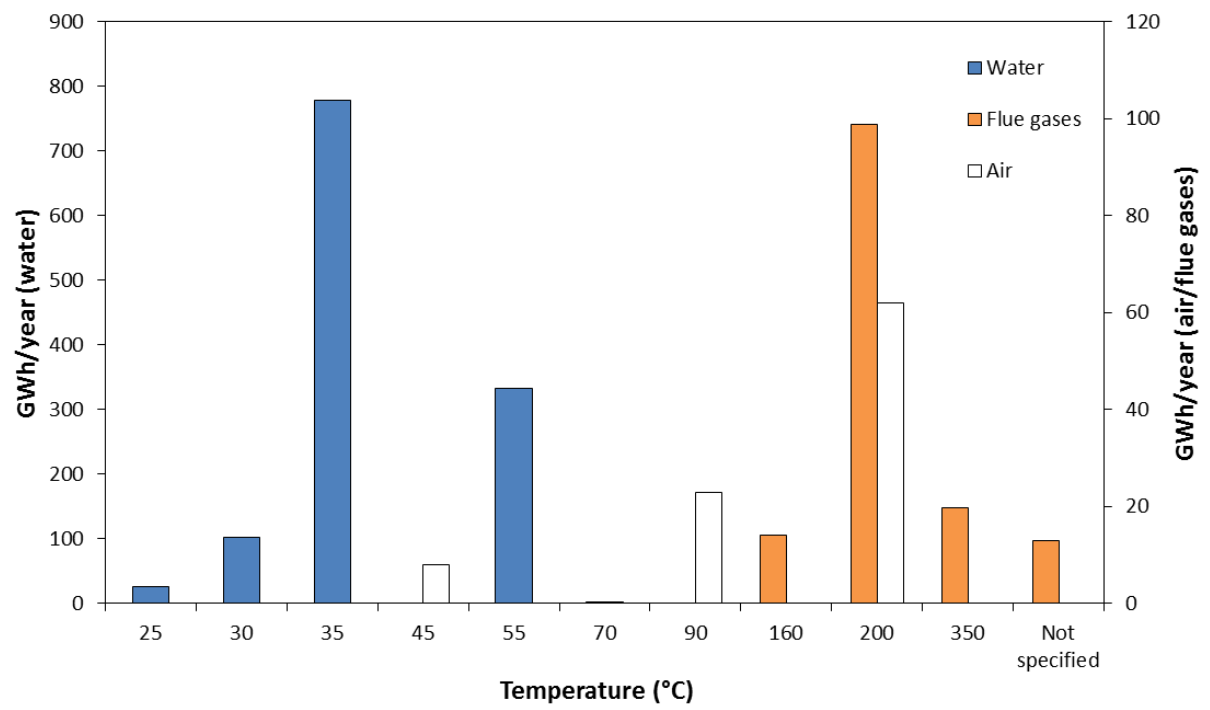

Figure 13. Annual untapped excess heat potential ${ }^{14}$ in Östergötland and Örebro counties differentiated by carrier medium and temperature. One figure in the graph is close to zero, this is (in approximate terms): water $\left(70^{\circ} \mathrm{C}\right) 0.2 \mathrm{GWh}$. Note that the left-hand y-axis applies to water while the right-hand y-axis applies to air and flue gases.

As can be seen in Figure 12 and Figure 13 large excess heat potentials exist. The largest share, in terms of quantity, is available as heat in water flows followed by heat in flue gases. This pattern is evident in both studies covering the three regions. These water flows are mainly low-temperature heat flows at a temperature of no more than $70^{\circ} \mathrm{C}$, but water flows at temperatures of up to $100^{\circ} \mathrm{C}$ were identified as well. On the other hand, heat in flue gases is mainly available at temperatures above $160^{\circ} \mathrm{C}$. Summing up the excess heat identified in the two studies, excess heat in Gävleborg totals almost $765 \mathrm{GWh}$ per year and in Östergötland and Örebro counties almost $1480 \mathrm{GWh}$ per year, totalling more than $2.2 \mathrm{TWh}$ annually.

As well as being unexploited because they are unidentified, excess heat opportunities may also remain unexploited because technical and economic restrictions limit the usefulness of the resource. This is discussed by Bendig et al. (2013), who distinguish between a theoretical excess heat potential and a potential accounting for technical and economic restrictions. The potential discussed in this section should therefore be viewed as a theoretical potential, though identifying the heat quality may facilitate further assessments of the reserve represented by this resource.

\footnotetext{
${ }^{14}$ In this figure as it appeared in Paper II, the annual untapped heat potential in $35^{\circ} \mathrm{C}$ water was
} unfortunately cut off, though it was included in the total potential specified in the text of the paper. 
Assuming that the share of excess heat identified in the studied counties reflects the situation in Sweden's other counties, i.e., that the relationship between energy input and excess heat output is valid, rough calculations can be made scaling up the potential to a national level using the following formula:

$$
\text { Identified EH potential } * \frac{\text { Swedish industrial energy use }}{\text { Energy use among companies with EH values and companies with no EH }}
$$

This type of calculation was performed and presented in Paper II based on data for Östergötland and Örebro counties, though the calculations were based on energy use by the companies that completed the questionnaire. New calculations were made for this thesis excluding the energy use among the companies that declared that they had excess heat but did not report specific values. Scaling up these data from Gävleborg gives a figure of approximately 12.7 TWh per year, whereas upscaling Östergötland and Örebro data gives a figure of approximately 21.4 TWh. These national excess heat potentials obviously do not match and a number of explanations will briefly be discussed here. First, the upscaling is based on data capturing different-sized resources, i.e., the energy use considered in the joint Östergötland and Örebro study is somewhat larger than that considered in the Gävleborg study. Second, one of the companies included in the Östergötland and Örebro study that gave figures for excess heat potentials did not give figures for total energy use. Since the upscaling is based on the companies' total energy use, the scaled figure becomes larger than it would otherwise have been. Third, although a large share of the counties' industrial energy use was considered, the total energy use was not, which might have affected the outcome. This possibility is supported by the fact that more companies specified having excess heat than provided actual excess heat potential figures. The upscaled Swedish untapped excess heat potentials are larger than the estimated untapped potentials reported by Cronholm et al. (2009). However, as the latter estimates were based on current excess heat deliveries to DH, they likely exclude excess heat at lower temperatures and may be underestimated.

Low-temperature heat flows have also been identified in Paper III. This paper studies the opportunities for and effects of biogas production at an industrial plant with the ability to use excess heat to cover biogas production process heat requirements. As part of this work, excess heat flows at the food company were partly mapped. The mapping of untapped excess heat focused on four sources of excess heat. The total identified untapped excess heat totals approximately $2.2 \mathrm{GWh}$ per year carried in hot water flows. The following flows were identified: excess heat from the boiler blow top process, approximately $90^{\circ} \mathrm{C}$, constant flow; excess heat from potato boiling, $98^{\circ} \mathrm{C}$, intermittent flow; excess heat from potato blanching, $75^{\circ} \mathrm{C}$, intermittent flow; and excess heat from the air compressor, $70^{\circ} \mathrm{C}$, intermittent flow. The potential from November 2012 until October 2013 can be seen in Figure 14. 


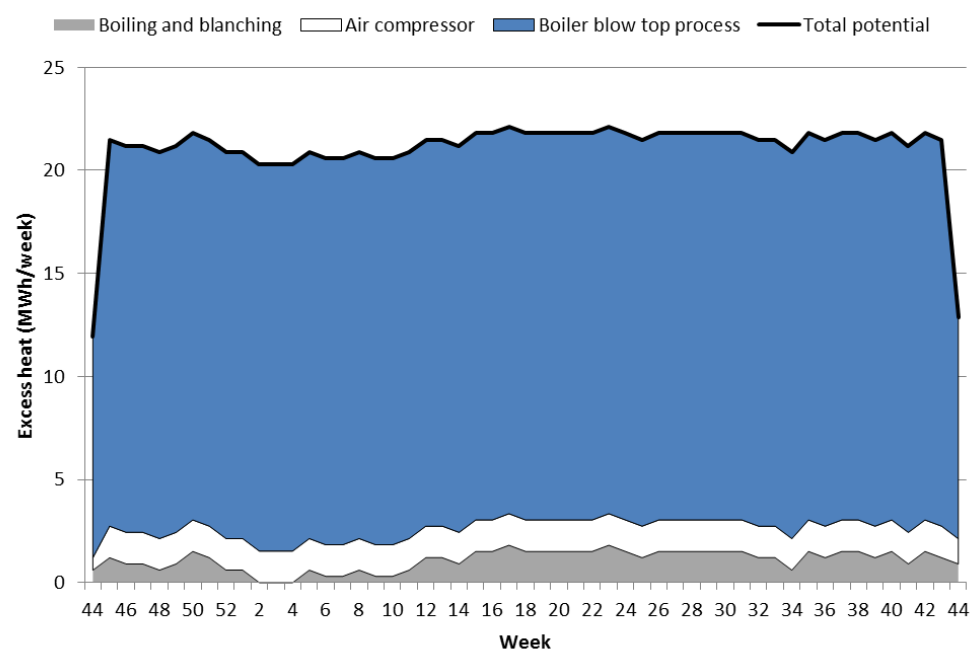

Figure 14. Excess heat potential at a food company (November 2012 until October 2013) originating from the boiler blow top process, potato boiling and blanching, and the air compressor system. The decrease in week 44 in 2012 and 2013 is attributable to these not being seven-day working weeks.

\subsection{Implications of different excess heat use options}

Research question 2:

What are the implications of using different technologies and systems solutions based on the use of industrial excess heat?

Research question 2 focuses on the implications of using different technologies and systems solutions based on industrial excess heat use. One such implication is the effects on the amount of emitted GHG as a consequence of this heat use. This aspect will not be considered in this section, however, as this is the focus of research question 3, presented in Section 7.3.

\subsubsection{Excess heat use}

Paper I presents a study of the range of alternatives for excess heat use and recovery, and categorizes these options into the following four categories: heat harvesting, heat storage, heat utilization, and heat conversion. Heat-harvesting technologies such as heat exchangers, heat pumps, and heat radiation collectors can be used to make excess heat accessible for further use. When the available excess heat, the heat source, does not match the heat sink, heat storage can be used to improve the matching of supply and demand by storing heat for later use. The simplest heat-storage system, a water tank, is based on sensible heat storage in which the temperature of the storage medium is elevated when the heat is stored. Heatutilization alternatives include measures in which excess heat is used in $\mathrm{DH}$, cooling 
production, and heat cooperation, i.e., excess heat is used without converting it into another form of energy, while heat-conversion technologies are used to convert the thermal energy in excess heat into electricity. Heat-utilization and heat-conversion alternatives are described in sections 2.3.2 and 2.4. This selection of recovery options indicates that adequate technical possibilities are already available or under development to allow more industries than today to deliver or use excess heat.

Two of these options for excess heat use are analysed in Paper I: excess heat use in DH or for electricity production. The identified excess heat streams in Gävleborg County, shown in Figure 12, constitute the basis for the calculations of energy recovery potentials. In these calculations, heat flows below $95^{\circ} \mathrm{C}$ were assumed to be infeasible for $\mathrm{DH}$ deliveries. In the electricity generation calculations, three complementary technologies were studied and heat sources above $25^{\circ} \mathrm{C}$ were included..$^{15}$ Therefore, a larger share of the available excess heat was used in calculating possible electricity production than in calculating $\mathrm{DH}$ deliveries. Despite this, Figure 15 shows that the energy recovery output for excess heat used in DH is larger than when used for electricity generation: annually, approximately $90 \mathrm{GWh}$ is recovered from DH only and $25 \mathrm{GWh}$ from electricity generation only. This difference can be explained by the lower conversion efficiency of electricity generation. The share of $\mathrm{DH}$ may even increase if heat sources below $95^{\circ} \mathrm{C}$ are upgraded via heat pumps to meet the temperature requirements for $\mathrm{DH}$.

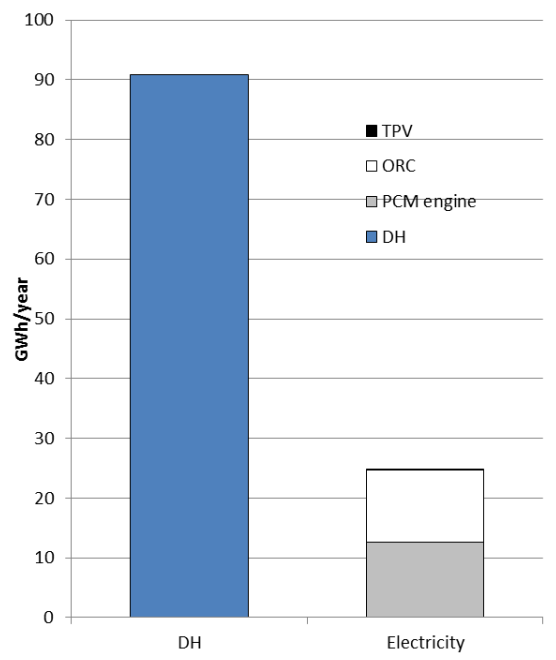

Figure 15. Use of excess heat for DH deliveries or electricity production. Calculations are based on data from Gävleborg County (see Figure 12). The following heat flows were used in the calculations: $\mathrm{DH}$ deliveries for heat sources above $95^{\circ} \mathrm{C}$, TPV for heat from hot materials above $1000^{\circ} \mathrm{C}, \mathrm{ORC}$ for heat sources (liquid or gaseous) above $80^{\circ} \mathrm{C}$, and PCM engine for liquid heat sources below $80^{\circ} \mathrm{C}$. $\mathrm{DH}=$ district heating, $\mathrm{ORC}=$ organic Rankine cycle, $\mathrm{TPV}=$ thermophotovoltaic, $\mathrm{PCM}=$ phasechange material.

\footnotetext{
${ }^{15}$ For heat sources below $80^{\circ} \mathrm{C}$, only water sources were considered.
} 
Paper I examines two extremes, that is, when the heat is used directly as heat or when it is converted into another energy form. A combination of these strategies increases the output. Using heat sources below $95^{\circ} \mathrm{C}$ for electricity production combined with $\mathrm{DH}$ deliveries would increase the total recovery output to approximately $104 \mathrm{GWh}$ per year (i.e., blue bar plus grey bar in Figure 15).

The use of the identified excess heat in Gävleborg County, as shown in Figure 12, was also studied in Paper V. In this paper, the available excess heat was modelled together with three heat application alternatives: deliveries to a $\mathrm{DH}$ system, use in heat-driven absorption cooling, and use in ORC electricity production. The model includes alternative heating and cooling technologies if the excess heat technology is not implemented. The year was divided into three periods (T1 - autumn/spring, T2 - winter, and T3 - summer) to capture the heating and cooling fluctuations as well as the electricity price fluctuations over the year. When altering the energy market conditions according to the 2030 EMSs presented in Table 4 (see Section 6.3), the trade-offs between the different technologies are identified, i.e., the systems solution with the lowest systems costs. The trade-off can be seen in Figure 16.

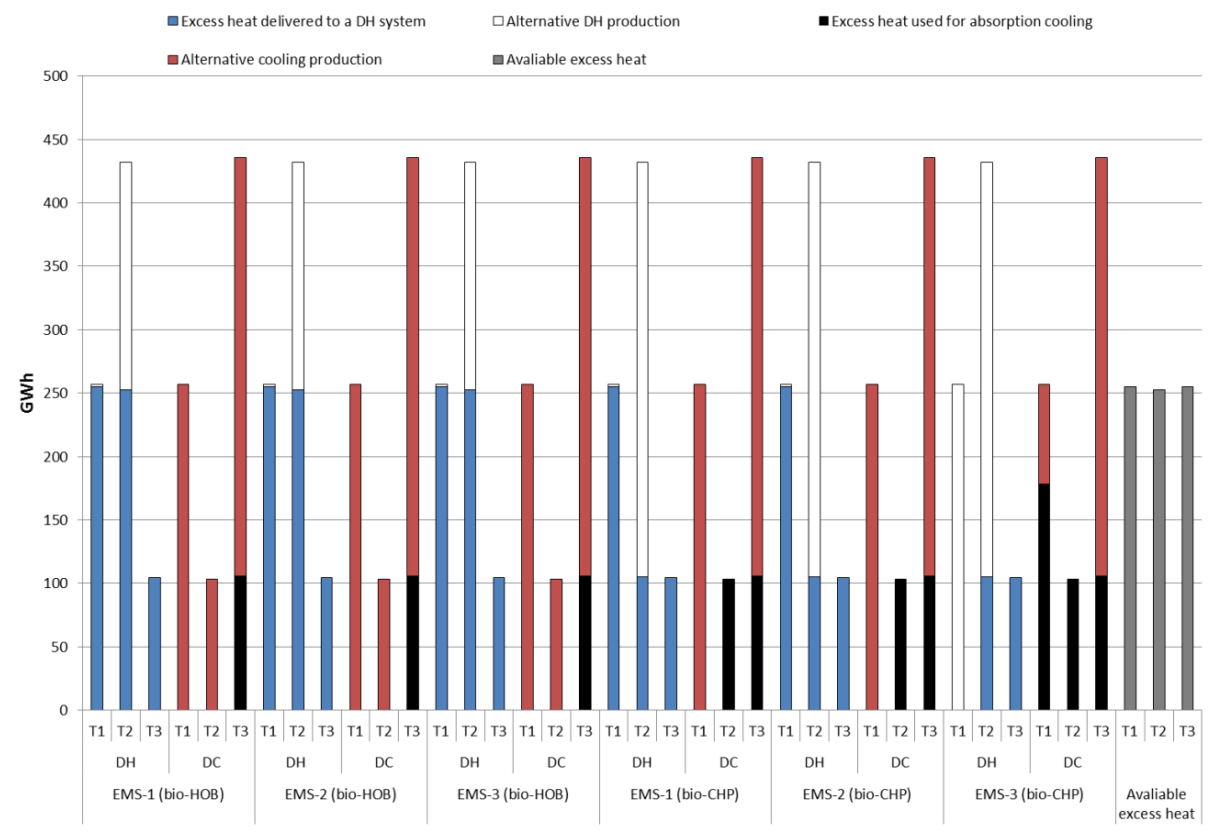

Figure 16. Heating and cooling supply in the system for six EMS for 2030. The varying heating and/cooling load throughout the year is captured using three periods: T1 (autumn/spring), T2 (winter), and $\mathrm{T} 3$ (summer). $\mathrm{DH}=$ district heating, $\mathrm{DC}=$ district cooling, $\mathrm{CHP}=$ combined heat and power, $\mathrm{HOB}=$ heat-only boiler.

No excess heat passes through the ORC in any of the scenarios. Instead, all excess heat is either delivered as heat to the DH system or used in the absorption chiller to supply the DC system with cooling. When the DH system is based on HOB, the system costs are minimized when available excess heat is used primarily for deliveries to the DH system. This is true for 
all three scenarios, that is, independent of the energy market conditions studied. When the DH system is based on CHP production, the pattern of excess heat use is not that clear. The combination of a low or intermediate electricity price with a low or intermediate biomass price affects the system by favouring excess heat deliveries to the DH network, while a high electricity price combined with a high biomass price favours heat-driven cooling. With rising electricity prices, the costs associated with electricity-driven cooling production increase as do the revenue losses coming from CHP-produced electricity.

\subsubsection{Effects of excess heat use}

In this thesis, excess heat is assumed to be free of charge and can therefore be viewed as a low-cost energy source. Using excess heat reduces the need for other fuels in an energy system. This creates economic opportunities for investments in excess heat use solutions. In Paper V, IO values have been calculated for the studied scenarios. The annual IO values in the six EMSs treated in Paper V can be seen in Table 6, which indicates that the opportunity to invest is greater in cases in which the DH system is based on HOB than on CHP production. This is due to reduced electricity generation revenues in the CHP plant resulting from reduced occupancy in that plant when excess heat is used in DH. Also, the DH fuel prices affect the IO; for example, the fuel prices in the EMS-2 bio-HOB and bio-CHP scenarios are generally lower than in the other scenarios, lowering the IO.

Table 6. Annual IO values for the six 2030 EMSs considered in Paper V.

\begin{tabular}{cccccc}
\hline \multicolumn{6}{c}{ Annual investment opportunity (MEUR) } \\
\hline EMS-1 & EMS-2 & EMS-3 & EMS-1 & EMS-2 & EMS-3 \\
(bio-HOB) & (bio-HOB) & (bio-HOB) & (bio-CHP) & (bio-CHP) & (bio-CHP) \\
\hline 25 & 22 & 26 & 16 & 14 & 17 \\
\hline
\end{tabular}

Through heat cooperation between nearby industries or other businesses, the use of excess heat can increase, having several positive effects. Papers III and IV study two such setups. Paper III studies biogas production at a food company (see Section 5.2). The company is currently delivering organic production wastes to an external biogas plant, and the gas is used as a fuel for transportation and DH. The paper examines a switch to internal biogas production in which the biogas can replace fossil fuels used in industrial production. This opens up the possibility of using the food company's low-temperature excess heat to cover the heat demand ${ }^{16}$ in the biogas digester. The opportunity for internal biogas production in the food industry has been discussed in the literature (Ammar et al., 2012), and their access to low-temperature excess heat (Nyström and Franck, 2002) as well as significant amounts of organic waste have been emphasized (Linné et al., 2008). In Paper III, the opportunity to invest in internal biogas production was calculated for two cases: 1) excess heat is used to heat the digester or 2) biogas is used to heat the digester. The annual IO is presented in Figure 17 and ranges from EUR 174-198 thousand.

${ }^{16}$ In Paper III, an operating temperature of $37^{\circ} \mathrm{C}$ was assumed in the biogas digester. 


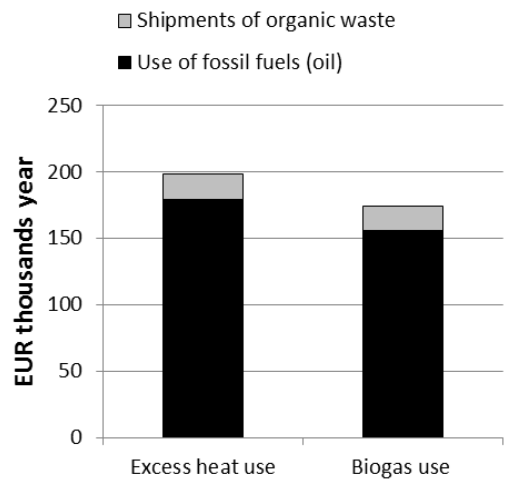

Figure 17. Opportunity to invest in the internal biogas production solution studied in Paper III. Annual IO (in EUR thousands) in two cases: 1) excess heat from the food company is used to heat the digester and 2) part of the produced biogas is used to heat the digester. The IO originates from the reduced use of fossil fuels in production and reduced shipments of organic waste to external facilities.

In Paper III, the opportunity to invest arises due to the reduced need for fossil fuels to cover the energy demand in production, and to the discontinued shipments of organic waste. Using available excess heat from the production processes to cover the heat demand in the biogas production process creates a larger IO (i.e., EUR 24 thousand larger) than when part of the biogas is used for this purpose. This additional economic opportunity, however, needs to take account of the additional investments necessary to use the excess heat. Several benefits come with the setup studied in Paper III. Besides the economic gains and the effects on GHG emissions (see Section 7.3), cooperation with a nearby farm enables industrial waste to be co-digested with manure to increase the biogas output. Consequently, more fossil fuels can be replaced and the farm can receive a nutritious digestate to spread on the fields.

First-generation biofuels production have been criticized, for example, for increasing the pressure on arable land, so efforts have begun to develop next-generation biofuels, including those generated from algae biomass. Despite various advantages, algae-based biofuels entail environmental, energy-related, and economic challenges (Razon and Tan, 2011; Clarens et al., 2010; Savage, 2011; Lardon et al., 2009). It is claimed that these can be overcome by using available WW and the nutrients it contains, recycling $\mathrm{CO}_{2}$ from flue gases as nutrients, and reducing the use of primary energy by using excess heat. In view of this, Paper IV studies a biorefinery concept in which a conventional WWTP is replaced with a combined algae cultivation, WWTP, and biofuels production process (see Section 5.3). $\mathrm{CO}_{2}$ is assumed to be added through integration with nearby industrial facilities and the biogas upgrading facility, to cover the carbon deficit in the WW. Due to uncertainty concerning algae growth, two growth rates were used in the paper: a low growth rate of $12 \mathrm{~g} \mathrm{~m}^{-2}$ day $^{-1}$ and a high growth rate of $40 \mathrm{~g} \mathrm{~m}^{-2}$ day $^{-1}$. Approximately $1400 \mathrm{GWh}$ of excess heat is available from two refineries next to the WWTP annually. Calculations were made as to whether this excess heat is enough to cover the heat demand in the cultivation pond and keep its temperature at 
$20^{\circ} \mathrm{C}$. The calculations take into account incoming solar radiation as well as heat losses due to convective heat transfer and water evaporation. Assuming the lower growth rate, the pond heat demand exceeded the available excess heat from November to February. At the higher growth rate, there was a heat deficit only in December. However, from March until September there was no need for excess heat to keep the pond temperature at a level favourable for growth in either of the cases. Problems with heat losses during winter support arguments for seasonal production, but this would have implications for product output and the economics of the process. Still, Paper IV demonstrates that excess heat can be beneficial in second-generation biofuel production systems. Algae cultivation requires a large amount of heat and if this heat were supplied by designated boilers, the use of primary energy resources would increase, changing the effects of such a setup on $\mathrm{CO}_{2}$ emissions.

\subsection{Emission-mitigation potential}

Research question 3:

\section{How do different excess heat use options and energy market conditions influence global $\mathrm{CO}_{2}$ emissions?}

Four papers in this thesis, Papers I, III, V, and VI, evaluate the impact of excess heat use on GHG emissions. In Papers I and V, the evaluations are based on future EMSs (see Section 6.3) using a system expansion including marginal use of biomass and build marginal electricity production. The evaluation in Paper VI combines such EMS calculations with LCA calculations (see Section 5.6) in which marginal biomass use is not accounted for. In Paper III, direct emissions are considered, i.e., GHG emissions derived from sources controlled by the studied businesses. In that paper, calculations are made assuming both that biomass is a limited resource and that it is not, that is, when the emissions from biomass use are accounted for and when they are valued at zero. The results of Papers I and V have been recalculated from $\mathrm{CO}_{2}$ emissions to $\mathrm{CO}_{2}$-eq. emissions instead, in line with calculations made in Papers III and VI.

Paper I studies the impact on GHG emissions of using excess heat from Gävleborg County ${ }^{17}$ for deliveries to a DH network and for electricity production. The results are shown in Figure 18. Using excess heat for electricity production reduces the emissions in all studied scenarios. When applying the marginal approach, the produced electricity replaces marginal electricity from CCP plants (EMS-1 and 2) or NGCC plants (EMS-3), which results in reduced emissions. Excess heat use in Swedish bio-HOB-based DH systems also reduces $\mathrm{CO}_{2}$-eq. emissions in all studied EMSs due to the reduced need for fuels in DH. Since the released biomass can be used by a marginal user of biomass, this user affects the size of the $\mathrm{CO}_{2}$-eq. emission reduction, resulting in a larger reduction when the biomass is co-fired in a CCP plant than when displacing fossil transportation fuels. Using excess heat in DH does not necessarily result in reduced emissions, however. Using excess heat in CHP-based DH

\footnotetext{
${ }^{17}$ The excess heat sources used are specified in Section 7.2. Some low-temperature heat flows (i.e., liquid heat sources below $80^{\circ} \mathrm{C}$ ) used for electricity production are not included in $\mathrm{DH}$ deliveries.
} 
systems may result in increased emissions, as can be seen in Figure 18 for EMS-1 and 2. Introducing excess heat into a CHP-based DH system reduces the electricity production. Consequently, more electricity has to be produced by the marginal electricity producer. The emission increases in EMS-1 and 2 in the bio-CHP-based systems derive from the large emissions associated with coal-based electricity production. However, under other energy market conditions, using excess heat in CHP-based DH can also result in reduced emissions, as in EMS-3. In this scenario, the increased GHG emissions coming from alternative NGCC electricity production is lower than the GHG emission gains when released biomass is co-fired in CCP plants.

Looking at the effect of excess heat use on GHG emissions as shown in Figure 18, it can be observed that the emission mitigation when using excess heat for electricity production is larger than when the heat is delivered to a DH system, except in the EMS-3 bio-HOB and bio-CHP scenarios. However, it must be kept in mind that the low-temperature excess heat sources (excess heat in water below $80^{\circ} \mathrm{C}$ ) used for electricity production in a PCM engine is not used in calculations of $\mathrm{DH}$ deliveries. Disregarding this heat source in electricity production as well would change this outcome in favour of $\mathrm{DH}$ deliveries, in terms of reduced emissions, in all scenarios except EMS-1 and 2 for CHP-based systems.

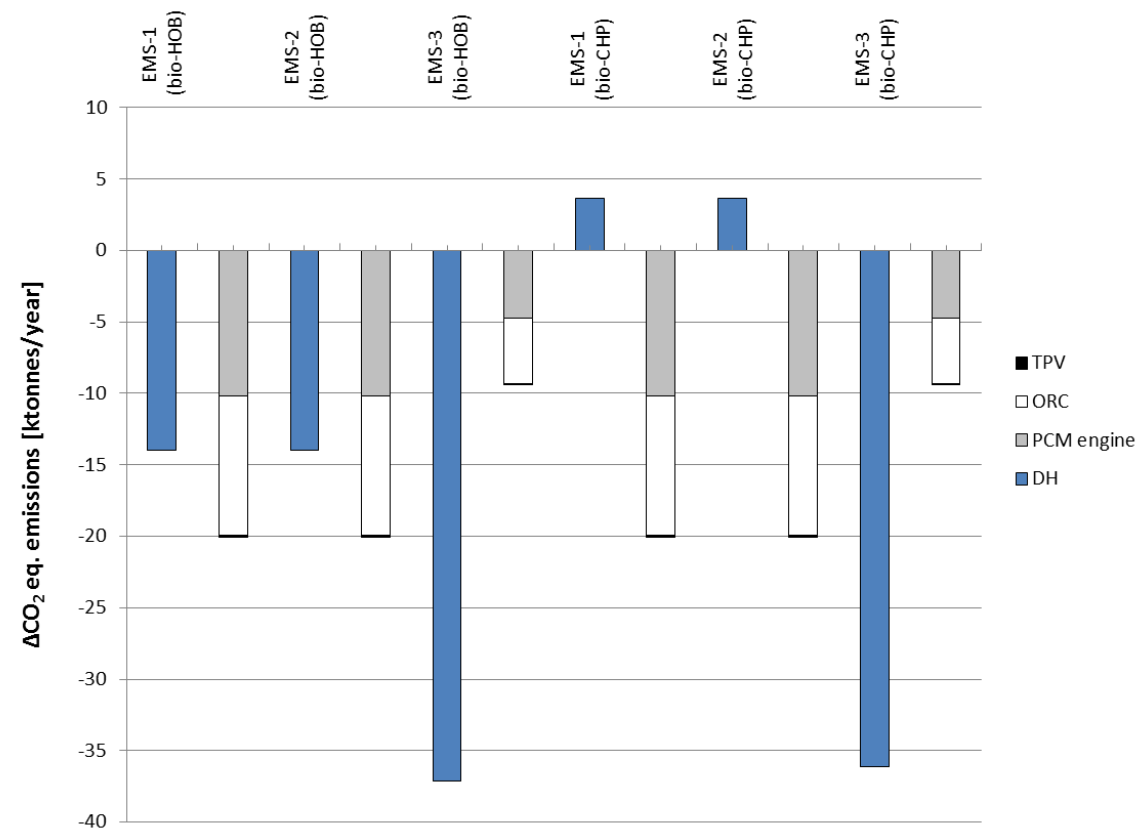

Figure 18. Effect on $\mathrm{CO}_{2}$-eq. emissions of using excess heat in Gävleborg County in 1) DH or 2) electricity production. Changes are calculated using three ENPAC EMSs for 2030 and two DH systems: bio-HOB based on wood-fuelled heat-only boilers and bio-CHP based on wood-fuelled CHP plants. Results originate from Paper I; negative values indicate reduced emissions. CHP = combined heat and power, $\mathrm{HOB}=$ heat-only boiler, $\mathrm{DH}=$ district heating, $\mathrm{ORC}=$ organic Rankine cycle, $\mathrm{TPV}=$ thermophotovoltaic, $\mathrm{PCM}=$ phase-change material. 
The effects on GHG emissions in Paper V, based on the trade-offs between different excess heat use technologies for identified excess heat in Gävleborg County, are shown in Figure 19. Calculations are based on the same 2030 EMSs used in Paper I. The optimal solution does not include heat-driven electricity production, so the emission evaluation is based on excess heat use in $\mathrm{DH}$ and heat-driven cooling production.

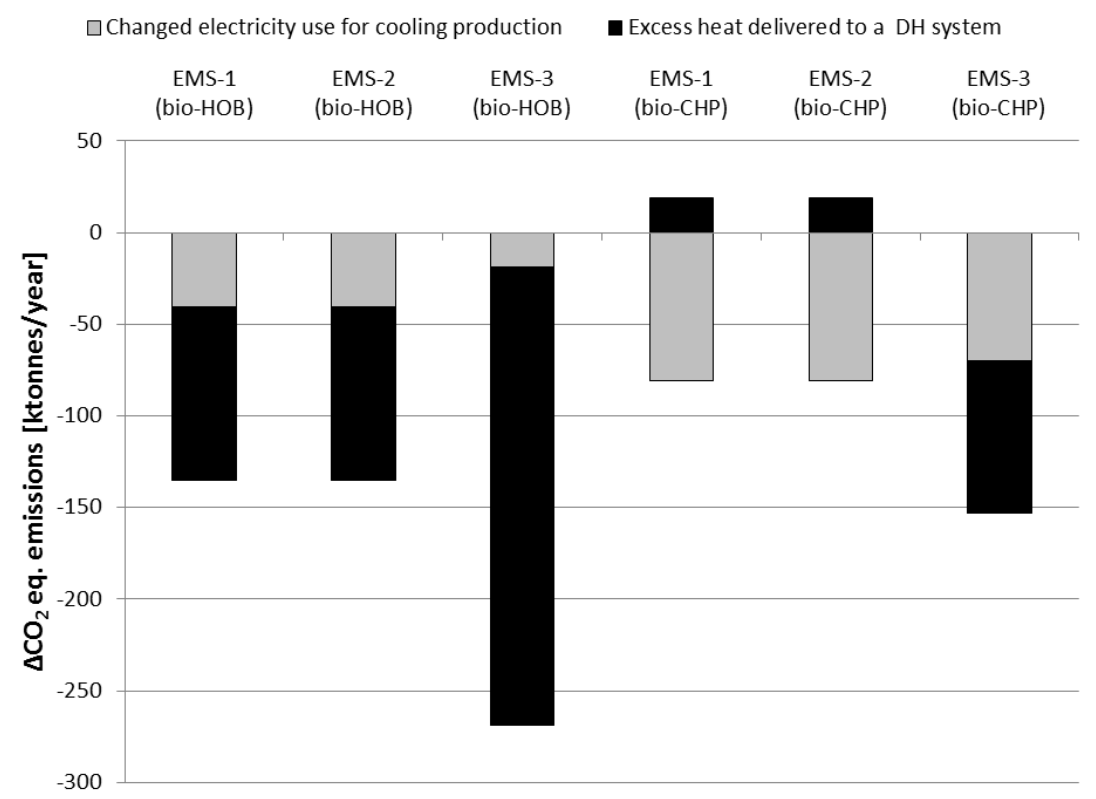

Figure 19. Effect on $\mathrm{CO}_{2}$-eq. emissions of excess heat used in $\mathrm{DH}$ or absorption cooling. Calculations are made for three ENPAC EMSs for 2030 and two DH systems: bio-HOB based on wood-fuelled heat-only boilers and bio-CHP based on wood-fuelled CHP plants. Results originate from Paper V; negative values indicate reduced emissions. $\mathrm{CHP}=$ combined heat and power, $\mathrm{HOB}$ = heat-only boiler, $\mathrm{DH}=$ district heating, $\mathrm{DC}=$ district cooling.

Using excess heat for absorption cooling production, as examined in Paper V, reduces the electricity demand for complementary compression cooling production. Therefore, the results follow the same trends as identified in Paper I. The bars in Figure 19 indicate the effect on GHG emissions of using excess heat in DH (black bars) and in cooling production (grey bars), as presented in Paper V. The impact of using excess heat to produce cooling, thereby reducing the marginal electricity production, reduces the system's emissions of GHG in all scenarios studied. Here too, using excess heat in HOB-based DH systems results in emission mitigation, while using excess heat in CHP-based DH production may result in increased emissions if the build margin for electricity production is CCP plants and the marginal use of biomass is FT diesel production. To sum up, using all the available heat according to the systems solutions with minimized systems costs, the final picture indicates reduced total $\mathrm{CO}_{2}$-eq. emissions (see Figure 19). 
The results of Paper VI are shown in Figure 20 and Figure 21. Paper VI combines GHG emission calculations from LCAs of six contemporary $\mathrm{DH}$ production cases with future EMSs for 2020 and 2030 to assess the system aspects of industrial excess heat in DH using a more comprehensive emission evaluation approach than used in Papers I and V. The LCA results indicate that using excess heat in a bio-HOB-based DH system is beneficial in terms of reduced emissions (production cases $\mathrm{A}$ and $\mathrm{B}, \mathrm{HOB}$ ). Excess heat deliveries to a bioCHP-based DH system, on the other hand, show no emission-reduction potential (production cases C-F, CHP). However, as can be seen in Figure 20, the size of the effect depends on the system boundary for lost electricity production. If European marginal electricity is applied (production cases $\mathrm{E}$ and $\mathrm{F}$ ), the increase in emissions is larger than when a Nordic electricity mix (production cases C and D), associated with lower emissions, is applied.

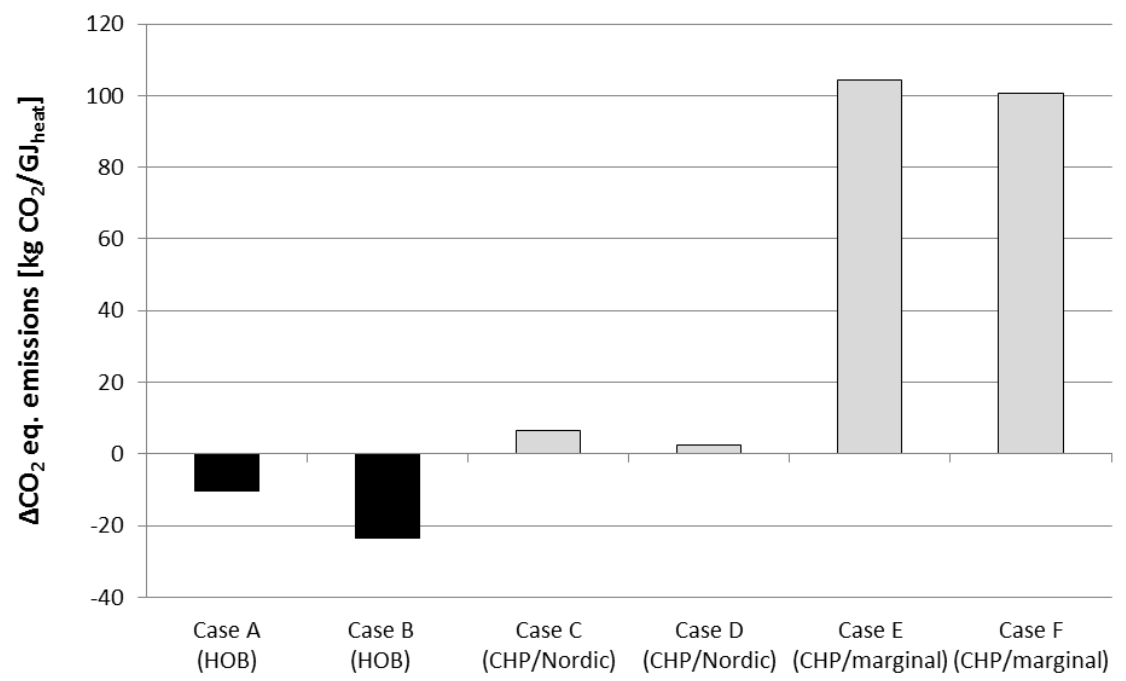

Figure 20. Effect on $\mathrm{CO}_{2}$-eq. emissions of using $1 \mathrm{GJ}$ of excess heat in $\mathrm{DH}$. Calculations are made for six contemporary DH production cases as presented in Table 3. Results originate from Paper VI; negative values indicate reduced emissions. Black bars represent $\mathrm{DH}$ production cases based on $\mathrm{HOB}$, and grey bars production cases based on CHP plants. 


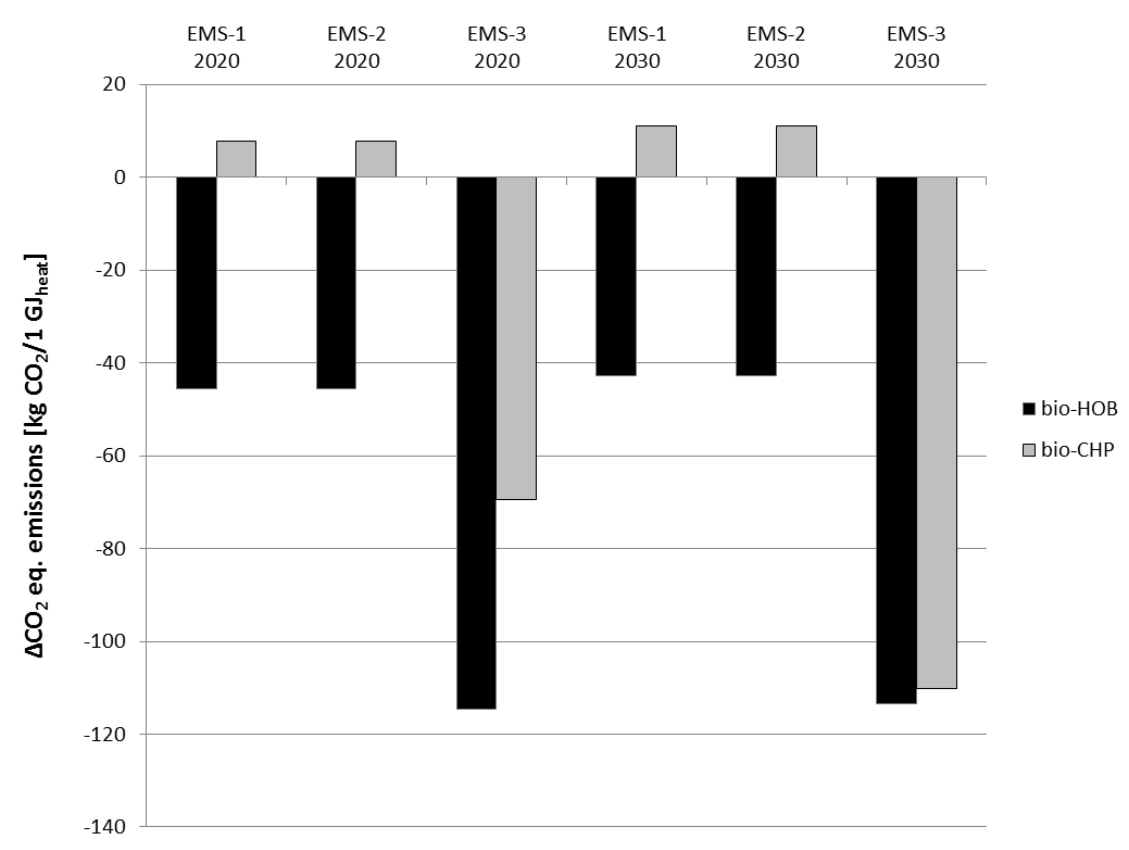

Figure 21. Effect on $\mathrm{CO}_{2}$-eq. emissions of using $1 \mathrm{GJ}$ of excess heat in $\mathrm{DH}$. The calculations are made for three ENPAC EMSs for 2020 and three EMSs for 2030 and two DH systems: bio-HOB based on wood-fuelled heat-only boilers and bio-CHP based on wood-fuelled CHP plants. Results originate from Paper VI; negative values indicate reduced emissions. $\mathrm{CHP}=$ combined heat and power, $\mathrm{HOB}=$ heat-only boiler.

Comparing the LCA calculations with the results based on future EMSs indicates that excess heat in HOB-based DH was also positive from a GHG emission perspective in all future scenarios. Possible recommendations based on the LCA results of excluding excess heat from CHP-based DH systems, however, may be questionable in future market settings with restricted biomass availability, as can be seen in Figure 21. The results when the EMS-3 2020 and 2030 scenarios are considered indicate that excess heat deliveries to $\mathrm{DH}$ can also be beneficial in CHP-based systems. In EMS-3, the released biomass is co-fired and thus replaces coal in CCP plants. Under such conditions, using excess heat in DH can be beneficial from a GHG emission perspective even if local electricity production is reduced. The greater reduction in 2030 compared with 2020 EMS-3 is due to the build margin technology for electricity production, which is NGCC production rather than CCP production. In the EMS-1 and 2 bio-CHP scenarios, the emission reduction associated with reduced use of fuels in $\mathrm{DH}$ and alternative use of biomass are not enough to compensate for the emissions related to marginal electricity production.

Paper III studies the effects on $\mathrm{CO}_{2}$-eq. emissions of using organic waste from a food company for internal instead of external biogas production. Two cases are evaluated: either excess heat or a portion of the produced biogas is used to heat the biogas digester. The change in the use of organic waste brings several system changes accounted for in the 
coloured bars in Figure 22. Some of the individual system changes result in increased emissions, whereas others result in decreased emissions. In total, the system changes have emission-reduction potential for both digester-heating alternatives, regardless of whether or not emissions related to biomass are accounted for; this can be seen in the grey bars in Figure 22. Looking into all the details illustrated in Figure 22 is beyond the scope of this thesis, so only selected effects will be discussed. Biogas production in proximity to the food company enables excess heat to be used to heat the biogas digester. This in turn enables more fossil fuels, currently used in production, to be replaced with biogas. The emission effect of this excess heat use is visualized in Figure 22 as the difference in emissions between cases 1 and 2. The figure shows that the heat cooperation between industrial production and biogas production further reduces the emissions of GHG. Even though the valuation of emissions from biomass does not affect the emission effects originating from excess heat use, it is still interesting to note that the aggregated emission effects of the system changes are perceived to be better if emissions from biomass are regarded as zero.

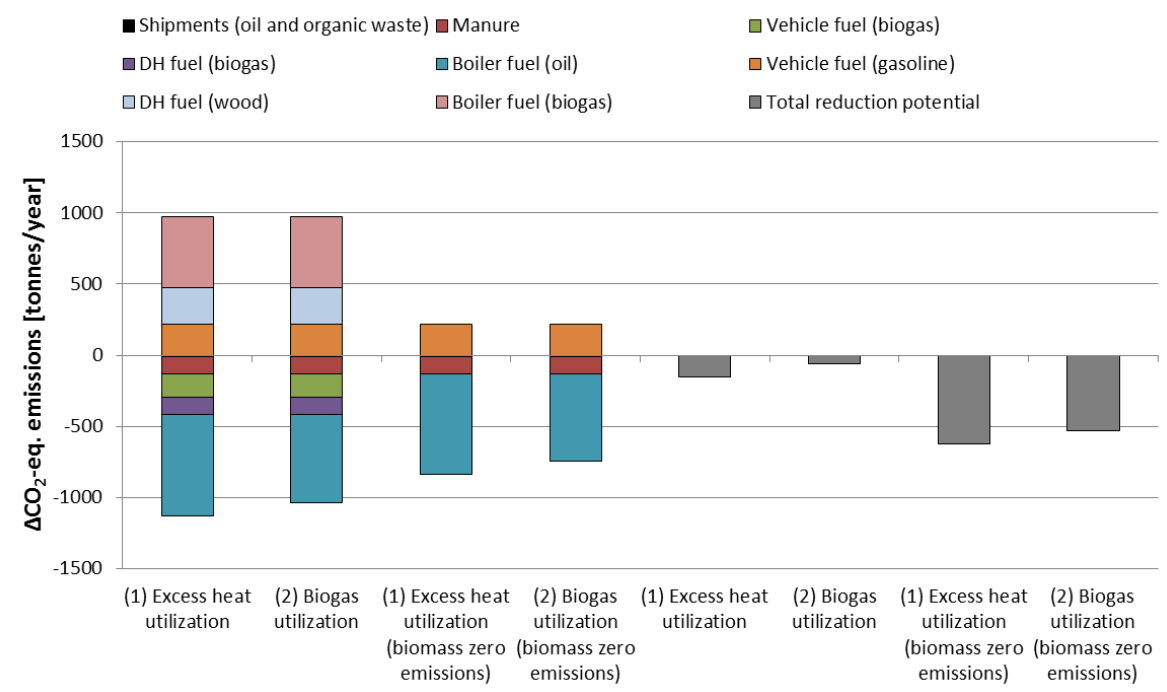

Figure 22. Effects on $\mathrm{CO}_{2}$-eq. emissions, and the origins of these effects, of internal biogas production at the food company studied in Paper III. The graph illustrates two cases: 1) excess heat from the food company is used to heat the digester and 2) part of the produced biogas is used to heat the digester. It also visualizes the outcome if emissions related to biomass are and are not accounted for. Grey bars visualize the total effect on GHG emissions; negative values indicate reduced emissions.

Although the resulting effects on $\mathrm{CO}_{2}$-eq. emissions presented in this section cannot be quantitatively compared, the results can be evaluated as a whole, so general conclusions can still be drawn. 


\subsection{Excess heat and policy}

Research question 4:

\section{How does policy influence industrial excess beat use?}

Although industrial excess heat and options for its reuse are generally well-known, this thesis clearly demonstrates that this resource has not yet been fully exploited in Sweden. Since policies can direct energy use towards more efficient resource use by creating incentives, policies can also affect the use of excess heat. The relationship between excess heat and energy policy has been studied in two of the constituent papers of this thesis, i.e., Papers II and VII. The relevant results will be presented according to the following six categories: use of excess heat; alternatives to $\mathrm{DH}$; awareness, commitment, and legitimacy; knowledge development; internal and external control; and investments and economic factors. Paper VII is based on interviews conducted with eight energy managers at Swedish companies. Since the study is based on interviews, its results are based on the respondents' experiences and perceptions. The study focuses on how energy policy instruments can be used to promote or discourage excess heat use.

\section{Use of excess heat}

A range of external excess heat use opportunities exists but the respondents referred mainly to excess heat use in DH. "I cannot see where we could use this otherwise", one respondent said. The lack of convenient opportunities was cited as a major factor limiting excess heat use; for example, the importance of proximity to DH systems was emphasized. The use of excess heat in DH may be problematic, however, as policy may favour other thermal sources, such as waste incineration and bio-CHP production. It has been demonstrated that the profitability of investing in CHP production has increased as a consequence of green electricity certificates (Knutsson et al., 2006), and the competition between excess heat use in DH and those technologies has been discussed (Arnell et al., 2013; Jönsson et al., 2007). This competition, often expressed as self-experienced by the respondents, was mentioned during the interviews, and it was stated that "the world can see that the competition is obvious". Despite this "obvious" competition, the respondents' had divergent opinions as to the actions needed in response. Whereas one respondent thought that use of excess heat was part of economizing the use of energy, in line with the environmental code (Swedish Government, 1998), another believed that waste incineration was needed and should therefore be prioritized. However, they all concluded that excess heat should not be forced into the system but rather should be used in $\mathrm{DH}$ if it was the best option.

Most of the interviewed companies for Paper VII currently deliver part of their excess heat as DH. These companies' experiences regarding cooperation were described in various terms, some positive and others negative. TPA has been discussed as a way to increase the use of excess heat in DH (SOU 2011:44 (Ministry of Enterprise Energy and Communications), 2011). Companies with negative cooperation experiences favoured the 
introduction of TPA and believed it would increase the use of excess heat in DH. One company believed it would unleash market forces that would promote excess heat use in cases in which it was the best option. On the other hand, several respondents said that the work, investments, and responsibilities associated with TPA were too far removed from their companies' core business activities.

If introducing TPA, industries producing excess heat may have to make the investment of connecting their plants to DH networks. Paper II presents the untapped excess heat potential in Östergötland and Örebro counties (see Section 7.1) and studies the economic incentives for investing in DH connections by calculating the net present value (NPV) for the companies producing excess heat above $90^{\circ} \mathrm{C}$. In the calculations performed in Paper II, the costs of piping and excavation constitute the costs while the revenues come from selling the heat and are based on four EMSs (see Table 5). The resulting NPV figures can be seen in Table 7. Future energy market developments, appearing as changes in heat prices and $\mathrm{CO}_{2}$ charges, were demonstrated to greatly influence the profitability of investment. The approximate distance to a $\mathrm{DH}$ network for companies $\mathrm{V}-\mathrm{Y}$ is less than $2 \mathrm{~km}$, while it is $15 \mathrm{~km}$ for company Z. The distance affects profitability, because the investment becomes larger with increased distance. Given the lower heat prices in scenarios 3 and 4 , the investment is associated with a higher risk than in the other scenarios, in which all investments are profitable. Despite their profitability, the investments are not always made since other factors, such as pay-back requirements, affect the decision. Of the companies studied in Paper II that reported a pay-back criterion, $81 \%$ reported a pay-back term of three years and the rest a pay-back term of two years for energy-efficiency investments. Investing in a connection with the $\mathrm{DH}$ network results in a pay-back time that exceeds the requirements of all companies $(\mathrm{V}-\mathrm{Z})$ in scenarios 3 and 4 , while this is true in all scenarios for company $Z$ (see Table 7). Even though not all costs are included in the calculations, they nevertheless give a hint of whether these investments will be made.

Table 7. Net present value and pay-back times of investment in excess heat deliveries to DH networks. The calculations are based on a discount rate of $6 \%$ and an economic life of 20 years.

\begin{tabular}{|c|c|c|c|c|c|}
\hline \multirow[t]{2}{*}{ Company } & \multirow{2}{*}{$\begin{array}{c}\text { Pay-back } \\
\text { criterion } \\
\text { (years) }\end{array}$} & \multicolumn{4}{|c|}{ NPV (EUR, thousands) / Pay-back for investment (years) } \\
\hline & & Scenario 1 & Scenario 2 & Scenario 3 & Scenario 4 \\
\hline $\mathrm{V}$ & 3 & $1428 / 2$ & $1910 / 1.5$ & $109 / 8.5$ & $17 / 11$ \\
\hline W & 3 & $1308 / 1.5$ & $1756 / 1.5$ & $81 / 6.5$ & $1 / 8$ \\
\hline $\mathrm{X}$ & $\mathrm{N} / \mathrm{A}$ & $3283 / 1$ & $4246 / 0.5$ & $645 / 3$ & $46 / 4$ \\
\hline $\mathrm{Y}$ & 3 & $2023 / 2.5$ & $2711 / 2$ & $142 / 9$ & $5 / 11.5$ \\
\hline Z & 3 & $4291 / 6$ & $6734 / 4.5$ & $-2384 / 23.5$ & $-2878 / 30$ \\
\hline
\end{tabular}




\section{Alternatives to $\mathrm{DH}$}

According to the respondents in Paper VII, heat-driven electricity generation ${ }^{18}$ would offer two advantages: First, it would increase year-round excess heat use, compared with the current situation in which excess heat-producing companies depend on the DH companies' willingness to receive heat. Second, it would reduce dependence on external electricity supply. Currently, green electricity certificates can be received if the excess heat is renewable in origin (Holmgren and Sjödin, 2008); the respondents believed that it was wrong to value excess heat based on origin and emphasized the importance of using available resources. Green electricity certificates or similar systems were mentioned as a means to create new economic opportunities for investing in heat-driven electricity generation technology. However, seven out of the eight studied companies had looked into making such investments and concluded that inefficient conversion made the investments unprofitable.

Other options for excess heat use were mentioned during the interviews, for example, excess heat use in biogas production and thermal storage. Heat cooperation requires a match between the heat source and the heat sink, and the difficulty of two companies with matching needs finding each other was emphasized.

\section{Awareness, commitment, and legitimacy}

Although the primary focus of PFE has been on electricity-saving measures, the positive effects on excess heat use efforts of participation in the programme were addressed by the respondents in Paper VII. The programme's activities made it necessary for the participating companies to commit time to energy-efficiency and energy-related work. Consequently, it was perceived legitimate, in respect of company management, to prioritize energy and energy-efficiency issues in general. This is in line with the findings of McKane et al. (2008) and Thollander and Ottosson (2010), who highlight the importance of top management support for successful energy-efficiency efforts. The mandatory energy audit within the programme provided an overview of the overall energy flows, not only electricity-related flows, within each participating company. In total, according to the respondents, PFE made energy visible and some believed that the programme setup would create opportunities for measures to use excess heat, while others believed that profitable investments would be made in any case. The companies requested a programme that focused not just on electricity use but on total energy use, and the respondents said that such a holistic approach could create incentives for increased excess heat use. They stressed the importance of a similar financial incentive as in PFE in such a programme, and the importance of not favouring unsustainable excess heat use.

\footnotetext{
${ }^{18}$ For a review of heat-driven electricity generation technologies, see Paper I.
} 


\section{Knowledge development}

Paper VII identified the need for various forms of information and education on excess heat use, addressing positive experiences of such information and education activities, such as participating in network or in-house communication between production sites. Such gatherings described as inspiring and serving as a platform for making new contacts and sharing experiences, ideas, and good examples of excess heat use. One respondent said: "I think it is really important to show concrete examples. So that it's not just theory". Generally, the respondents experienced a relative openness to sharing ideas on energy-saving measures between companies. Networking and sharing good examples have previously been highlighted, for example, by Palm and Thollander (2010) and Worrell et al. (2009), as driving forces and ways to improve energy efficiency.

The respondents seemed to agree that they understood their processes well, including the overall excess heat potentials. However, personnel resources were deemed insufficient for larger innovative excess heat use projects, in line with what was found by Johansson (2014) regarding energy-efficiency solutions in general. The respondents therefore emphasized the need for external support in the initial phase of such projects, to take the projects from concept to management approval. Though they believed that energy consultants could possess great knowledge gained from previous projects, at the same time, they felt that the complexity of their production processes made it difficult to find relevant external competence. To avoid the question of trust, respondents mentioned the need for support on soft issues, for example, during contractual processes for cooperation projects. The need for help with administrative procedures, such as completing investment grant applications, was also raised.

\section{Internally and externally based control}

The importance of internal support, goals, and policy instruments to energy-efficiency work was raised during the interviews for Paper VII; one respondent said, "For our part, we have internal company goals - they have been our policy instruments, so to speak". Concrete internal goals, such as $\mathrm{CO}_{2}$-emission requirements and company core values, were described as driving the companies' environmental work and leading to energy issues being given higher priority. This was said to have resulted in increased awareness of energy-efficiency and cost-saving opportunities. The importance of personnel committed to working on energy issues was emphasized as well. Again, the importance of management support and of a long-term energy strategy to improved energy efficiency was stressed (e.g., (McKane et al., 2008; Thollander and Ottosson, 2010; Thollander et al., 2007).

According to the respondents, municipal goals and energy plans could promote increased excess heat use. They believed that the municipality had the ability to influence local heating systems and thus excess heat use in those systems. Still, the respondents said that they felt that their contact with the municipality was inadequate and that they wanted more active dialogue and greater awareness of the potential of excess heat use. Connected to the 
discussion of regional DH networks, a concern was raised that municipal boundaries could hamper the development of such boundary-crossing systems.

\section{Investments and economic factors}

The respondents in Paper VII all reported a 1-3-year pay-off criterion for excess heat recovery investments and said that these investments competed with other investments at their companies. "The actual investment is almost always the Achilles' heel when it comes to excess heat recovery", one respondent said. Accordingly, previous research has ranked access to capital as a key barrier to improved energy efficiency (see, e.g., (Rohdin et al., 2007). Several of the studied companies had, directly or indirectly, received investment grants for excess heat measures, mainly for transmission lines to enable heat supply to DH. According to the respondents, the grants were either crucial to making the investments at all or enabled them to be made earlier than otherwise possible. In addition, the grants made it possible to make investments with longer pay-back periods than normally deemed acceptable.

Several respondents had noticed increased interest in excess heat recovery as a result of increased energy prices and reduced subsidies, but believed that current energy prices were not high enough to actually stimulate heat-recovery measures. Taxes were discussed as having both positive and negative effects on increased excess heat use depending on how they were designed. The importance of economic factors was raised in statements such as: "It is when the heat is priced that the organization begins to work" and "You do not recover the heat just for fun". Generally, it was stressed that long-term policy instruments could reduce the risk associated with investments by enabling more reliable profitability calculations. 


\section{Concluding remarks}

This chapter is divided into two parts: the first presents a discussion related to the constituent studies of this thesis; the second section presents the conclusions related to the stated research questions.

\subsection{Discussion}

This thesis has studied opportunities associated with excess heat use by performing a number of system studies of the use of industrial excess heat. In two of the papers (Papers I and II), the excess heat potential in three Swedish counties was mapped through bottom-up studies using questionnaires. Questionnaires enable a larger sample than if using energy audits, though control over the collected data is limited. The identified excess heat available in the studied counties is probably underestimated. Not all companies receiving the questionnaire completed it and not all companies declaring that they had excess heat reported values for these heat potentials. Still, a significant amount of excess heat was identified in a variety of energy carriers and at a wide range of temperatures. Currently in Sweden, excess heat constitutes $7 \%$ of the DH energy supply. Without deeper analysis of possible constraints, this figure suggests that there may be a potential to increase the share of excess heat in DH. The excess heat potential identified in this thesis must be regarded as theoretical, as technical and economic restrictions will probably limit the usable share of this heat potential. Mapping not only the quantity but also the quality of the available excess heat offers an opportunity to better overview the potentials of this resource. The excess heat identified here originates from different companies and different heat sources within these companies' production plants. Combined with the characteristics of the heat, this may limit the economic feasibility of using this excess heat. In addition, the distance between the excess heat sources and current DH networks imposes restrictions on excess heat use.

As different parts of the energy system are entangled, the consequences of introducing excess heat may be complex to assess. Papers I, III, V, and VI study the GHG emission-reduction potential of using excess heat. It is stated that using excess heat may provide environmental benefits, but it can be questioned whether this is necessarily true. Although it may be controversial to question the existence of these benefits, this thesis demonstrates that excess heat in DH can result in increased GHG emissions under certain energy market conditions. Excess heat deliveries to a CHP-based DH system showed no GHG reduction potential unless the released biomass from the CHP plants replaced coal in 
CCP plants. Hence, as discussed in Paper VI, directing the use of released biomass so as to lower GHG emissions may gain also excess heat use in CHP-based DH. In addition, the emission valuation of lost electricity production in CHP systems affects the GHG reduction potential of excess heat use. Allocating higher emissions to lost electricity production, as in electricity production from CCP plants, reduces the emission-reduction potential of excess heat use. The specifics of the energy system and its system boundaries influence whether or not excess heat use should be viewed as benefitting the climate. However, the fact that excess heat use in DH may be beneficial from a GHG perspective in both HOB- and CHP-based DH systems justifies discussion of policies promoting the increased use of excess heat in DH. Introducing TPA in Sweden to increase the share of excess heat in DH was previously considered, although this policy has now been put on hold. Due to the economic risks associated with investment in connecting industrial plants to DH networks, and in light of several statements from energy managers that such investment is too far from their core business activities (see paper VII), more effective policy guidance may need to be developed.

Various excess heat use options have been studied in this thesis. Excess heat in DH, as discussed above, may be the most obvious one, but other recovery options do exist. The development of heat-driven electricity generation technologies would permit excess heat use even when there is no nearby $\mathrm{DH}$ network or when $\mathrm{DH}$ companies are unwilling to accept excess heat. Internal electricity generation at the industrial plant could also increase the security of electricity supply. Paper I shows an emission-reduction potential of heat-driven electricity production, but demonstrates that the output of using excess heat for electricity production is noticeably less than when it is used for $\mathrm{DH}$. The effects of the low efficiency of heat-driven electricity production technologies are also illustrated in Paper V, where the solutions considered for the optimal use of excess heat do not include electricity production. However, as excess heat may be viewed as a low-cost energy source, creating an opportunity to invest in heat-recovery applications, electricity production may still constitute an attractive heat-recovery option when alternatives are lacking. Cooperation between nearby industrial plants or businesses may also enable further excess heat use, as discussed in Papers III and IV. Though such heat cooperation may bring several benefits, such setups are still scarce. During the interviews performed for this thesis, the difficulty of finding suitable actors whose demand matches available excess heat was raised. This statement might be something to take note of, that is, how to facilitate and enable such heat-cooperation arrangements. Papers II and VII both touch on excess heat and energy policy. That energy policy does affect the use of excess heat is clear. Paper VII is however organized mainly as an explorative study and can be seen as a preliminary screening. More studies in the area are therefore needed.

Throughout this work, many assumptions have been made that affect the results presented. One main assumption is that no emissions are allocated to excess heat. This assumption can of course be questioned, primarily if the heat is not "true" excess heat. The emission-mitigation potential of the use of excess heat, as presented here, would of course be affected if emissions were allocated to excess heat: In such a case, the scenarios indicating 
increased emissions would indicate a larger increase and the scenarios indicating decreased emissions would be less beneficial. Allocating emissions to excess heat, however, may raise a discussion of the origin of these heat resources, i.e., the "colour" of the heat. Excess heat originating from fossil or nuclear energy sources might then be deemed less attractive, which could counteract the resource use efficiency that comes with excess heat use. Several of the appended papers use future EMSs. Though predicting the future energy market is not possible, the tool used to construct these scenarios takes into account the interdependency of various energy market parameters. Although these scenarios may not accurately predict the actual future, those consistent future scenarios provide cornerstones offering a way for studying excess heat use under future extreme.

\subsection{Conclusions}

1. What is the current untapped potential for industrial excess heat in terms of quantity, quality, and carrier medium?

Based on the systems studied in this thesis, it can be concluded that the availability of untapped excess heat in Sweden is significant. Despite the current use of excess heat in $\mathrm{DH}$, for example, potentials for the additional use of excess heat still exist. The three studies mapping untapped excess heat identify a theoretical potential of more than $2.2 \mathrm{TWh}$ of excess heat annually. Excess heat was identified in water, flue gases, hot air, as well as in materials. In terms of quantity, the largest share was found in low-temperature hot water followed by flue gases. Excess heat in water was mainly at temperatures below $70^{\circ} \mathrm{C}$, while flue gases were mainly at $160^{\circ} \mathrm{C}$ or higher.

Assuming that the relationship between energy input and excess heat output in the systems studied is valid for Sweden as a whole, the identified potential can be scaled up to a national level. Based on data from the two studies in Gävleborg County and Östergötland and Örebro counties, this gives a national potential of 12.7 and $21.4 \mathrm{TWh}$, respectively. The fact that these numbers do not match indicates a need for a methodology for large-scale excess heat identification.

\section{What are the implications of using different technologies and systems solutions based on the use of industrial excess heat?}

Various options exist or are under development to enable increased use of excess heat. Industrial excess heat can be used as the same form of energy, as in $\mathrm{DH}$, cooling production, and heat cooperation, or it can be converted into electricity using heat-driven electricity production technologies. Using excess heat for $\mathrm{DH}$ network deliveries means a larger output than when using the heat for electricity production due to the low conversion efficiencies of heat-driven electricity production technologies. This is also evident when optimizing the trade-offs in excess heat use between DH deliveries, cooling production, and heat-driven electricity production while minimizing the system cost when the heat source is not used for electricity production. When the $\mathrm{DH}$ system is based on $\mathrm{HOB}$, excess heat use in $\mathrm{DH}$ 
minimizes the system costs independent of the future energy market conditions studied. When the DH system is based on CHP production, the optimal use is more ambiguous. A combination of low and medium electricity and biomass prices, however, favours deliveries to a DH system while a combination of high electricity and biomass prices favours heat-driven cooling production.

Regarding industrial excess heat as a low-cost energy source opens up opportunities to invest in technologies for excess heat use, though the size of the IO depends on several factors. Future fuel prices as well as the type of DH system affect the magnitude of the opportunity to invest. DH based on HOB gives a larger IO than does CHP-based DH systems due to the reduced revenues from electricity production. Heat cooperation between nearby industries or businesses can also lead to benefits, such as opportunities to invest. Cooperation between a food company and a biogas production plant is one such cooperation arrangement.

\section{How do different excess heat use options and energy market conditions influence global $\mathrm{CO}_{2}$ emissions?}

When accounting for marginal electricity, using excess heat for electricity production reduces GHG emissions. Consequently, excess heat applications that reduce the use of electricity, such as replacing conventional electricity-driven cooling technology with heat-driven cooling, also possess GHG emission-mitigation potential. It can also be concluded that cooperation between nearby businesses that enables the use of excess heat can reduce GHG emissions.

Excess heat deliveries to $\mathrm{DH}$, on the other hand, do not necessarily result in reduced $\mathrm{CO}_{2}$-eq. emissions. The $\mathrm{CO}_{2}$-eq. reduction potential of excess heat use in $\mathrm{DH}$ can be concluded to depend on the energy market development and type of heating system. Using excess heat in HOB-based DH systems showed to be beneficial from a GHG emission perspective, while the GHG emission reduction potential of excess heat use in CHP-based systems is more ambiguous. This is because replacing the electricity production lost by using excess heat in CHP-based DH may in fact lead to increased $\mathrm{CO}_{2}$-eq. emissions. The size of this effect depends on the system boundary used when calculating the lost electricity. Under certain market settings, however, when applying a marginal use of released biomass, using excess heat in CHP-based DH can be beneficial from a GHG emission perspective. Therefore, policies that more effectively direct the use of biomass to where it has the most favourable effects could reduce GHG emissions from excess heat even in CHP-based DH systems.

\section{How does policy influence industrial excess beat use?}

Results from the interviews conducted for this thesis indicate that the studied industries regard $\mathrm{DH}$ as the main alternative for excess heat use. Current policies favouring $\mathrm{DH}$ production from bio-CHP plants and waste incineration disfavour excess heat use in DH. The interviews revealed that the energy managers did still not want to force excess heat into DH systems. TPA has been discussed to increase the use of excess heat in $\mathrm{DH}$, but the respondents' opinions on TPA were not unanimous: some believed that it would increase the 
use of excess heat, whereas others emphasized that the associated work was too far from their core business activities. Investing in DH deliveries would also mean financial risk due to uncertainty in the development of the energy market. Also, financial support for excess heat-driven electricity generation may favour the development of inefficient systems, as previous investigations have found no profit potential in such generation.

Policies that make energy visible and legitimate to work with, towards company management, were considered to promote excess heat use. Networking and other educational or informative activities were also deemed beneficial for increased excess heat use. Lack of resources, personnel, and capital were stressed as factors that discourage investment in excess heat use. Therefore, policies that can overcome these obstacles may favour increased excess heat use. The energy managers also highlighted their belief that municipal policies could influence and increase the use of excess heat in municipal heating systems. Beyond external measures, internal policies, such as company goals and core values, were emphasized as important for driving improved energy efficiency and increased excess heat use. 


\section{Further work}

This section makes suggestions for further research.

Several ideas for further research emerged during the work on this thesis, some of will be presented here. The ideas presented here are in line with the aim of this thesis and would allow for an even more comprehensive overview and further conclusions to be drawn on the industries' opportunities to contribute with benefits from the use of excess heat.

The work presented in this thesis examines a limited number of real cases and regions. Although a lot can be learned from these studies, it is difficult to generalize the results from single companies or of local-level studies to the national level. Also, several of the constituent studies of this thesis are based on future EMSs derived using the ENPAC tool. This tool uses the heat production mix of an average Swedish DH network, so local heat production conditions are not taken into account. Therefore, there is a need for more studies addressing local conditions, for example, and studying the use of excess heat in other industries, such as combined biogas production and excess heat use in the pulp and paper industry. It would also be interesting and instructive to further develop the model used in Paper V to include specific local conditions, such as distances between the various excess heat sources and the sites of their respective heat-recovery measures, as well as the impacts of policy measures. This development would permit more extensive analyses, such as the economic assessment of system solutions taking account of investment costs.

In this thesis, data on available excess heat in three Swedish regions were collected using questionnaires. With the same time and effort, questionnaires permit data to be collected from more industries than does the use of energy audits, for example. However, questionnaires provide less insight into how the data have been collected and thus less information on data reliability. Also, there is a risk that important actors producing excess heat may not complete the questionnaire, so their available excess heat will not be included in the statistics. It would be interesting to look into developing a methodology that still allows large amounts of data on available excess heat to be collected, but that addresses the weaknesses of the method used here and, furthermore, can be used to scale up the results of local and regional level studies of available heat to a national or European level.

Reducing GHG emissions is an important task in efforts to achieve a more sustainable industrial sector and society in general. The impact on GHG emissions of the use of industrial excess heat has been studied in several of the appended papers; however, to 
provide a comprehensive overview of the opportunities for excess heat use, several additional dimensions are interesting to study, such as the resource efficiency associated with the use of the excess heat resource.

Another interesting issue to study is the barriers to and drivers of excess heat use and of various energy cooperation arrangements. Paper VII studied such barriers and drivers from a policy perspective, but other factors beyond policy may influence whether or not excess heat is used. In addition, the explorative interview study presented in Paper VII provides a basis for larger-scale studies that may allow generalizations to be made regarding the effects of policy on excess heat use. These studies could be complemented with additional interviews, for example, with actors from DH companies, politicians, and various interest groups, as well as with actors from additional excess heat-producing companies in various sectors to identify similarities and differences between company groups. This would offer a more comprehensive view of the impacts of policy instruments and of other barriers and drivers. 


\section{Appendix 1}

\section{Questionnaire}

The empirical data in Papers I and V were gathered using the following questionnaire. The questionnaire was formulated and sent out in Swedish; for this thesis, the questionnaire has been translated into English by the author. The original version of the questionnaire also contained questions related to energy management, but since that is not the topic of this thesis, those questions are not presented here.

\section{Introductory information}

Company name:

Location/facility name:

Main production/activity:

Corporate form:

Number of employees:

Annual turnover (2011):

Name and title:

E-mail:

\section{Excess heat from the facility}

Below are a number of questions related to excess heat from your facility.

1. Annual energy use at the company?

i. Biofuel (MWh/year):

ii. Fossil fuels (MWh/year):

iii. Electricity (MWh/year):

iv. District heating (MWh/year):

v. Other (MWh/year), comment:

2. Do you produce excess heat?

i. Yes: 
ii. No:

iii. Do not know:

3. Have you examined the possibility of using the excess heat internally?
i. Yes:
ii. No:
iii. Do not know:

4. If you answered "yes" to question 3, what was the outcome?

i. Not profitable:

ii. Profitable, but not yet implemented:

iii. Implemented, comment (How much and for what?):

5. Have you examined the possibility of using the heat externally?
i. Yes:
ii. No:
iii. Do not know:

6. If you answered "yes" to question 5, what was the outcome?

i. Not profitable:

ii. Profitable, but not yet implemented:

iii. Implemented, comment (How much and for what?):

7. The proposal for TPA means that external actors, such as industrial companies producing excess heat, would have the right to supply heat to DH networks without negotiating with the network owners or utility companies. Would the introduction of TPA affect your use of excess heat?
i. Yes, comment:
ii. No:
iii. Do not know:

\section{Excess heat potential}

More specific questions regarding your excess heat potential are listed below. Specify, if possible, your excess heat potential in the form of steam, water, flue gases, air, and byproducts. Besides temperature, specify the flow and/or annual excess heat potential.

The potential requested is the total excess heat potential both for delivery to an external recipient and for internal use at the company itself.

If you have any doubts regarding the total heat potential in $\mathrm{MWh} /$ year, fill in the remaining fields. Provide figures that are as accurate as possible, though reasonable estimates are preferred to non-responses.

Note: If there are several heat flows within the facility, for example, in water, enter the data for each flow separated with commas.

8. Excess heat potential in water:

$$
\text { i. Temperature }\left({ }^{\circ} \mathrm{C}\right) \text { : }
$$


ii. Flow $\left(\mathrm{m}^{3} / \mathrm{h}\right)$ :

iii. Total annual excess heat potential for external delivery and/or internal use (MWh/year):

iv. Potential for delivery to an external recipient, as a percentage of the total potential above (\%):

v. Which energy carrier (biofuel/fossil fuel/electricity/district heating/other) does the heat in water originate from (if several energy carriers, try to specify per partial flow):

vi. Comments:

9. Excess heat potential in steam:

i. Temperature $\left({ }^{\circ} \mathrm{C}\right)$ :

ii. Flow (ton $/ \mathrm{h})$ :

iii. Total annual excess heat potential for external delivery and/or internal use (MWh/year):

iv. Potential for delivery to an external recipient, as a percentage of the total potential above $(\%)$ :

v. Which energy carrier (biofuel/fossil fuel/electricity/district heating/other) does the heat in steam originate from (if several energy carriers, try to specify per partial flow):

vi. Comments:

10. Excess heat potential in flue gases:

i. Temperature $\left({ }^{\circ} \mathrm{C}\right)$ :

ii. Flow $\left(\mathrm{m}^{3} / \mathrm{h}\right)$ :

iii. Moisture content $(\%)$ :

iv. Total annual excess heat potential for external delivery and/or internal use (MWh/year):

v. Potential for delivery to an external recipient, as a percentage of the total potential above $(\%)$ :

vi. Which energy carrier (biofuel/fossil fuel/electricity/district heating/other) does the heat in flue gases originate from (if several energy carriers, try to specify per partial flow):

vii. Comments:

11. Excess heat potential in air:

i. Temperature $\left({ }^{\circ} \mathrm{C}\right)$ :

ii. Flow $\left(\mathrm{m}^{3} / \mathrm{h}\right)$ :

iii. Moisture content (\%):

iv. Total annual excess heat potential for external delivery and/or internal use (MWh/year):

v. Potential for delivery to an external recipient, as a percentage of the total potential above (\%):

vi. Which energy carrier (biofuel/fossil fuel/electricity/district heating/other) does the heat in air originate from (if several energy carriers, try to specify per partial flow):

vii. Comments: 
12. Excess heat potential in by-products:

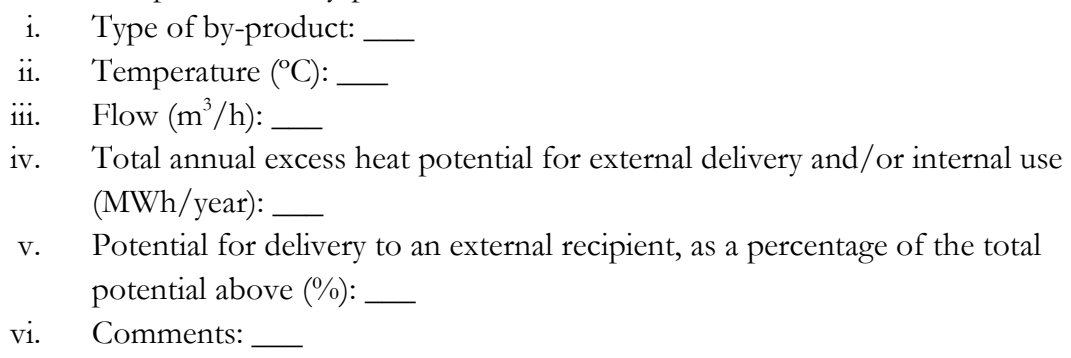

13. What type of data was used to derive the above potential (in water, flue gases, steam, air, and by-products)?
i. Measured:
ii. Estimated:
iii. Calculated:
iv. A combination of above/other, comment:

14. Out of the total heat potential above (in water, flue gases, steam, air, and byproducts), what share is available during winter and summer, respectively? (\%)

i. Water

i. Summer, April-September (\%):

ii. Winter, October-March (\%):

iii. Additional information, such as uneven distribution:

ii. Steam
i. Summer, April-September (\%):
ii. Winter, October-March (\%):
iii. Additional information, such as uneven distribution:

iii. Flue gases

i. Summer, April-September ( $\%)$ :

ii. Winter, October-March (\%):

iii. Additional information, such as uneven distribution:

iv. Air

i. Summer, April-September (\%):

ii. Winter, October-March (\%):

iii. Additional information, such as uneven distribution:

v. By-products

i. Summer, April-September (\%):

ii. Winter, October-March (\%):

iii. Additional information, such as uneven distribution:

15. Are you interested in participating in additional studies related to excess heat at your company?

i. Yes:

ii. No:

16. Other comments: 


\section{Appendix 2}

\section{Interview guide}

The interviews that form the basis of the empirical data in Paper VII were based on the following interview guide. The interviews were conducted in Swedish, which was the language of the interview guide itself. For this thesis, the interview guide has been translated into English by the author.

\section{Introductory questions}

1. How long have you been employed at this company?

a. What was your previous employment?

b. Describe your educational background.

2. Can you describe your working day yesterday?

a. Was that a typical working day?

b. Do you work full time on energy issues?

\section{Energy work and industrial excess heat}

3. Industrial excess heat can be difficult to define; different people include different things in the definition, for example, surplus gases or heat that can be used internally. What does excess heat mean to you?

4. Are you and in case of, how are you working on excess heat use?

a. (No work on the issue) Why is it that you are not working on it?

b. Has it changed over time?

c. When did it change?

\section{Policy instruments}

5. TPA has been discussed as a way to create a competitive market and incorporate more excess heat into the DH network. Would TPA to the DH network affect you? 
a. (Relevant to deliver) How willing have you found DH companies to be to use excess heat?

b. (Deliver heat today) How has cooperation with the DH company worked out?

c. (Relevant to deliver heat but no delivery today) Why have you not started cooperation on excess heat deliveries?

d. (Relevant to deliver) Does the (monetary) valuation of the heat affect your use of the heat?

e. (Not relevant to deliver) Why is it not relevant for you to deliver excess heat to a DH network?

6. A way to avoid tax on electricity is to participate in PFE and thereby commit to working actively on energy issues. Has today's PFE influenced your work on excess heat recovery?

a. (Yes) In what way?

b. (Not relevant) Why is PFE not relevant to you?

c. (Not relevant) Have you participated in the Swedish energy audit programme and, if so, has it affected your work on excess heat?

d. (No) Why is that?

7. Could a revised PFE stimulate increased use of excess heat and heat cooperation?

a. (Yes) How should the programme be structured?

8. Investment grants have been discussed as a way to increase the use of excess heat. Have you used investment grants such as LIP or Klimp?

a. (Yes) Has the investment grant affected your excess heat use? How?

b. (Yes) Would these investments have been made even without the investment grant?

c. (No) Why not?

d. (Application denied) Why did you not receive the grant?

9. Educational efforts and information have been discussed as ways to increase the use of excess heat. Would this type of support affect your excess heat use?

a. What kind of support would you need?

b. Do you attend any type of energy network?

i. How do you regard these networks?

ii. Who took the initiative to attend the meetings?

c. Who should be responsible for education or information interventions?

10. Support in the form of an excellence centre has been discussed. Do you think an independent centre of expertise could be helpful at various stages of excess heat utilization?

a. (Yes) What kind of competence do you need?

11. Energy-directed taxes have been discussed as affecting the demand for excess heat. How does today's energy taxation system affect your use of excess heat?

a. (Uses biofuels) How would the introduction of a tax on biofuels affect you?

12. The Environmental Code calls for companies to save energy within their own facilities. Currently, one does not need to take into account available excess heat 
when locating a waste incineration plant or a bio-fuelled CHP plant. What do you think about that?

a. Would it affect your excess heat use if the environmental code were developed to take excess heat into account when locating these facilities?

13. Technologies exist for electricity generation based on excess heat. However, if you look at the electricity certificate system, electricity certificates are only valid for electricity generated from bio-based excess heat. Does today's electricity certificate system affect your utilization of excess heat?

a. (Yes) How?

b. (No) Why not?

14. How would it affect you if electricity certificates were valid for electricity generation from excess heat regardless of origin?

15. What role do you think that the municipality and the municipal energy plan have in the use of excess heat?

16. Could the municipal energy plan work as a tool to increase the use of excess heat?

17. What policy instruments do you see that favour the use of excess heat?

a. In what way?

18. What policy instruments do you see that hamper the use of excess heat?

a. In what way?

19. From a policy perspective, what would it take for you to use your excess heat?

20. More generally, beyond policy instruments, what is your motivation for using your excess heat?

21. Is there anything else you think I should have asked you about? Or anything you wish to add? 


\section{References}

Ammar Y, Joyce S, Norman R, Wang Y and Roskilly AP. (2012) Low grade thermal energy sources and uses from the process industry in the UK. Applied Energy 89: 3-20.

Andersson V, Broberg S and Hackl R. (2011) Integrated Algae Cultivation for Biofuels Production in Industrial Clusters, Working paper no. 47 Linköping University, Sweden.

Andersson V, Viklund SB, Hackl R, Karlsson M and Berntsson T. (2014) Algae-based biofuel production as part of an industrial cluster. Biomass and Bioenergy 71: 113-124.

Andrews R and Pearce JM. (2011) Environmental and economic assessment of a greenhouse waste heat exchange. Journal of Cleaner Production 19: 1446-1454.

Arnell J, Bolin L, Holmgren K, Staffas L, Adolfsson I and Lindblad M. (2013) Condistions for incresed use of excess heat [Förutsättningar för ökad nytta av restvärme ] - In Swedish. Swedish District Heating Association, Stockholm, Sweden

Axelsson E and Harvey S. (2010) Scenarios for assessing profitability and carbon balances of energy investments in industry. AGS Pathways report 2010:EU1. AGS, the Alliance for Global Sustainability, Gothenburg, Sweden

Axelsson E, Harvey S and Berntsson T. (2009) A tool for creating energy market scenarios for evaluation of investments in energy intensive industry. Energy 34: 2069-2074.

Axelsson E and Pettersson K. (2014) Energy price and Carbon Balance Scenario tool (ENPAC) - a summary of recent updates. Heat and Power Technology, Department of Energy and Environment, Chalmers University of Technology, Göteborg, Sweden

Bauer T, Forbes I and Pearsall N. (2004) The potential of thermophotovoltaic heat recovery for the UK industry. International journal of ambient energy 25: 19-25.

Bendig M, Maréchal F and Favrat D. (2013) Defining "Waste Heat" for industrial processes. Applied Thermal Engineering 61: 134-142.

Bengtsson C, Karlsson M, Berntsson T and Söderström M. (2002) Co-ordination of pinch technology and the MIND method-applied to a Swedish board mill. Applied Thermal Engineering 22: 133-144.

Berntsson T and Åsblad A. (2015) Annex XV: Industrial Excess Heat Recovery Technologies and Applications. Final report - Phase 1. IETS (Industrial EnergyRelated Technologies and Systems). 
Boolsen MW. (2007) Qualitative analyzes: research process, people, society [Kvalitativa analyser: forskningsprocess, människa, samhälle] - in Swedish. Gleerups Utbildning AB

Broberg Viklund S and Karlsson M. (2015) Industrial excess heat use: Systems analysis and CO2 emissions reduction. Applied Energy 152: 189-197.

Broberg Viklund S and Lindkvist E. (2015) Biogas production supported by excess heatA systems analysis within the food industry. Energy Conversion and Management 91: 249-258.

Bryman A. (2012) Social research methods. New York, USA Oxford University Press

Byman K, Rydstrand C, Ilskog E and Åkesson H. (2005) Opportunities with excess heat an evaluation of LIP-funded excess heat projects [Goda möjligheter med spillvärme - en utvärdering av LIP-finansierade spillvärmeprojekt] - in Swedish. Swedish Environmental Protection Agency, Report no. 5373, Stockholm, Sweden.

Campana F, Bianchi M, Branchini L, De Pascale A, Peretto A, Baresi M, Fermi A, Rossetti N and Vescovo R. (2013) ORC waste heat recovery in European energy intensive industries: Energy and GHG savings. Energy Conversion and Management 76: 244-252.

Capros P, Mantzos L, Papandreou V and Tasios N. (2008) European energy and transport: Trends to 2030 - update 2007. European Commission: DirectorateGeneral for Energy and Transport

Chertow MR. (2000) Industrial symbiosis: literature and taxonomy. Annual review of energy and the environment 25: 313-337.

Churchman CW. (1968) The Systems Approach. . New York, USA: Dell Publishing Co

Clarens AF, Resurreccion EP, White MA and Colosi LM. (2010) Environmental life cycle comparison of algae to other bioenergy feedstocks. Environmental science \& technology 44: 1813-1819.

Connolly D, Lund H, Mathiesen BV, Werner S, Möller B, Persson U, Boermans T, Trier D, Østergaard PA and Nielsen S. (2014) Heat Roadmap Europe: Combining district heating with heat savings to decarbonise the EU energy system. Energy Policy 65: 475-489.

Cronholm L- $\AA$, Grönkvist S and Saxe M. (2009) Excess heat from industries and premises [Spillvärme från industrier och värmeåtervinning från lokaler] - in Swedish. Report no. 2009:12. Swedish District Heating Association, Stockholm, Sweden

Cruz E, Vatanakul M, Hynes R, Sarvinis J and McKenna K. (2011) Waste heat utilization to increase energy efficiency in the metals industry In: Energy technology 2011: Carbon dioxide and other greenhouse gas reduction metallurgy and waste heat recovery Hoboken, NJ, USA: John Whiley \& Sons.

Dotzauer E. (2010) Greenhouse gas emissions from power generation and consumption in a nordic perspective. Energy Policy 38: 701-704.

Ecoinvent Centre. (2010) Ecoinvent data, version 2.2. Avaliable at: www.ecoinvent.org. The Centre for Life Cycle Inventories.

EEA. (2014) Trends and projections in Europe 2014 - Tracking progress towards Europe's climate and energy targets for 2020. Report no. 6/2014, Luxembourg, Publication office of the European Union.

Eklund G. (2012) Quantivatively oriented methodology and method [Kvalitativt inriktad metoologi och metod] - In Swedish. Åbo Akademi University, Vasa, Finland 
Elforsk. (2008) Increased demand for biomass in Sweden - Effects on the energy and forest sector? [Ökad efterfrågan på biomassa i Sverige - Hur påverkas energi- och skogssektorn?] - In Swedish Elforsk, Stockholm, Sweden

Ellersdorfer M and Weiss C. (2014) Integration of biogas plants in the building materials industry. Renewable Energy 61: 125-131.

Euroheat \& Power. (2013) Heat roadmap Europe 2050 - Second pre-study for the EU27. Department of Development and Planning, Aalborg University, Aalborg, Denmark

European Commission. (2005) Biomass Action Plan COM(2005) 628 final. European Commission. Brussel, Belgium.

European Commission. (2009) Directive 2009/28/EC of the European Parliament and of the Council on the promotion of the use of energy from renewable sources and amending and subsequently repealing Directives 2001/77/EC and 2003/30/EC.

European Commission. (2010) Europe 2020: a strategy for smart, sustainable and inclusive growth: Communication from the Commission. Brussels.

European Commission. (2011) Communication from the Commission to the European Parliament, the Council, the European Economic and Social Committe and the Commitee of the Regions - Energy Efficiency Plan 2011. Report no. COM/2011/0109. European Commission. Brussels, Belgium.

European Commission. (2012) Directive 2012/27/EU of the European Parliament and of the Council of 25 October 2012 on energy efficiency. Directive 2012/27/EU. Brussels

European Commission. (2014a) Climate Action - 2030 framework for climate and energy policies. Accessed: 2014-11-11. Available at: http://ec.europa.eu/clima/policies/2030/index en.htm.

European Commission. (2014b) Climate Action: The EU Emisson Trading System (EU ETS). Accessed: 2014-11-04. Available at: http://ec.europa.eu/clima/policies/ets/index_en.htm.

Eurostat. (2014) Energy statistics - quantities - Final energy consumption by sector. Accessed 2014-01-20. Available at: http://ec.europa.eu/eurostat/web/energy/data/main-tables.

Gode J, Byman K, Persson A and Trygg L. (2009) Environmental evaluation of electricity from a systems perspective - A guide for sutainable development [Miljövärdering av el ur ett systemperspektiv - En vägledning för hållbar utveckling] - In Swedish. Report no: B1882. IVL (Swedish Environmental Research Institute).

Gode J, Ekvall T, Matrtinsson F, Särnholm E and Green J. (2010) Primary energy in waste and excess heat - methodological issues [Primärenergi $\mathrm{i}$ avfall och restvärme - Metodfrågor] - In Swedish. Swedish Districh Heating Association, Stockholm, Sweden

Gottfridsson RJ, Isabelle. (2011) Investigation of the opportunity for heat integration at Preemraff Göteborg. Division of Heat and Power Technology, Chalmers University of Technology

Grönkvist S, Dahlberg L, Lundberg H, Martinsson C and Stenkvist M. (2008) Analysis of methods to increase the incentives for excess heat use [Analys av metoder för att öka incitament för spillvärmesamarbete] - in Swedish. Report no. ER 2008:16. Swedish Energy Agency, Eskilstuna, Sweden

Grönkvist S and Sandberg P. (2006) Driving forces and obstacles with regard to cooperation between municipal energy companies and process industries in Sweden. Energy Policy 34: 1508-1519. 
Gustafsson L, Lanshammar H and Sandlblad B. (1982) Systems and models: an introduction to systems analysis [System och modeller: en introduktion till systemanalysen] - in Swedish. Lund, Sweden: Studentlitteratur.

Heyne S and Harvey S. (2013) Assessment of the energy and economic performance of second generation biofuel production processes using energy market scenarios. Applied Energy 101: 203-212.

Holmgren S and Sjödin J. (2008) Policy instruments for industrial excess heat - A prestudy [Styrmedel för industriell spillvärme - En förstudie] - in Swedish. Report no. ER 2008:15. Swedish Energy Agency.

IEA. (2011) World Energy Outlook 2011. International Energy Agency, Organisation for Economic Co-operation and Development, Paris, France.

IEA. (2014) CO2 emissions from fuel combustion - Highlights. International Energy Agency, Paris, France.

Ingelstam L. (2012) Systems - To think of technology and society [System - Att tänka över teknik och samhälle] - In Swedish. Swedish Energy Agency. Eskilstuna, Sweden

IPCC. (2014) IPCC: Greenhouse gas emissions accelerate despite reduction efforts Many pathways to substantial emissions reductions are available. IPCC (Intergovermental Panel on Climate Change) Geneva, Switzerland.

Jaffe AB and Stavins RN. (1994) The energy-efficiency gap What does it mean? Energy Policy 22: 804-810.

Johansson D, Franck P- $\AA$ and Berntsson T. (2013) CO2 capture in oil refineries: Assessment of the capture avoidance costs associated with different heat supply options in a future energy market. Energy Conversion and Management 66: 127142.

Johansson MT. (2013) Bio-synthetic natural gas as fuel in steel industry reheating furnaces - A case study of economic performance and effects on global $\mathrm{CO} 2$ emissions. Energy 57: 699-708.

Johansson MT. (2014) Improved energy efficiency within the Swedish steel industrythe importance of energy management and networking. Energy Efficiency: 1-32.

Johansson MT and Söderström M. (2014) Electricity generation from low-temperature industrial excess heat - an opportunity for the steel industry. Energy Efficiency 7: 203-215.

Jönsson J, Ottosson M and Svensson I-L. (2007) Excess heat use from chemical pulp mills - A socio-technical analysis of internal and external potentials [Överskottsvärme från kemiska massabruk - En socioteknisk analys av interna och externa användningspotentialer] - In Swedish. Working paper no. 38. Energy Systems Programme, Linköping University, Linköping, Sweden.

Jönsson J, Svensson I-L, Berntsson T and Moshfegh B. (2008) Excess heat from kraft pulp mills: Trade-offs between internal and external use in the case of SwedenPart 2: Results for future energy market scenarios. Energy Policy 36: 4186-4197.

Karlsson M. (2011) The MIND method: A decision support for optimization of industrial energy systems - Principles and case studies. Applied Energy 88: 577-589.

Karlsson M, Gebremedhin A, Klugman S, Henning D and Moshfegh B. (2009) Regional energy system optimization-potential for a regional heat market. Applied Energy 86: 441-451.

Karlsson M and Söderström M. (2002) Sensitivity analysis of investments in the pulp and paper industry - On investments in the chemical recovery cycle at a board mill. International Journal of Energy Research 26: 1253-1267. 
Kautto N, Arasto A, Sijm J and Peck P. (2012) Interaction of the EU ETS and national climate policy instruments-Impact on biomass use. Biomass and Bioenergy 38: $117-127$.

Klugman S. (2008) Energy systems analysis of Swedish pulp and paper industries from a regional cooperation perspective - Case study modeling and optimization. Dissertation no. 1194. Division of Energy Systems, Department of Management and Engineering. Linköping, Sweden

Knutsson D, Werner S and Ahlgren EO. (2006) Combined heat and power in the Swedish district heating sector-impact of green certificates and $\mathrm{CO} 2$ trading on new investments. Energy Policy 34: 3942-3952.

Kvale S and Brinkmann S. (2009) The qualitative research interview [Den kvalitativa forskningsintervjun] - in Swedish. Studentlitteratur. Lund, Sweden.

Lardon L, Hélias A, Sialve B, Steyer J-P and Bernard O. (2009) Life-cycle assessment of biodiesel production from microalgae. Environmental science \& technology 43: 6475-6481.

Law R, Harvey A and Reay D. (2013) Opportunities for low-grade heat recovery in the UK food processing industry. Applied Thermal Engineering 53: 188-196.

Linné M, Ekstrandh A, Engelsson R, Persson E, Björnsson L and Lantz M. (2008) The Swedish biogas potential from domestic residues [Den svenska biogaspotentialen från inhemska restprodukter] - in Swedish. BioMill AB and Envirum AB

Mansikkasalo A, Michanek G and Söderholm P. (2011) Industrial energy efficiency policy instruments and interactions [Industrins energieffektivisering - syrmedlens effekter och interaktion] - in Swedish. Report no. 6460. Swedish Environmental Protection Agency.

Mantzos L, Capros P and Zeka-Paschou M. (2004) European energy and transport Scenarios on key drivers. European Commission: Directorate-General for Energy and Transport.

Martin M and Eklund M. (2011) Improving the environmental performance of biofuels with industrial symbiosis. Biomass and Bioenergy 35: 1747-1755.

McKane A, Williams R, Perry W and Li T. (2008) Setting the Standard for Industrial Energy Efficiency. Industrial Management Issues.

Ministry of the Environment and Energy. (1998) Constitution (1998:899) on environmental hazardous activities and health [Förordning (1998:899 om miljöfarlig verksamhet och hälsoskydd] - in Swedish

Morandin M, Hackl R and Harvey S. (2014) Economic feasibility of district heating delivery from industrial excess heat: A case study of a Swedish petrochemical cluster. Energy 65: 209-220.

Moriarty P and Honnery D. (2012) What is the global potential for renewable energy? Renewable and Sustainable Energy Reviews 16: 244-252.

Nilsson K. (1993) Cost-effective industrial energy systems - multiperiod optimazation of operating strategies and structural choices. Linköping Studies in Science and Technology, Dissertation no. 315, Linköping University, Linköping, Sweden.

Nyström I and Franck P- $\AA$. (2002) Presence of industrial excess heat at low temperatures [Förekomst av industriellt spillvärme vid låga temperaturer] - in Swedish. CIT Industriell Energianalys AB.

OES Opcon group. (2015) Opcon powerbox ORC - Documents. Accessed: 2015-02-13. Available at: http://www.opcon.se/web/Dokument_1.aspx.

Palm J and Thollander P. (2010) An interdisciplinary perspective on industrial energy efficiency. Applied Energy 87: 3255-3261. 
Pérez-Lombard L, Ortiz J and Velázquez D. (2013) Revisiting energy efficiency fundamentals. Energy Efficiency 6: 239-254.

Persson U, Möller B and Werner S. (2014) Heat Roadmap Europe: Identifying strategic heat synergy regions. Energy Policy 74: 663-681.

Persson U and Werner S. (2012) District heating in sequential energy supply. Applied Energy 95: 123-131.

Pietrapertosa F, Cosmi C, Macchiato M, Salvia M and Cuomo V. (2009) Life Cycle Assessment, ExternE and Comprehensive Analysis for an integrated evaluation of the environmental impact of anthropogenic activities. Renewable and Sustainable Energy Reviews 13: 1039-1048.

Porter ME. (1998) Clusters and the new economics of competition. Volume 76. Harvard Business Review Boston.

Razon LF and Tan RR. (2011) Net energy analysis of the production of biodiesel and biogas from the microalgae: Haematococcus pluvialis and Nannochloropsis. Applied Energy 88: 3507-3514.

Rezaie B and Rosen MA. (2012) District heating and cooling: Review of technology and potential enhancements. Applied Energy 93: 2-10.

Rohdin P, Thollander P and Solding P. (2007) Barriers to and drivers for energy efficiency in the Swedish foundry industry. Energy Policy 35: 672-677.

Ryan GW and Bernard HR. (2003) Techniques to identify themes. Field methods 15: 85109.

Ryan L and Campbell N. (2012) Spreading the net: the multiple benefits of energy efficiency improvements. OECD Publishing/IEA.

Rydstrand M, Martin V and Westermark M. (2004) Heat driven cooling [Värmedriven kyla] - In Swedish. Report no. 2004:112. Swedish District Heating Association, Stockholm, Sweden

Sandvall AF, Börjesson M, Ekvall T and Ahlgren EO. (2015) Modelling environmental and energy system impacts of large-scale excess heat utilisation - A regional case study. Energy 79: 68-79.

Savage N. (2011) Algae: the scrum solution. Nature 474:15-16.

SCB. (2012) Energy use in manufacturing industry, 2012 - Final data [Industrins årliga energianvändning 2012 - Slutsliga uppgifter] - in Swedish. Report no. EN 23 SM 1401. Statistics Sweden Örebro, Sweden

SCB. (2014) Kommunal och regional energistatistik [Municipal and regional energy statistics] - in Swedish. Accessed: 2014-09-22. Available at: http://www.statistikdatabasen.scb.se/pxweb/sv/ssd/START_EN EN0203/SlutA nvSektor/?rxid=b6c6f941-573d-41f2-9008-375aee6c429f.

SEA. (2002) Marginal electricityproduction and CO2-emissions in Sweden [Marginal elproduktion och CO2-utsläpp i Sverige] - In Swedish. Report no: ER 14:2002.

Swedish Energy Agency, Eskilstuna, Sweden.

SEA. (2005) Tax reduction on electricity: effective use of electricity in industry [Skattebefrielse på el: för effektiv elanvändning i industrin]’'- in Swedish. Swedish Energy Agency

SEA. (2010) Electricity certificate system 2010 [Elcertifikatsystemet 2010] - in Swedish.

Swedish Energy Agency Eskilstuna, Sweden

SEA. (2013) Energy in Sweden 2012. Swedish Energy Agency, Eskilstuna, Sweden

SEA. (2014a) Energy in Sweden 2013. Report no. ET 2013:29. Swedish Energy Agency, Eskilstuna, Sweden 
SEA.Energy in Sweden 2014 - Facts and figures. Swedish Energy Agency Eskilstuna, Sweden

SEA. (2014c) Program for energy efficiency in energy intensive industries [Program för energieffektivisering i energiintensiv industri] - in Swedish. Accessed: 2014-1112. Swedish Energy Agency Available at: http://www.energimyndigheten.se/Foretag/Energieffektivisering-i-foretag/PFE/.

SEA. (2015) Guidance to some cost-benefit analyses within energy issues [Vägledning till vissa kostnads-nyttoanalyser på energiområdet] - In Swedish. Accessed: 201502-24. Swedish Energy Agency. Available at: http://www.energimyndigheten.se/Foretag/Energieffektivisering-iforetag/Anvanda-sig-av-spillvarme/Vagledning-CBA-/.

Sjödin $\mathbf{J}$ and Grönkvist S. (2004) Emissions accounting for use and supply of electricity in the Nordic market. Energy Policy 32: 1555-1564.

Sköldberg H, Unger T and Olofsson M. (2006) Marginal electricity approach and environmental assessment of electricity [Marginalel och miljövärdering av el] - In Swedish Report no: 06:52, Elforsk, Stockholm, Sweden

Sorell S, O’Malley E, Schleich J and Scott S. (2004) The Economics of Energy Efficiency - Barriers to Cost-Effective Investment. Cheltenham, UK: Edward Elgar Publishing.

SOU 2011:44 (Ministry of Enterprise Energy and Communications). (2011) District heating on a competitive market - reflections on TPA [Fjärrvärme i konkurrens Betänkande av fjärrvärmeutredningen] - in Swedish. Frizes Offentliga Publikationer, Stockholm, Sweden.

SOU (Ministry of Enterprise Energy and Communications). (2012) Suggested measures to develop district heating markets for the benefit of customers and suppliers of excess heat [Förslag på åtgärder för utvecklade fjärrvärmemarknader till nytta för kunder och restvärmeleverantörer] - in Swedish. Report no. N2012/1676/E. Stockholm, Sweden.

Srikhirin P, Aphornratana S and Chungpaibulpatana S. (2001) A review of absorption refrigeration technologies. Renewable and Sustainable Energy Reviews 5: 343372.

Stenqvist C and Nilsson L. (2012) Energy efficiency in energy-intensive industries - an evaluation of the Swedish voluntary agreement PFE. Energy Efficiency 5: 225241.

Swedish District Heating Association 2010. Excess heat 2010 [Spillvärme 2010] - In Swedish. Swedish District Heating Association.

Swedish District Heating Association. (2014) Statistics district heating [Statistik fjärrvärme] - in Swedish. Accessed: 2014-06-30. Available at: http://www.svenskfjarrvarme.se/Statistik--Pris/Fjarrvarme/.

Swedish District Heating Association. (2015) District cooling [Fjärrkyla] - In Swedish. Accessed: 2015-02-12. Swedish District Heating Association. Available at: http://www.svenskfjarrvarme.se/Fjarrkyla/.

Swedish Environmental Protection Agency. (2012) Policies to achieve the environmental quality objectives [Styrmedel för att nå miljökvalitetsmålen - en kartläggning] - in Swedish 6415.

Swedish Environmental Protection Agency. (2013) The climate investment programme Klimp 2003-2012 - final report [Klimatinvesteringsprogrammen Klimp 20032012 - Slutrapport] - in Swedish Report no. 6517, Stockholm, Sweden. 
Swedish Government.Law (1998:808) Environmental code [Lag (1998:808) Miljöbalken] - in Swedish.

Swedish Government. (2014a) Government bill 2013/14:174 Implementation of the energy efficiency directive [Regeringens proposition 2013/14:174 Genomförande av energieffektiviseringsdirektivet] - In Swedish.

Swedish Government. (2014b) Government bill 2013/14:187 Regulated access to the district heating networks [Regeringens proposition 2013/14:187 Reglerat tillträde till fjärrvärmenäten] - in Swedish 2013/14:187.

Svensson I-L, Jönsson J, Berntsson T and Moshfegh B. (2008) Excess heat from kraft pulp mills: Trade-offs between internal and external use in the case of SwedenPart 1: Methodology. Energy Policy 36: 4178-4185.

Svensson I-L and Moshfegh B. (2011) System analysis in a European perspective of new industrial cooling supply in a CHP system. Applied Energy 88: 5164-5172.

The Confederation of Swedish Enterprise. (2013) Environmental benefits - Tomato cultivation using industrial synbiosis reduces climat impact [Miljönytta Tomatodling i industriell symbios minskar klimatpåverkan] - in Swedish. Accessed: 2015-02-20. The Confederation of Swedish Enterprise. Available at: http://miljonytta.se/ekologiskt/tomatodling-i-industriell-symbios-minskarklimatpaverkan/.

Thekdi A and Belt C. (2011) Waste heat reduction and recovery options for metals industry In: Energy technology 2011: Carbon dioxide and other greenhouse gas reduction metallurgy and waste heat recovery Hoboken, NJ, USA: John Whiley \& Sons.

Thollander P, Danestig M and Rohdin P. (2007) Energy policies for increased industrial energy efficiency: evaluation of a local energy programme for manufacturing SMEs. Energy Policy 35: 5774-5783.

Thollander P and Ottosson M. (2010) Energy management practices in Swedish energyintensive industries. Journal of Cleaner Production 18: 1125-1133.

Thollander P, Rohdin P, Trygg L, Karlsson M, Söderström M and Moshfegh B. (2010) EU's 2020 targets for primary energy - A study of the effects on the Swedish industry [EUs 2020-mål avseende primärenergi - En studie av effekterna för svensk industri] - In Swedish. Linköping University, LIU-IEI-R--10/0113--SE Linköping, Sweden.

Torén J, Dees M, Vesterinen P, Rettenmaier N, Smeets E, Vis M, Böttcher H, Wirsenius S, Anttila P, Ermert J, Paappanen T, Verkerk PJ and Woynowski A. (2011) Biomass Energy Europe: Executive summary, evaluation and recommendations, Chalmers University of Technology, Gotheburg, Sweden

U.S. Department of Energy. (2008) Waste heat recovery: Technology and opportunities in the U.S. industry. U.S. Department of Energy USA.

Vanek F and Albright L. (2013) Energy Systems Enginnering: Evaluation \& Implementation [Energisystemteknik] - In Swedish. Liber AB Stockholm, Sweden

Watson RT, Noble IR, Bolin B, Ravindranath N, Verardo DJ and Diokken DJ. (2000) Land use, land-use change and forestry Cambridge University Press, UK: IPCC (Intergovernmental Panel on Climate Change).

Weiland P. (2010) Biogas production: current state and perspectives. Applied Microbiology and Biotechnology 85: 849-860.

Wetterlund E, Leduc S, Dotzauer E and Kindermann G. (2012) Optimal localisation of biofuel production on a European scale. Energy 41: 462-472. 
Wetterlund E, Pettersson K and Harvey S. (2011) Systems analysis of integrating biomass gasification with pulp and paper production - Effects on economic performance, CO2 emissions and energy use. Energy 36: 932-941.

Wolf A, Eklund M and Söderström M. (2007) Developing integration in a local industrial ecosystem-an explorative approach. Business Strategy and the Environment 16: 442-455.

Wolf A and Karlsson M. (2008) Evaluating the environmental benefits of industrial symbiosis: discussion and demonstration of a new approach. Progress in Industrial Ecology, an International Journal 5: 502-517.

Wolfson R. (2011) Essential University Physics Addison-Wesley.

Worrell E, Bernstein L, Roy J, Price L and Harnisch J. (2009) Industrial energy efficiency and climate change mitigation. Energy Efficiency 2: 109-123.

Ådahl A and Harvey S. (2007) Energy efficiency investments in Kraft pulp mills given uncertain climate policy. International Journal of Energy Research 31: 486-505. 



\section{Papers}

The articles associated with this thesis have been removed for copyright reasons. For more details about these see:

http://urn.kb.se/resolve?urn=urn:nbn:se:liu:diva-120500 